\title{
THE PLACE OF FOOD: CONSTRUCTING A SENSE OF PLACE AMONG NEW URBAN-ORIENTED FARMERS IN RURAL FARMING COMMUNITIES IN SOUTHERN ONTARIO
}

\section{By}

\section{MINH K. NGO}

\author{
A thesis submitted to \\ the Faculty of Graduate Studies and Research \\ in partial fulfillment of \\ the requirements for the degree of \\ Master of Arts \\ Department of Geography and Environmental Studies
}

Carleton University

Ottawa, Ontario 
Library and Archives

Canada

Published Heritage Branch

395 Wellington Street Ottawa ON K1A ON4 Canada
Bibliotheqque et

Archives Canada

Direction du

Patrimoine de l'édition

395, rue Wellington

Ottawa ON K1A ON4

Canada
Your file Votre référence

ISBN: 978-0-494-83095-6

Our file Notre référence

ISBN: 978-0-494-83095-6
NOTICE:

The author has granted a nonexclusive license allowing Library and Archives Canada to reproduce, publish, archive, preserve, conserve, communicate to the public by telecommunication or on the Internet, loan, distribute and sell theses worldwide, for commercial or noncommercial purposes, in microform, paper, electronic and/or any other formats.

The author retains copyright ownership and moral rights in this thesis. Neither the thesis nor substantial extracts from it may be printed or otherwise reproduced without the author's permission.
AVIS:

L'auteur a accordé une licence non exclusive permettant à la Bibliothèque et Archives Canada de reproduire, publier, archiver, sauvegarder, conserver, transmettre au public par télécommunication ou par l'Internet, prêter, distribuer et vendre des thèses partout dans le monde, à des fins commerciales ou autres, sur support microforme, papier, électronique et/ou autres formats.

L'auteur conserve la propriété du droit d'auteur et des droits moraux qui protège cette thèse. $\mathrm{Ni}$ la thèse ni des extraits substantiels de celle-ci ne doivent être imprimés ou autrement reproduits sans son autorisation.
In compliance with the Canadian Privacy Act some supporting forms may have been removed from this thesis.

While these forms may be included in the document page count, their removal does not represent any loss of content from the thesis.
Conformément à la loi canadienne sur la protection de la vie privée, quelques formulaires secondaires ont été enlevés de cette thèse.

Bien que ces formulaires aient inclus dans la pagination, il n'y aura aucun contenu manquant. 


\begin{abstract}
While a rural renaissance appears to be re-emerging as part of the local food movement, there has been limited research exploring the counterurban experiences of new urban-oriented farmers (NUOFs) working towards becoming a part of the rural agricultural landscape. To this end, my thesis explores how NUOFs construct a 'sense of place' for themselves. Conducted in the summer of 2009, this ethnographic research examined the experiences of nine NUOFs living and working in rural communities in southern Ontario. Using a multi-dimensional 'sense of place' framework, this study found that NUOFs drew from the rural and urban environment to inform their place identity while the emotive bond to the physical and social environment varied greatly between each farmer. A networked 'sense of community' seemed based on interest rather than geography. Overall, the findings suggest the development of a sense of place among NUOFs is a diverse, dynamic and differentiated process.
\end{abstract}




\section{ACKNOWLEDGEMENTS}

This thesis was possible because of the contribution and support of many. I would like to thank my thesis advisor Dr. Michael Brklacich for his time, humour, and patience in helping me secure my grasp on this study in all its twists and turns. I also offer my thanks to Dr. Fiona Mackenzie for taking the time to share her insights and sit on my thesis committee. In addition, I would like to thank the faculty and staff at Carleton University for helping me make my way through the program. To my family, who may not always understand what it is I do but faithfully support me nonetheless, I am beyond grateful. Also, a big thank you to my friends and fellow graduate students for their kind words and thoughtful feedback. I would also like to thank Mathew Brown for his support throughout this process and for always finding a way to be there for me at the right place and the right time. Finally, I would like to extend a sincere appreciation to the new urban-oriented farmers who took the time to be a part of this study. Your openness and generosity made this endeavor of curiosity into a remarkable journey of tremendous academic and personal growth. For that, I thank you. 


\section{TABLE OF CONTENTS}

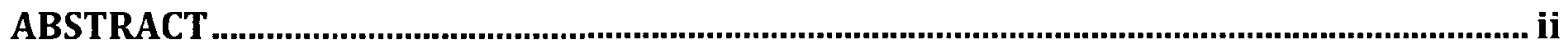

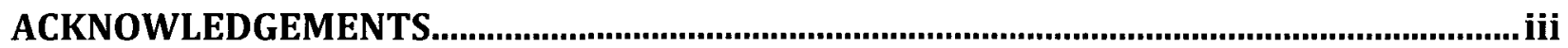

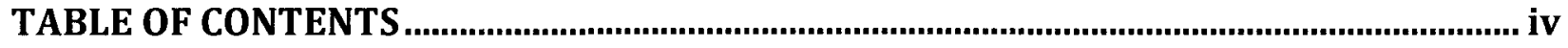

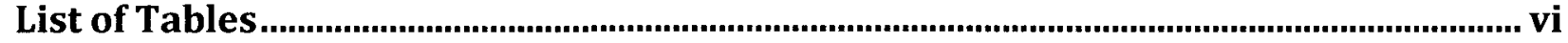

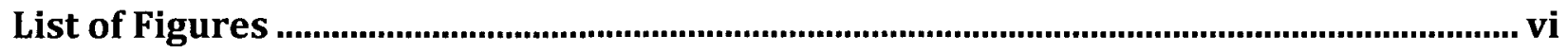

List of Photos ....................................................................................................................................... vi

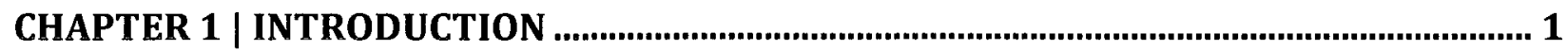

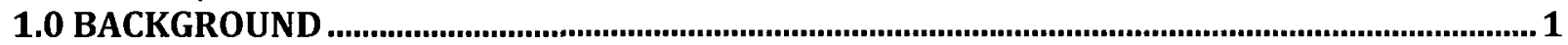

The Farmer Demographic Shift.............................................................................................................. 3

1.2 RESEARCH QUESTION, OBJECTIVE AND SIGNIFICANCE .............................................................. 5

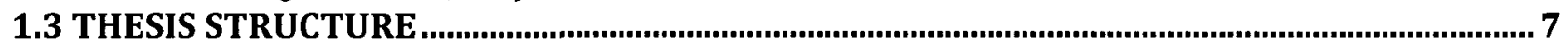

2.1 THE LOCAL FOOD MOVEMENT AND THE POLITICS OF PLACE................................................. 8

2.2 CHANGING FACES, CHANGING PLACES-RURAL POPULATION DYNAMICS........................... 15

The Role of Counterurbanization ..................................................................................................................17

2.3 FROM THEORY TO PRACTICE ........................................................................................................... 22

CHAPTER 3 | FUNDAMENTALS OF THE RESEARCH PROCESS...........................................27

3.1 RESEARCH DESIGN－FRAMEWORK........................................................................... 27

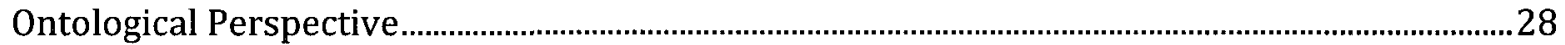

Epistemological Perspective ......................................................................................................................29

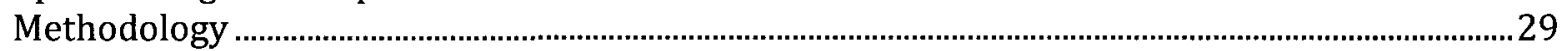

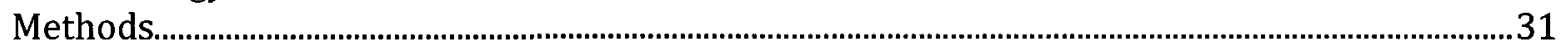

Participant Observation........................................................................................................................................................3

In-depth semi-structured interviews ...................................................................................................................33

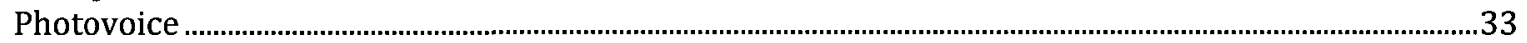

Resource Network Mapping ...........................................................................................................................................35

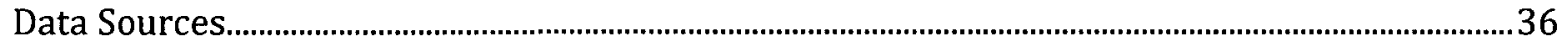

3.2 RECRUITMENT STRATEGY..................................................................................................... 38

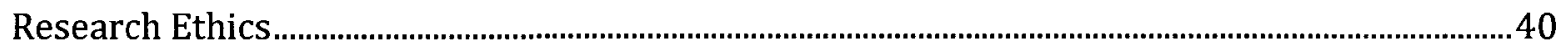

An Introduction to the Research Participants...........................................................................................40

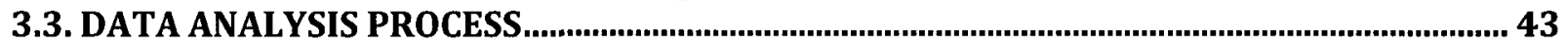

Reflecting on the research process...............................................................................................................45

CHAPTER 4 | RESULTS AND ANALYSIS ..............................................................................50

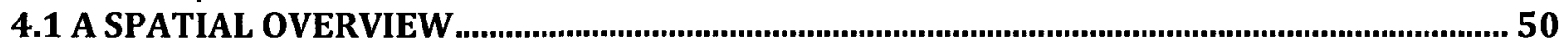

4.2 THE 'EVERYDAY' EXPERIENCE …..................................................................................... 58

Place Identity ..................................................................................................................................................5

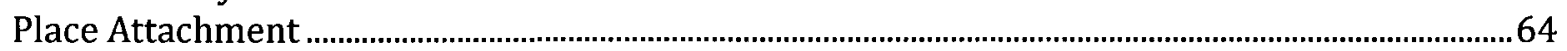

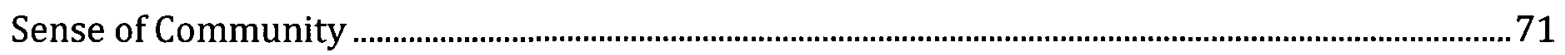

Addressing social isolation ........................................................................................................................................7

Building a 'sense of community' ..........................................................................................................................................77

CHAPTER 5 | CONCLUSION ...........n... 


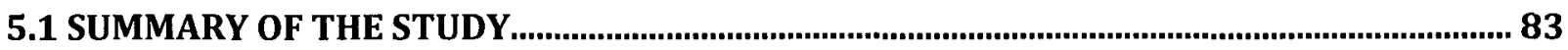

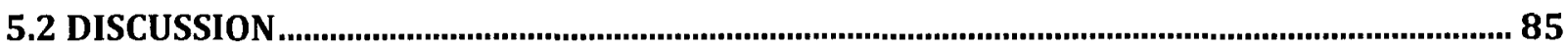

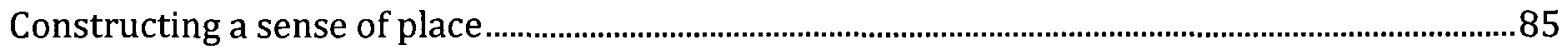

5.3 RESEARCH IMPLICATIONS............................................................................................................ 90

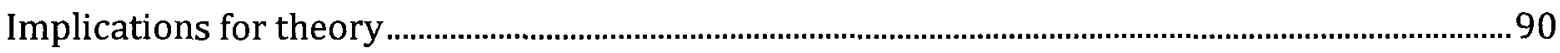

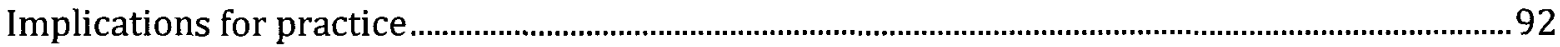

5.4 RESEARCH SCOPE AND FUTURE RESEARCH AREAS ............................................................. 93 


\section{List of Tables}

TABLE 1. NUMBER AND PERCENTAGE DISTRIBUTION OF FARM OPERATORS BY AGE, CANADA AND PROVINCES, CENSUS YEARS 1991 TO 2006

TABLE 2. APPROACH TO STUDYING A 'SENSE OF PLACE' ........................................................................................28

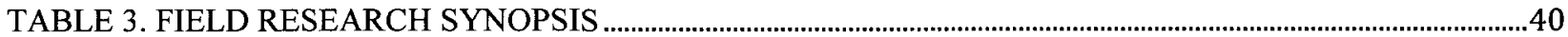

TABLE 4. CENSUS DIVISION DEMOGRAPHIC PROFILE OF NUOFS' COMMUNITIES IN 2006 ......................42

TABLE 5. DEMOGRAPHIC PROFILE OF NUOFS PARTICIPANTS..............................................................................43

TABLE 6. NUOFS' FARM OPERATION CHARACTERISTICS ......................................................................................4 43

TABLE 7. SPATIAL DISTRIBUTION OF NUOFS' RESOURCE NETWORKS ..............................................................51

\section{List of Figures}

FIGURE 1. URBAN AND RURAL POPULATION, CANADA FROM 1851-2006 …..................................................16

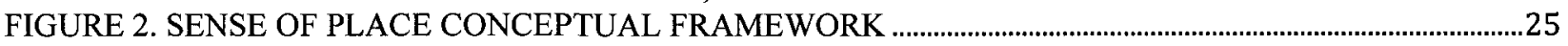

FIGURE 3. 2006 CENSUS DISTRICTS, SOUTHERN ONTARIO..................................................................................41

FIGURE 4. QUALITATIVE DATA ANALYSIS …….......................................................................................................44

FIGURE 5. NUOFS' NETWORK DISTRIBUTION BY RESOURCE CATEGORY ......................................................52

\section{List of Photos}

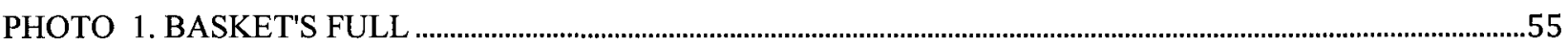

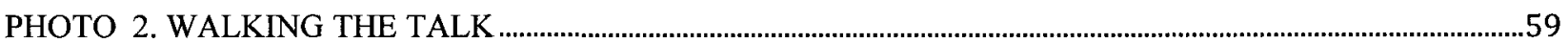

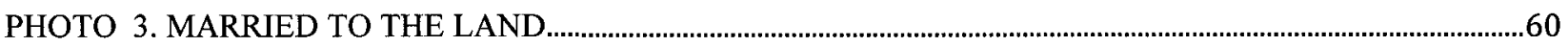

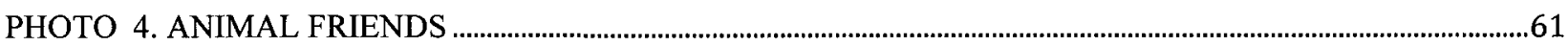

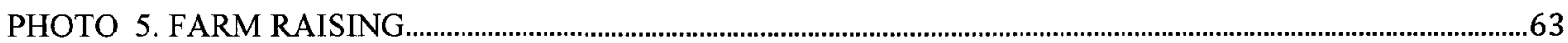

PHOTO 6. ANTS

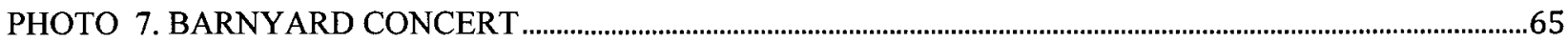

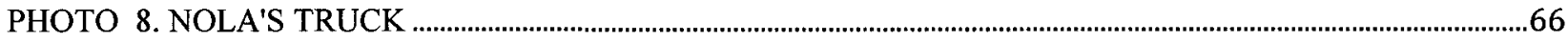

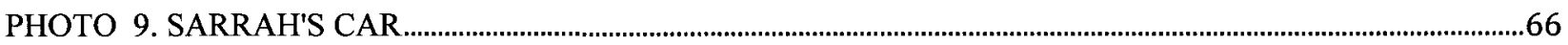

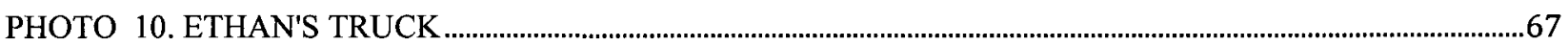

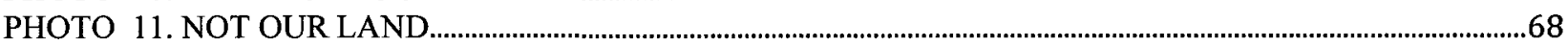

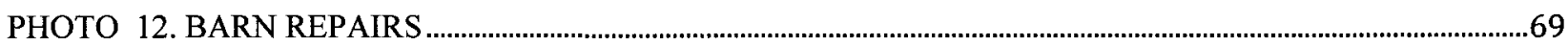

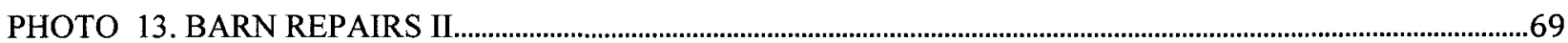

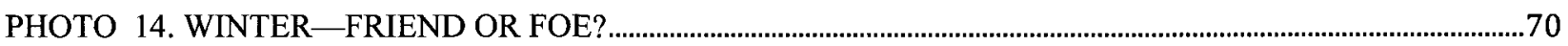

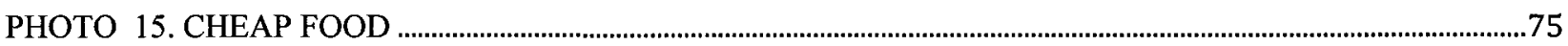

PHOTO 16. FORM 300-GOVERNMENT REGULATIONS .................................................................................................76

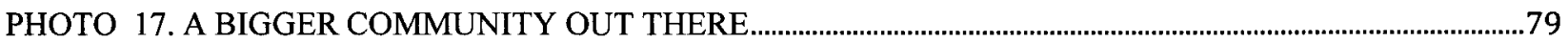

PHOTO 18. FARMING COLLEAGUES ……….........................................................................................................

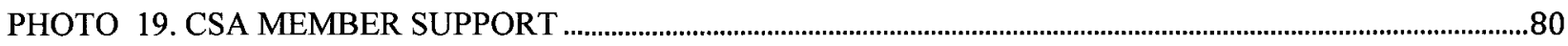

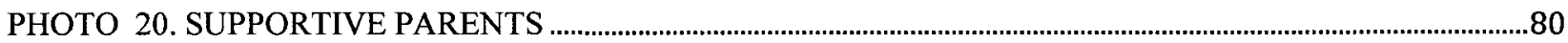

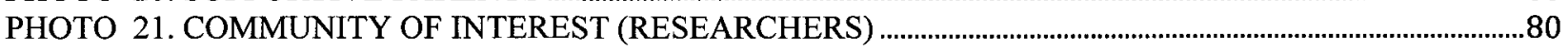




\section{CHAPTER 1 | INTRODUCTION}

\subsection{BACKGROUND}

Almost fifty years have passed since the "Green Revolution" captivated the imagination of ordinary citizens and leaders around the world. For many, through the appropriation of new technologies such as improved crop varieties, synthetic fertilizers, pesticides and intensive irrigation systems, industrial agriculture was a means to increase food production and supply in order to sustain a growing world population (Erlich et al., 1993). Industrial agriculture increased global food production and supply; however, escalating concerns regarding uneven development and the adverse effects of large scale, highly industrialized and exploitive farming practices on the economic, environmental and social landscape of communities suggest that food security is and perhaps never was simply a matter of supply and demand (Allen et al., 2003; DeLind, 2009).

A local food systems approach to food security is gaining popularity in both theory and practice. As Clare Hinrichs (2003) describes, a local food system "embod[ies] a range of initiatives aimed at counteracting distant economic concentration, social disempowerment and environmental degradation" (p. 33). These initiatives come by a variety of names such as alternative food initiatives, alternative food networks, market-oriented initiatives or short food supply chains but overall, the aim is "to reconnect farmers and consumers though farmers' markets, community-supported agriculture, and the reinvigoration of small family farms; their goals are to develop community-based food systems grounded in regional agriculture and local decision-making" (Allen et al., 2003, p. 61). Moreover, the principles of local food systems are being incorporated into regional development and governance models which some scholars have identified as the (re)turn to 'quality', ecological modernization, and the new agrarian ecoeconomy (Marsden and Smith, 2005; Buller and Morris, 2004; Sonnino and Marsden, 2006). 
In the summer of 2008 , my experience working as a farmhand with a family who ran a 200 acre mixed-operation organic farm near the town of Iroquois, Ontario provided much food for thought. At that time, I was a young professional working in Ottawa when a certain longing to revisit my agricultural roots re-emerged. The arrangement was simple: from Monday to Thursday I would work in the city and then on the farm during the weekend. Over the course of several months, the opportunity to work on a farm just outside the city limits had me traveling on a weekly basis from the city to the country, from the urban to the rural. In less than an hour, approximately 100 kilometers $(\mathrm{km})$ from Ottawa's city centre, I couldn't help but feel like I was a world away. Conversations in the field and over shared meals revealed that their children expressed reservations about taking over the family farm. Their parents were not entirely surprised or disappointed with their children's desire to explore different career opportunities, sharing several times that "being a farmer is tough". As for myself, while I enjoyed farming, the experience highlighted the differences between living and working in an urban and rural environment; it made me re-consider whether I could adjust to and thrive in a rural community. Trying to reconcile this situation with what I saw as a growing interest for local, human-scaled food systems and a shrinking farming population, left me wondering who exactly is going to farm? 


\section{The Farmer Demographic Shift}

Concerns over a declining farming population have received considerable attention in recent years since the Census of Agriculture in 2006 showed that the farming population fell to historical lows and "like the population as a whole, got older" (Statistics Canada, 2008, p. 3). In 2006, farmers between the ages of 35-54 made up more than half of the farming population followed by those older than 54 years old ( $41 \%$ ) while less than $10 \%$ were under the age of 35 (see Table 1). The number of young farmers fell significantly by $35 \%$ from 1996 to 2001 and dropped another $25 \%$ in 2006 . The number of farm operators in the mid-age category dropped $12 \%$ from the previous census while the 55+ age group reported a $10 \%$ increase from 2001 to 2006.

Table 1. Number and percentage distribution of farm operators by age, Canada and provinces, census years 1991 to 2006

\begin{tabular}{|l|c|c|c|c|c|c|c|c|c|}
\hline Canada & $\mathbf{1 9 9 1}$ & $\mathbf{1 9 9 6}$ & $\mathbf{2 0 0 1}$ & $\mathbf{2 0 0 6}$ & $\mathbf{1 9 9 1}$ & $\mathbf{1 9 9 6}$ & $\mathbf{2 0 0 1}$ & $\mathbf{2 0 0 6}$ \\
\hline Age of farm operators & \multicolumn{6}{|c|}{ Number of operators } & \multicolumn{5}{|c|}{ Percentage of distribution } \\
\hline Under 35 years & 77,910 & 61,055 & 39,915 & 29,920 & 19.9 & 15.8 & 11.5 & 9.1 \\
\hline $35-54$ years & 187,585 & 200,170 & 185,570 & 164,160 & 48 & 51.9 & 53.6 & 50.2 \\
\hline 55 years and over & 125,380 & 124,380 & 120,705 & 132,975 & 32.1 & 32.3 & 34.9 & 40.7 \\
\hline Total number of operators & 390,875 & 385,605 & 346,190 & 327,055 & 100 & 100 & 100 & 100 \\
\hline Average age of farm operators & 47.4 & 48.4 & 49.9 & 52.0 & $\cdots$ & $\cdots$ & $\cdots$ & $\cdots$ \\
\hline
\end{tabular}

Source: Statistics Canada. (2006a). Census of Agriculture, 2006. Website: http://www.statcan.gc.ca/pub/95-632x/2007000/t/4185586-eng.htm. Accessed Dec 4, 2008.

Although the Census of Agriculture may not capture every farm operator in Canada, especially small-scale farmers, it does provide a general overview of the agricultural industry and perspective on long-term trends. In this case, it is important to acknowledge that the declining 
farming population is not new; in fact, this has been the case since the 1930s. Nevertheless, the pace and persistence of this demographic shift has not gone unnoticed, as the need for more and new farmers is recognized by both the industrial and sustainable farming community. Responses from the agricultural industry include, but are not limited to, promoting effective farm succession planning (Errington, 2002; Culver et al. 2001) as well as expanding foreign, seasonal agricultural worker programs (Martin, 2003; Preiblisch and Binford 2007). Within the local food movement, there is a strong campaign to encourage more people to get involved in agriculture. In particular, attention to the needs of new farmers, especially those with little to no agricultural background, has been gaining momentum.

In its inaugural issue published in December 2010, the Journal of Agriculture, Food Systems and Community Development dedicated the special topic to new farmer research. Articles covered a range of issues from best practices in farm succession planning, characteristics of successful farm start-ups, resource accessibility for multicultural and disadvantaged farmers, and evaluative strategies for new farmers training programs. While these authors predominately highlighted practices in the United States, these issues are certainly pertinent in Canada as a number of education institutions (e.g. the University of British Columbia's Sowing the Seed for the Future Internship, the University of Kwantlen's Farm School program), community-based organizations (e.g. Everdale and FarmStart) and informal networks such as Stewards of Irreplaceable Land (SOIL) and Collaborative Regional Alliance of Farmer Training (CRAFT) are developing farmer education tools and initiatives designed to support people with limited farm experiences or rural origins to take up agriculture ${ }^{1}$. The majority of these programs focus on

\footnotetext{
1 For more information about these organızatıons, please visit

- UBC's Sowıng the Seed for the Future Internship (http //www landfood ubc ca/ubcfarm/apprenticeship php)

- Kwantlen's Farm School (http //www kwantlen bc ca/1sh/RFS html)

- Everdale Environmental Learning Centre (http //everdale org/)
} 
production and business skills development; in other words, the mechanics of producing someone who has the basic technical competencies to grow food and run an economically viable farm business.

An indication of a rural renaissance fueled by the local food movement has been suggested by some researchers such as Kate Mailfert (2007) who writes that "[a] significant number of people are moving 'back-to-the-land' in search of a fulfilling lifestyle and self-defined economic success" (p. 21). But the author also poses the question of whether these 'neo-farmers' actually find what they are looking for. Overall, there is a relatively limited understanding of the experiences of urban people who move to rural communities to farm and take part in the local food movement. What is it like for individuals who have been socialized in an urban environment and then (re)place themselves within a rural context? Will they find their sense of place? Will production and business acumen sustain their agrarian dreams? Or will they discover that there is more to farming than just farming?

\subsection{RESEARCH QUESTION, OBJECTIVE AND SIGNIFICANCE}

As previously mentioned, even though the number of farm operators is at a new historical low, there are people with limited farm and rural experience moving 'back-to-the-land'. Many participate in alternative food initiatives as part of the local food movement not only in response to rising consumer demand for local and organic produce but also to exercise certain values and beliefs. However, migration involves much more than just the physical relocation of individuals and families to new communities. The flow of people brings with it an undercurrent of

- FarmStart (http://www.farmstart.ca)

- SOIL (http://www.soilapprenticeships.org/

- CRAFT (http://www.craftontario.ca/) 
potentially diverse, and sometimes conflicting, attitudes, beliefs, and values systems that must be navigated in relation to new social, economic, political and environmental terrains. Recognizing that migration is far from a simple 'cut-and-paste' process, the research question is: having chosen to participate in the local food movement, how are new urban-oriented farmers (NUOFs) constructing a 'sense of place' within rural farming communities? To help work towards this understanding, the research is guided by three main sub research questions. They are:

- What does a 'sense of place' look like from a spatial perspective?

- What are the motivations and values behind farming that bring NUOFs to rural places?

- What are the 'everyday' experiences of transitioning to a rural livelihood and lifestyle?

With a growing interest and demand for local food systems, understanding NUOFs' urban-to-rural migration experiences seems like a critical juncture for the local food movement in light of a rapidly declining farmer population. The objective of the research is to understand the motivations, opportunities and challenges new farmers experience in their daily lives and to explore what a 'sense of place' looks like for NUOFs who make the transition to being a part of the rural and agricultural landscape. As new farmer training programs are gaining in popularity, the focus of this research to surface the social dimensions of NUOFs lived experiences and address Michael Winter's (2003) observation that within the local food movement discourse, there has been few efforts examining the requirements to promote social sustainability in farming. 


\subsection{THESIS STRUCTURE}

This thesis is organized into five chapters. Chapter 1 has provided an introduction to the research topic and study. Chapter 2 sets the context of the research with an overview of relevant literature and details the 'sense of place' conceptual framework used as an analytical tool to answer the research question. Chapter 3 details the fundamentals of the research process, including the methodology, research design and data analysis procedures. A summary of the research participants is also provided. Chapter 4 reports the research findings and provides an analysis. Chapter 5 includes a summary of the research, a discussion on key findings, the research implications, the limitations of the study and concludes with suggestions for future research. 


\section{CHAPTER 2 | SETTING THE CONTEXT}

The goal of this chapter is to set the context for this research. The chapter begins by critically examining key concepts and controversies related to the politics of place within the local food movement (LFM) discourse. Next, a review of literature pertinent to the study illustrates the importance of expanding the LFM's current engagement with the concept of place to include a 'sense of place' with respect to the counterurbanization movement and shifting constructions of rurality. Lastly, a description of the 'sense of place' conceptual framework that informs this study brings the chapter to a close.

\subsection{THE LOCAL FOOD MOVEMENT AND THE POLITICS OF PLACE}

Place has a long, tangled history in geographical thought and encompasses much more than just cartography. By nature, place research is a pluralistic domain that encompasses a wide range of interpretations and operational definitions. John Agnew (2005) describes three central ways that place can be conceptualized: (1) location (2) locale and (3) sense of place. Place as a location refers to a physical site in space whereas a locale is seen more as where life is lived (e.g. workplaces, home, places of worship, and so on); thus, a locale is "no mere address but the where of social life and environmental transformation" (p. 89, emphasis added). Finally, being able to identify with and feel a sense of 'belonging' to a place are qualities indicative of a 'sense of place'. Similarly, Foote and Azaryahu (2009) write that a 'sense of place' is the "emotive bonds and attachments, both positive and negative, that people develop or experience in particular locations and environments" (p. 96). 
Given the centrality of place in both the academic and popular discourse around the local food movement, it is somewhat peculiar that Feagan (2007) would suggest that "the place of food seems to be the quiet centre of the discourses emerging with these movements" (p. 23, original emphasis). Local food advocates would also argue that the importance of place is central, if not fundamental. Various articulations of a local food system exist but for the purpose of this research, the term local food system (LFS) is used to loosely include initiatives such as alternative food initiatives (Allen et al., 2003), alternative food networks (Jarosz, 2008), short food supply chains (Renting et al., 2003) that embody four key principles. As outlined by Jarosz (2008, p. 232), they are:

1. a shortened distance between producers and consumers;

2. the adoption of small-scale, sustainable farming practices;

3. the development of short food chain supply models such as food cooperatives, farmers' markets, and community supported agriculture (CSA) schemes;

4. a commitment to the social, economics and ecological dimensions of sustainable food system from production, distribution and consumption.

By reducing the space between producers and consumers, a re-localization of the food system may be better situated to address the food security priorities of a community than profitoriented global multinational companies (Blay-Plamer, 2008). For instance, a 2005 survey conducted in Nebraska (Schneider and Francis, 2005) found that in addition to quality and taste, environmentally friendly production, support for local farmers and the local economy were important factors in consumers' food purchasing decisions. Based on a qualitative study with 12 CSA farmers in California, Perez (2004) reported that the majority of the farmers indicated that promoting ecological responsibility, developing relationships with people who eat their food and building a sense of community were equally important motivations for being LFS practitioners. 
She also found that economic viability was one of the most frequently mentioned reasons for establishing a CSA among the farmers participating in her study. Likewise, results from a survey among a group of farmers participating in farmers' markets in Maine conducted by Hunt (2007) found that most of the farmers (68\%) rated having a direct relationship with their customers as the most important motivation for selling at farmers' markets. Interestingly, Hunt observed that making more profit was rated most important by only $36 \%$ of the farmers. He also found that the farmers showed a willingness to adopt different production practices to meet customer demands, which suggests to him that a direct farmer-consumer relationship could influence the agricultural practices of the local agriculture industry.

Once considered on the fringe, the politics of place seems to be at the center of LFS discourse and making its way into political agendas across cities in North America (Mendes, 2007; Allen et al., 2003). The principles of a local food system are looked to as a means to cultivate food democracy, which at its core is about citizens having the ability to shape the food system and "the power to determine agro-food policies and practices locally, regionally, nationally, and globally" (Hassenein, 2003, p. 79). Yet despite its popularity (or because of it), there is a growing body of literature critically examining the promises and practices of a local food system to transform the way we understand and interact with the environment, economy, and each other. The 'local trap' is referred to by researchers like Born and Purcell (2006) to describe the tendency among food activists, advocates and researchers to assume something inherent about the 'local' scale, and by virtue of its locality, the 'local' lays claim to being ecologically sustainable, participatory and the purveyor of more nutritious, wholesome food. However, there is nothing inherent about any scale and like the global food system, local food 
systems are equally susceptible to be "just or unjust, sustainable or unsustainable, secure or insecure" (Born and Purcell, 2006, p. 1).

Taking a closer look at the ambiguities and political tensions interlaced within food system localization, Allen and Hinrichs (2007) reported that the benefits of a local food system are not always black and white. They highlighted a Swedish study, conducted by Wallgreen in 2006 that examined the transportation energy cost between locally procured and imported food products (e.g. fruit juices and lamb meat). Wallgreen concluded that while there were positive impacts associated with producing food closer to its market, the positive impacts could be counterbalanced by the low loading capacity of vehicles commonly used for produce transportation at farmers' markets itself. In other words, there were trade-offs. In their own research examining Buy Local campaigns in the United States, Allen and Hinrichs (2007) found that under closer scrutiny these campaigns also revealed mixed messages. On one hand, the Buy Local campaign reaffirmed that for those people already participating in these initiatives, the face-to-face opportunities created the possibility for more meaningful interactions between producers and consumers. On the other hand, it seemed to support a type of "defensive localism" which cultivated a representation of the global 'other' as periphery and thereby limited the geography of responsibilities to what one can see, touch, and feel. This type of localism, Allen and Hinrichs report, can gloss over inconsistency and contradictions such as poor labor conditions for migrant workers but still appeal to the 'local' designation. Furthermore, Allen and Hinrichs raised the issue of political consumerism to express uncertainties about the transformative power of "fighting capitalism with capitalism". Overall, they cast assertions and assumptions about the local food system in between "shades of alternativeness". 
A little closer to home, Eaton (2008) traced attempts by the region of Niagara (Ontario, Canada) to foster local, sustainable food projects as a part of the community economic development strategy in the early 1990s during two distinct periods of provincial governance, one of which was characterized as a socially democratic government and the other, a "particularly virulent, revanchist form" of neoliberal governance. Regardless, Eaton found that both governments accommodated global neoliberal ideology that, more or less, required community organizations and activists to develop market-led reforms of local food and agritourism projects. According to Eaton, these food projects "were significantly hollowed out and their local and light green nature was harnessed as accumulation strategies" (p. 994). As a result, she reported that a turn to the local did not necessarily privilege a set of better ecological or social relations (p. 1004). Similarly, an earlier study by Feagan et al. (2004) examining the potential of farmers' markets to promote the goals of sustainability concluded that "...developing local opportunities via direct marketing for addressing social justice aims of sustainability is a big conceptual leap from a simple food purchase" (p. 250).

The emerging critiques are not meant to undermine the local food movement but to highlight that food politics delineated along simplistic economic local versus global designations no longer suffice as a mechanism for achieving "the alternative sociologies, economies, and agriculture espoused by contemporary food movements" (Roff, 2006, p. 513). There is no denying that place plays a central role in the discourse surrounding local food politics; however, the theoretical engagement with place needs to "move away from the idea that food systems become just by virtue of making them local and toward a conversation about how to make local food systems more just" (DuPuis and Goodman, 2005, p. 364). Some researchers suggest that this involves extending the LFM's engagement with the concept of place from one that is fixed 
on location to one that seeks an understanding of the food system through the lives of the people and places that give it shape and substance (DeLind, 2009; Hinrichs, 2007). In that way, the focus is directed away from place as a product to place as a process in which people can have an active role in creating; and through that experience realize the potential for change.

While appreciative that food politics is gaining mainstream momentum thanks to a number of popular writers advocating food re-localization (e.g. Smith and MacKinnon's The 100 Mile Diet: A Year of Local Eating (2007), Michael Pollans's The Omnivore's Dilemma: A Natural History of Four Meals (2007), and Food Rules: An Eater's Manual (2009), Barbara Kingsover's Animal, Vegetable, Miracle (2007)), DeLind (2009) cautions “...the public-at-large is not being asked to re-connect to context—-to the soil, to work (labour), to history, or to placebut to self-interest and personal appetite" (p. 7). To that extent, the local food movement's engagement with the concept of place has been characterized as relatively superficial. Reservations rest in what seems to be a shift from understanding the local food movement as a concept rooted in concern for justice, active citizenship, and sustainability to one that casts individual choice as individual freedom and market participation as community engagement. Echoing Allen and Hinrichs sentiments, DeLind is unsettled by the local food movement's emphasis on neoliberal ideology of consumptive engagement where people, consumed with "voting with their dollars", fail to question the underlying structures of the marketplace. If they had, DeLind argues, they would realize that the marketplace is neither a place nor a democracy where the "one person, one vote" has true currency.

In short, what researchers like DeLind are suggesting is a shift from seeing place as a location to uncovering the processes that create a 'sense of place' to help situate an understanding of the geography of responsibility that may transcend "food miles". Currently, 
research on the local food movement and its impact on community food security, urban planning and sustainability education (Jacobson, 2007; Mendes, 2007; Vallianatos et al., 2004) all seem to be flourishing. Yet, an understanding of how it is that people and places involved in the production of food come together to create the basic infrastructure to support and sustain a local food system is limited. And, perhaps this is what Feagan (2007) meant when he observed that the place of food has been silent, even in the midst of a fervent enthusiasm for the local.

In A Global Sense of Place (1994), place theorist Doreen Massey makes the case to consider place as a product of practices, relations, connections (or disconnections) that is constantly under construction through the practices of our everyday lives. While she acknowledges that an accumulated history can certainly characterize a sense of place, the construction of place is an on-going project in which its specificity is not pre-determined by history but rather "constructed out of a particular constellation of social relations, meeting and weaving together at a particular locus" (Massey, 1994, p. 154). Supporting a non-territorial reading of a politics of place, Massey's understanding of place is fluid, with neither fixed identities nor boundaries. Furthermore, in an era of globalization, Ash Amin (2004) adds that the rise of transnational flow and networks "no longer allow a conceptualization of place politics in terms of spatially bound processes and institutions" (p. 33). Massey, however, speculates that for this very reason, people will increasingly look inwardly for a sense of place, which is often associated with stability and the source of a unified identity. She problematizes this conservative notion of place by reminding us that people occupy different positions within any community and thus experience place differently. Communities constructed around single, essentialized identities run the risk of invoking "insider-outsider" sentiments that do not truly reflect how places, how localities, come to be. Today, a sense of place necessitates a "global sense of the 
local" where a defining characteristic of place is its unique set of interactive social relationsnear and far. In short, place must be understood on a "far larger scale than we happen to define for that moment as the place itself"' (Massey, 1994, p. 154).

\subsection{CHANGING FACES, CHANGING PLACES-RURAL POPULATION DYNAMICS}

Processes of global restructuring are attracting regional and national economies to consolidate primary sector industries (e.g. agriculture, forestry, mining) in exchange for more value-added opportunities in the manufacturing, service and information-based economy. One of the outcomes of this is a shift in human settlement patterns around the world towards urbanization, rural depopulation and a diminishing share of the workforce directly employed in land-based economies such as agriculture (Lucas Jr., 2001). As a result many rural communities are experiencing drastic population changes as economic and educational opportunities either push or pull people towards cities, exacerbating the rural-to-urban migration trend (Taylor and Martin, 2001).

Within the Canadian context, rural decline is ever present as it is reported that urban dwellers make up $80 \%$ of the Canadian population (Census of Population 2006, Statistics Canada). In a study that examined demographic changes in Canada from 1971 to 2001, Malenfant et al. (2007) found that the population living in a metropolitan area rose from 16.2 to 23.6 million people, an increase of $45 \%$. In contrast, over the past 30 years, the rural population grew only by $13 \%$, resulting in 6.1 million residents in 2001 . Figure 1 illustrates that the rural-tourban migration has been a persistent trend since the early 1900s; however, the growing disparity between the urban and rural population may give weight to what Michael Troughton (1995) 
understood of the situation in rural Canada_ "fragmented, increasingly powerless, and near collapse" (p. 296).

Urban and Rural Population, Canada from 1851-2006

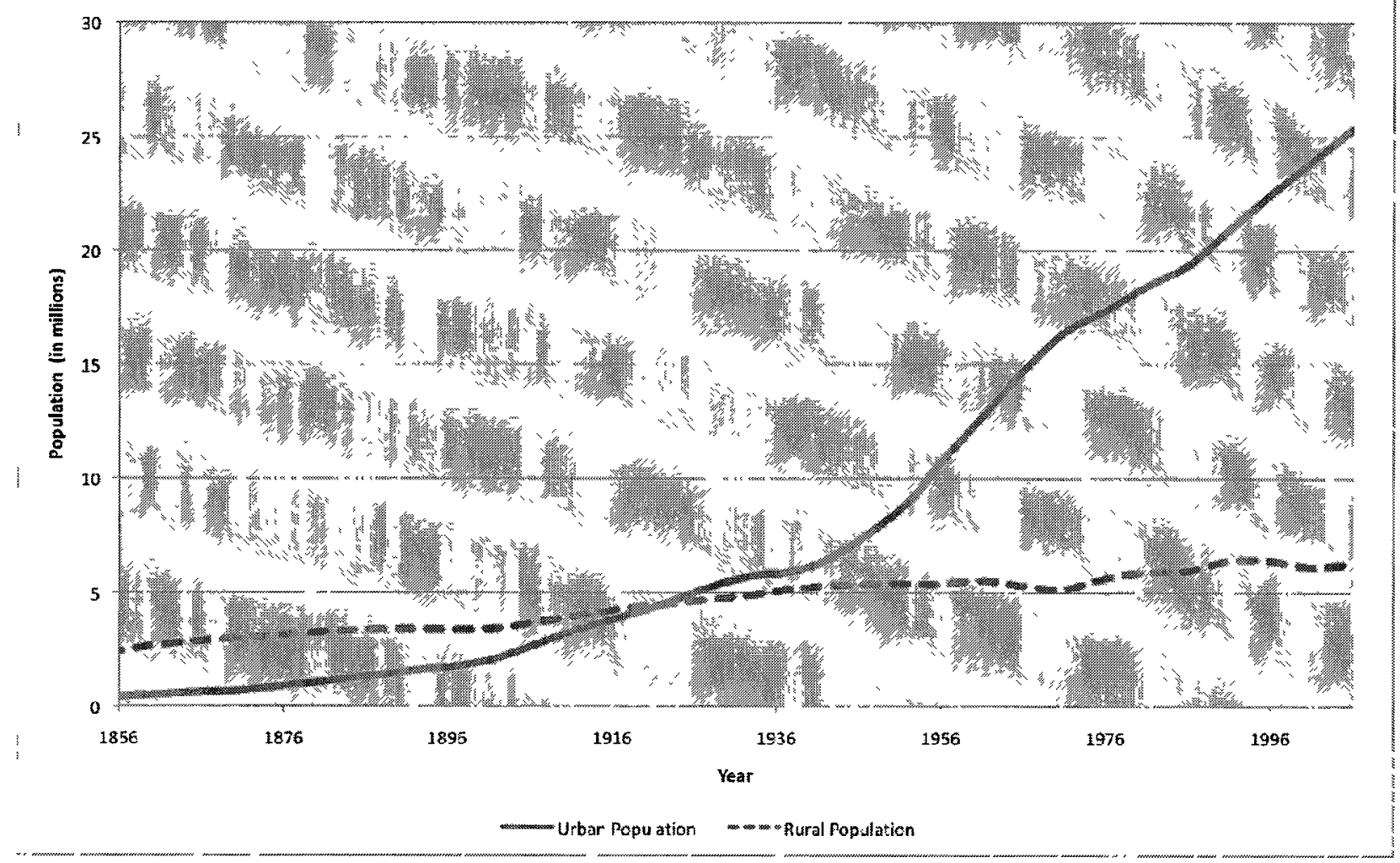

Figure 1. Urban and rural population, Canada from 1851-2006 ${ }^{2}$

Some may view urbanization as the demise of small and rural communities but others see different processes at play that are reconfiguring the nature and narratives of what constitutes urban and rural places itself. For instance, Paul Milbourne (2007) offers another perspective on the rural situation saying, “...rural mobilities are more than just movements between locations, they are bound up with shifting meanings of rural places and ruralites" (p. 382). Thus, a more critical engagement in the discourse of mobility requires an examination of inter-connected

\footnotetext{
${ }^{2}$ Source: Statistics Canada, Census of Population, 1851 to 2006.

Website: http://www40.statcan.ca/101/cst01/demo62a-eng.htm. Accessed January 9, 2009.
} 
realities, representations and everyday practices. This attentiveness to understanding the construction of rural places through relations and movement (as opposed to location) parallels Massey's concept of a 'global sense of place" in which the specificity of a place is created by a network of social and material interactions. Moreover, it opens up the conversation of rural mobility to include not just those who are leaving but also those who are taking part in reconstructing the new rural. In comparison to rural migration, counterurbanization from a numbers perspective seems inconsequential, but the movement represents an interesting dynamic that highlights how rural spaces are in store for some potentially major changes in which definitive "urban" and "rural" boundaries are blurring.

\section{The Role of Counterurbanization}

The counterurbanization phenomenon has been recognized for some time, namely in countries and regions in the global north; however, an increasing number of studies have highlighted these migration patterns, processes, and experiences in the global south (e.g. Potts, 2005). The most common understanding of counterurbanization is a movement from a more densely populated area to one that is less populated (Mitchell and Bryant, 2009). However, since being coined by Berry (1976), the definition of counterurbanization remains loose as the concept takes on many forms and functions to describe a variety of activities from population decentralization (Champion, 1994), net migration trends (Kalogirou, 2005), to urban residents' motivations for

relocating from metropolitan to non-metropolitan areas (Halfacree, 2006). While a fixed definition to describe counterurbanization falls short of reflecting the complexity of the phenomenon, Claire Mitchell (2004), nevertheless, notes that the word 'counterurbanization' is "too broad to cover its depth of meaning" (p. 15). Moreover, the discipline can benefit from an element of organized chaos to provide more consistency and better comparability between 
studies examining the phenomenon. To this end, Mitchell proposes the 'counterurban', 'counterurbanizing' and 'counterurbanization' conceptual framework to distinguish and organize the process of population distribution as it relates to the growth of rural places. As a pattern, the counterurban is a deconcentration settlement phenomenon to be explained. As a process, counterurbanizing entails the different processes such as net migration and net natural increase that bring out the counterurban pattern. Finally, counterurbanization is understood as a movement, situated among other settlement movements such as rural-to-urban and lateral migration. Counterurbanization as a movement is the focus in this research.

Additionally, within this movement, Mitchell (2004) describes three distinctive types of counterurbanization based on motivations, economic, and environmental ties to the community of origin and destination. In brief, exurbanization occurs when employment is retained in the larger community of origin and if the sole reason for the migration decision is the rurale appeal. Displaced urbanization is almost at the opposite end of exurbanization in that it tends to capture those who move out of economic necessity (e.g. cheaper, affordable, living cost, employment). Lastly, individuals who sever employment ties with the community of origin and relocate to pursue a livelihood and lifestyle in a rural environment are said to be associated with antiurbanization (ruralisation). With the exception of those who feel squeezed out of cities due to their economic situation (i.e. displaced urbanites), the rurale appeal is said to play significant role in fueling counterurbanization. Arnon and Shamai $(2010$, p. 707) broadly define the rurale appeal as the non-economic "quality of life" motivations based on:

...the desire to replace the negative sides of the urban environment (noise, pollution, crowds, impersonal and artificial relationships) with the positive idyllic cultural stereotyped image of rural life and values: living in less dense, safer and healthier rural areas, close to nature in harmony with the landscape; 
and a happy and meaningful social life in the community, especially for the sake of their children.

However, even within the discipline, there are debates challenging this widely held belief among academics. For instance, Paniagua (2002) conducted a qualitative study on recent urbanrural migrants (less than 5 years since relocation) in three rural areas in Spain to examine their socio-economic characteristics, the migration process, new business characteristics and their interaction with the local community. Contrary to research that implies counterurbanization motivations stem primarily from an idealized view of the countryside, her research suggested that the desire to be self-employed and the freedom and responsibilities that came with that were key, and while important, environmental considerations were secondary. In other words, counterurbanization is not a homogenous movement.

Still, the rurale appeal has a certain draw as evidenced by the practice of place branding (see Govers and Go, 2009) and the rise in rural development strategies leveraging rural amenities to attract new residents, often middle class urbanites in search of opportunities to live their dream lifestyle (Paniagua, 2002, Tonts and Greive, 2002, Mitchell and Bryant, 2009). For instance, in the same study by Paniagua (2002), she found that urban-rural migrants participating in her research were typically skilled, often married, and university educated middle-to-late aged people seeking to redefine work conditions that align with their desired lifestyle. The majority of the migrants established family-run, rural hospitality services even though they had limited experience or specialized training in how to start or practice their new activity. Reliance on personal assets derived from the city (e.g. savings, sales of home) was often used to finance the start-up cost and support the family while developing the business. 
Interestingly, the question of whether or not counterurbanization should be considered a distinct phenomenon has been at the centre of debate over the last few decades. Phillips (2010) points to the close association between rural gentrification and counterurbanization saying the two concepts has been seen "as highly interrelated concepts, such that they might be synonymous, or as least highly commensurable with each other" (p. 540). As early as the 1980s some scholars have been suggesting what is actually happening in rural and small towns is an extension of urbanization in which the "urban-rural movement seems to be rather a mechanism of the diffusion of urban-centred behaviour and culture than an expression of any true countertrend to urbanization in a socio-cultural meaning" (Vartiainsen, 1998 as cited in Mitchell, 2004, p. 18). Akin to Vartiainsen's discussion on rural gentrification, Walker (2000) speaks to the transformations taking place in rural and small towns as urbanites move in large numbers to the countryside. Examining communities near the rural-urban fringe and the urban shadow in the Greater Toronto area, Walker notes that an infusion of affluent in-migrants hoping to live out their vision of the rural idyll involves struggles over social infrastructure, amenities, privacy and so on as "newcomers turn their new homes and home territories into their own image" (p. 1). These struggles, effectively, become a part of an iterative process involved in constructing the new rurale to reflect the values, imaginaries, and mobilities of a shifting social demographics.

In the opening chapter, a rural renaissance was suggested to be emerging as part of the local food movement (Mailfert, 2007) with "new argriculturalist" attempting to make connections to rurality (Halfacree, 2007). Given the declining farmer population and concerns about the ability for many rural communities to sustain themselves due to a shrinking population base, the arrival of in-migrants with an entrepreneurial spirit could be viewed as promising. In history, there has already been a similar movement in North America and parts of Europe (e.g. 
Britain, Netherlands, Denmark, German) where urbanites abandoned the city life in search of a more authentic, meaningful lifestyle. This typically involved people migrating to a more rural location with a desire to reconnect to the land and "a kind of social movement resisting the dominant forces promoting capitalist globalization and neoblieralism" (Halfacree, 2007, p.5). The "back-to-the-land" movement, as it is commonly known, marked the 1960s and 1970s.

Like other counter-urbanites, there can be many types of "back-to-the-landers" but more often than not they comprise urbanites who seek to escape the city life for a lifestyle change. Hoey (2006) uses the term "corporate refugee" to describe these individuals who are starting over as they "...move not only along asphalt roads to new geographic places but also along lesstangible personal paths of introspection and self-discovery blazed by individual negotiations between work, family, and self" (p. 349). Many are motivated by their perception and construction of the rural idyllic, and hope to find a better a sense of community and lifestyle that appeared to be elusive in the urban landscape (Mitchell et al., 2004; Halfacree, 2006). The success of the 'back-to-the-land' movement, past and present, is difficult to discern; however, Halfacree suggests the longevity of these initiatives is questionable as it was not uncommon to find people reverting back to some element of their previous lifestyle after "attempts at living off the land often proved too arduous" (2006, p. 319).

At the moment, within the local food movement, there is an ever-increasing dialogue and call for new farmers, along with the drive to engage individuals from non-farming, urban backgrounds to become a part of reshaping the agricultural landscape. However, little attention has been paid to their experiences transitioning to rural farming communities by understanding their sense of place. Overall, there is relatively limited research on new urban-oriented farmers but of the ones that do exist, the focus has been about NUOFs' production and business skills 
development (see Niewonly and Lillard, 2010) which serves the purpose of developing better, more effective and successful farmers. In other words, there has been a focus on how NUOFs can impact the agricultural economic landscape. However, the practice of agriculture is grounded in places; and like other counter-urbanites, the importance of a sense of place- imagined, real, or constructed-lead NUOFs to making a substantial decision to uproot themselves, and sometimes their family too.

Mailfert (2007) reports that compared to new farmers with a rural background, "neofarmers' struggle at times with being accepted as "proper" farmers by the community they lived and worked in. Thus, assessing the evolution of their 'sense of place' exposes the social and spatial relations in shaping identities, differentiating social cohesion and influencing the dynamics of community life (Foote and Azaryahu, 2009). And perhaps from that 'sense of place', we can broaden an understanding of how to support NUOFs who are not only taking up the challenge to be a part of the agricultural landscape but also one that is embedded in the rurale. As Halfacree has noted, while some find their paradise, others do not as a "truly consubstantial back-to-the-land lifestyle is an extremely challenging project for all but the most prepared" (2006, p. 330).

\subsection{FROM THEORY TO PRACTICE}

The previous sections discussed the politics of place within the local food movement and called for a shift in understanding place as a location to a 'sense of place'. Broadening this scope effectively situates the LFM discourse within larger processes at play that impact how new urban-oriented farmers can, have been and will be involved in constructing a sense of place for themselves. The purpose of this section is to introduce the 'sense of place' framework used to explore how NUOFs construct their 'sense of place'. 
Sense of place can be defined in a number of ways. These possibilities facilitate dynamic discussions yet at the same time make it difficult to differentiate consistent dimensions of sense of place for empirical research. Terms such as belonging, sense of community, place bonding, place attachment or affiliation appear with regularity in the literature and are sometimes used interchangeably. For instance Pretty et al. (2003) report that Altman's understanding of place attachment involves emotional ties and affiliations with place which resembles Cuba and Hummon's (1993) operational definition of place identity. While Pretty et al. (2003) suggest that loose terms and definitions contribute to the "theoretical quagmire" (p. 274) they also recognize, that given the nature of this phenomenon, 'sense of place' may not be suitable for positivist traditions of standardization. Nevertheless, researchers are developing various frameworks to investigate 'sense of place' by conceptually organizing the relationships between people and places. This process is not meant to be overly prescriptive or set boundaries around 'sense of place'; but as Jorgensen and Stedman (2001) suggest, it is a mechanism to better "...systematize important theoretical statements about the interplay between the physical environment, human behavior, symbolic meanings, and sense of place" (p. 683).

Nielsen-Pinncus et al. (2010) examined sense of place through an environmental psychological lens that emphasized the attitudinal relationship between people and their environment. They used place identity, place attachment and place dependence to assess the differences between new and longtime residents as well as absentee and local residents' sense of place', or as they preferred, 'place bonding'. Williams et al. (2010) contend that such conceptual frameworks are less place-based because of a focus on the psychological components. In their study, a more authentic geographic concept of a 'sense of place' is claimed by subscribing to a definition provided by The Dictionary of Human Geography (2009) which states that sense of 
place refers to "the attitudes and feeling that individuals and groups hold vis-à-vis the geographical areas in which they live. It further commonly suggest intimate, personal, and emotional relationship between self and place" (p. 921). And shortly after, William et al. (2010) state that sense of place refers to "geographical place, social community/environment, and having psychoanalytical meaning" (p. 921). Instead of highlighting theoretical inaccuracies, William et al.'s comments reinforce that a 'sense of place' is a very complex and interdisciplinary subject matter that cannot be fully understood by restricting its possibilities into pre-determined academic fields. In that respect, 'sense of place' research exists on a continuum and differences are to be anticipated. But as Stedman (2003) maintains, it is important to keep in mind that sense of place is a variation of a "three component view that weaves together the physical environment, human behaviours and social and/or psychological processes" (p. 671).

Taking a similar tripartite approach like Nielsen-Pinncus et al. (2010) and Stedman (2003), this study adopts a sense of place framework that integrates three core concepts: place identity; place attachment and sense of community. The figure below illustrates my understanding of the framework where each concept is distinctive but feeds into one another; and as a whole, emphasizes the complexity in constructing a 'sense of place'. 


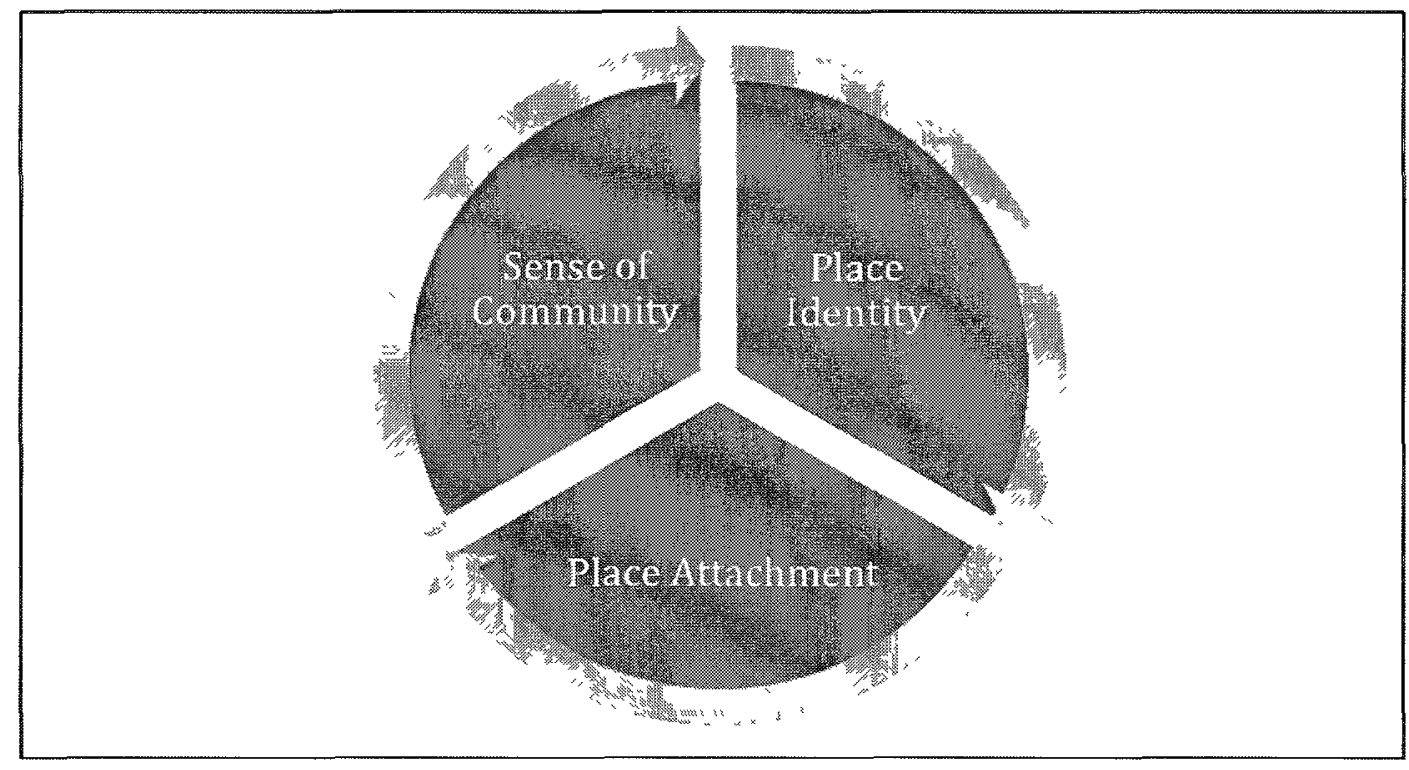

Figure 2. Sense of place conceptual framework

Place identity can be thought of as how an individual uses the environment to situate his or her identity (Cuba and Hummon, 1993). Put another way, it is how places can become a way of articulating who we are. Lappegard and Kolstad (2007), for example, examined people's perceptions about their place of residence as an expression of their identity at a neigbhourhood level. They reported that the majority of the research respondents indicated that their place of residence reflected some aspect of who they are (e.g. personality, taste, interests, life phase and social status). As such, Stedman (2003) sees place identity as a form of place attachment because of the symbolic importance of the physical environment in defining oneself. However, in this study, place attachment refers to the emotive bond, positive or negative, that develops between people and their environment. Some researchers consider place attachment as only the positive bonds between people and the physical environment, but this is not reflective of the larger emotional spectrum that can exist between people and places (Manzo, 2005). Lastly, a 'sense of community' element is integrated into the framework to draw attention to the social space. 
McMillan and Chavis (1986) describe this 'sense' as social attachment to the community where people have a sense of belonging and “... a feeling that members matter to one another and to the group, and a shared faith that members' needs will be met through their commitment to be together" (p. 9). 


\section{CHAPTER 3 | FUNDAMENTALS OF THE RESEARCH PROCESS}

"[H]uman geography is always produced by individual, flesh and blood nameable people who you can see and perhaps meet." $\sim$ Cloke et al., 2004, p. 5

The quotation above describes research of a socio-spatial nature as a process bound by and to the human form. As such, the production of knowledge and the choices that shape the design of the study is the responsibility of the researcher. For this reason, it is vital that the fundamentals of the research process are made visible. This chapter discusses the methodological perspectives underpinning this research, provides information about the recruitment strategy and research participants, and outlines the analytical approach. Reflections about the research process conclude the chapter.

\subsection{RESEARCH DESIGN-FRAMEWORK}

To begin, five fundamental building blocks must be considered in undertaking social science research. As outlined by Colin Hay (2002), they include the researcher's ontological, epistemological and methodological orientation as well as the methods and data sources. Hay's approach is employed to articulate the foundations of the research process used to guide this exploratory study that examines how new urban-oriented farmers construct a 'sense of place'. A description of the elements and its application in the context of this research is provided below with Table 2.0 showing the relationship between the building blocks. 
Table 2. Approach to studying a 'sense of place'

\begin{tabular}{|c|c|c|c|c|}
\hline Ontology & Epistemology & Methodology & Methods & Sources \\
\hline Constructivism & Interpretivist & $\begin{array}{l}\text { Ethnography: a } \\
\text { small number of } \\
\text { in-depth case } \\
\text { studies; } \\
\text { qualitative and } \\
\text { quantitative } \\
\text { research strategy; } \\
\text { participatory }\end{array}$ & $\begin{array}{l}\text { Semi-structured } \\
\text { interviews; } \\
\text { participant } \\
\text { observations; } \\
\text { photovoice; } \\
\text { resource network } \\
\text { mapping }\end{array}$ & $\begin{array}{l}\text { Interview } \\
\text { transcripts; } \\
\text { field notes; } \\
\text { photographs; } \\
\text { spatial data }\end{array}$ \\
\hline
\end{tabular}

\section{Ontological Perspective}

Ontology is concerned with the nature of reality and in essence the lens through which we see the world and the starting point to understanding the foundation of how we know what we (can) know. Cited in Grix (2002, p. 177), Norman Blaikie describes ontological expressions as "claims and assumptions that are made about the nature of social reality, claims about what exists, what it looks like, what units make it up and how these units interact with each other. In short, ontological assumptions are concerned with what we believe constitutes social reality". A constructivist perspective frames the study reported here where reality is understood as a social phenomenon, created by the interactions between humans and their world and the meaning they make from it. Put another way, there is no objective reality independent of social actors and "there is no one truth waiting to be discovered" (England, 2006, p. 288). Effectively, the production of knowledge is a very humanistic endeavor that reflects the contributions of the research participants and the researcher to describe an evolving social phenomenon contextualized by a particular moment in time and space. This research did not seek to unearth any truths; rather it strived to offer a perspective into how the research participants define their 'sense of place'. 


\section{Epistemological Perspective}

Epistemology is the study of knowledge and the process of knowing what is believed to exist. With the belief that individuals are constantly constructing meaning and an understanding of the world as they interact with it, an interpretivist perspective was chosen for this research topic. Interpretativism explores the subjective significance in place-making and celebrates the "human part of human geography" (Cloke et al., 2004, p. 22). In contrast, a positivist epistemology tends to privilege objectivity and portray human beings "as little more than mere objects or at best robots with no interior sense of themselves, no intentions, no hopes or fears and no creative role to play in shaping their surroundings" (Cloke et al., 2004, p. 22). By embracing the idea that people are shaped by their experiences and background, an interpretivist strategy acknowledges the differences between people, the importance of 'situated knowledge' and the challenges of producing value-free knowledge and universal truths.

\section{Methodology}

Methodology refers the strategy used to acquire knowledge and the reasoning behind the data collection process. Working on the premise that "all knowledge is produced in specific circumstances and that those circumstances shape it in some way" (Rose, 1997, p. 305), an ethnographic approach was an appropriate choice to explore the richness and complexities of how individuals experience and understand their sense of place. Grounded in the everyday, an ethnographic perspective sought to understand rather than to explain, with the goal of "investigat[ing] some aspect of the lives of people who are being studied, and this includes finding out how these people view the situations they face, how they regard one another, and also how they see themselves" (Atkinson and Hammersley, 2010, p. 4). 
Atkinson and Hammersley (2010) describe five core features of ethnographic work—all of which informed the design of this study. First, data collection took place in the context of the participant's environment. The element of field research was central to this research and all interviews were conducted in the participant's community. Wherever possible, the researcher lived and worked with each participant on their farm to contextualize people's action and accounts. Second, data was gathered from a range of sources. Informal semi-structured interviews, along with photo documentation and a resource network mapping activity provided qualitative and quantitative data that when combined can "...provide a more comprehensive and detailed understanding of the phenomenon under study" (Dunning et al., 2008, p. 147). Third, data collection was relatively 'unstructured' and flexible to incorporate participants' input and insights into the situation. While more strategic questioning was used towards the end of the field research to explore emerging themes, categories used for interpretation were not pre-determined prior to the data collection but generated through the process of data analysis. Fourth, a small group of individuals drawn from different rural communities was the focus of this in-depth study. Lastly, the data analysis sought to understand the participants' point of view in constructing a sense of place.

A key principle of this research not yet addressed is its participatory nature. Seeing the importance of local knowledges and the everyday as a space where people make sense of who they are and the world in and around them, participatory approaches "lend themselves to research where people's relations with and accounts of space, place and environment are of central concern" (Pain, 2004, p. 652). In this case, the ethnographic methodology was a form of participatory research in which the research participants were encouraged to "us[e] their own words and frameworks of understanding" (Pain and Francis, 2003, p. 46). For the researcher, this 
involved immersing oneself in the farmer's daily lives to experience "how practices and beliefs... are constructed, reaffirmed or reworked through the social encounters ${ }_{9}$ experiences and dilemmas of everyday life" (Long, 2001, p. 170). More importantly, the participatory process opened up opportunities for reciprocity between the researchers and the research participants. The offer to work and help with farm activities was an effort to create a mutually beneficial learning exchange.

\section{Methods}

Methods are tools and procedures used to gather and analyze data. This study used semistructured interviews, participatory photography, resource mapping and participant observation to collect qualitative and quantitative data. In the processing stage, a mixed methods approach allows for triangulation, an analysis technique employed to improve rigour and credibility (Streubert Speziale and Carpenter, 2003; Hay, 2000), while at the same time allowing for "difference[s] to be held in productive tension, and may keep our research sensitive to a range of questions and debates" (England, 2006, p. 291). This section outlines each of the research tools, followed by an overview of the data processing procedures.

\section{Participant Observation}

Participant observation is often associated with research of an ethnographic nature whereby the researcher is "participating, overtly or covertly, in people's daily lives for an extended period of time, watching what happens, listening to what is said, asking questions-in fact, collecting whatever data are available to throw light on the issues that are the focus of the research" (Hoggart et al., 2002, p. 252). There are options to the level of engagement from a complete observer to participant role. The former tries to remain detached from the situation while the latter participates in the situation, thus becoming a participant-observer. Regardless of which role 
the researcher takes Robin Kearns (2000) argues "even those who believe that they are present but not participating in a research context often unwittingly alter the research setting" (p. 110). For this study, the researcher took a participant-observer role as it facilitated two important processes: (1) making the most of opportunistic moments in the field (Punch, 2001), (2) building a relationship of trust with people over time (Dowler, 2001; Hay, 2000). For instance, while working in the field one day, one of the farmers suggested I talk to her neighbour who was also a new farmer but came to farming in a very different manner. This particular farmer suggested her neighbour could add a different perspective to the research. I felt honoured that this farmer considered the research in a larger context and offered to introduce me to her neighbour. Had I only conducted a survey or interviewed her over the phone, I'm not sure if this opportunity would have presented itself.

Participating in everyday activities such as sharing meals, watching movies, attending social functions, and spending time with their family contributed to the research process as a lived experience for both the research participants and researchers. For the researcher, it was an opportunity to come a little "closer to an adequate understanding of their culture and lifestyle" (Punch, 2001, p. 166). That said, I would argue that we both caught a glimpse of each other's lives. During the field research, field notes were recorded in a journal detailing key events and impressions of my experiences. Over the course of the summer, it became an intimate confidant as I discussed the things that happened, expressed sentiments of excitement, frustration, and personal reflections. It was a rich source of information used to help contextualize element of the research, especially in the data analysis phase. 


\section{In-depth semi-structured interviews}

In-depth interviews were used to develop a better understanding about the farmers themselveswhere they came from, their motivations to farm, what successes and struggles they faced. An informal semi-structured approach to the interview allowed for flexibility but also ensured that any relevant themes were addressed and a level of consistency between the farmers interviewed. The questions were open-ended, and as suggested by Hay (2000), the interviews provided different insights, opened up debates and highlighted consensus on some issues (p. 52). All interviews were conducted and recorded in the context of the participants working or living environment (e.g. in their house, in the field, or in the car en route to the market). The length of the interviews ranged between 45 minutes to $21 / 2$ hours.

\section{Photovoice}

The principle behind photovoice is that an image illustrates a point of view "about the world based on individual experiences and represents deeply held values" (Beilin, 2005, p. 59). In this study, photovoice was used to help participants articulate their thoughts and experiences around living and working in a rural farming context that might surface unexamined or taken-forgranted thoughts. There is more to visual images than meets the eyes (Wang and Burris, 1994). Researchers like Michael Crang and Ian Cook (2007) write,

[a]s a non-verbal medium, photos may serve almost as projective stimuli that reveal routinised or unconscious responses that are scarcely thought about by the participants-for instance, in the way some images are accepted or constructed and in the tension between how some absences are not noted or remedied in photography but, at the time, might still be spoken about. (p. 112)

In terms of process, participants were asked to take photographs that represented life as new urban-oriented farmers in their respective community with three key questions in mind: (1) What does being a farmer mean to you? (2) Having decided to farm, how do you feel 
challenged? (3) Having decided to farm, how do you feel supported? Farmers were instructed to take up to 10 photos per category and managed their own time to complete the activity. Some completed the activity within an hour while others extended the process over several days. In all cases, a digital camera was used. Participants were then asked to explain the significance of each image, specifically the idea behind the construction of the images which effectively gives 'voice' to the photograph (Beilin, 2005, p. 60). The technique of combining photos with an interview is a useful process to undergo, "first, because it gives detailed information about how informants see their world; and second, because it allows interviewees to reflect on things they do not usually think about" (Rose, 2007, p. 243).

The original intent was for the participants to produce the images themselves; however, over the course of the research process, it became apparent that the research participants wanted to include photos they already had that could better capture the essence of what they wanted to express. For example, participants wanted to include photos of family members and friends who were not currently at the farm to represent their support network. The slight variation in the method may have allowed some participants to widen their scope compared to others who were not given that option. However, even with the constraint, some farmers demonstrated their creativity to convey their intended message. For instance, a photo of a birthday card from a farmer's parents was used to illustrate the significance of family instead of a picture of the parents. Furthermore, knowing that participants had to go through the thought process of deciding what they wanted to communicate through the photos and discuss the content of each photo supported the decision to include existing photos. In the bigger picture, incorporating photos that were not technically produced by the participants still had the ability to "provide clues to the ways in which [the participant] view their environments and to the elements that they 
see as significant" (Hall, 2009, p. 457). In retrospect, it foreshadowed the geographically dispersed nature of NUOFs' sense of community and also highlighted the temporal dimensions of this research as an image of winter sparked an unlikely conversation. More importantly, it was a reminder that in undertaking ethnographic research of a participatory nature, the process should be open to different possibilities and not be exclusively controlled by the researcher.

\section{Resource Network Mapping}

Resource mapping was used in this study to elicit and record geographical data to develop a spatial understanding of what a 'sense of place' looked like for NUOFs. Essentially, a bird's eye view helped identify major socio-spatial relationships or associations between NUOFs and their environment. Similar to the technique of participatory photography, allowing NUOFs to identify their own key resources provides an opportunity for their perspective to come through first and foremost which, according to Perkins (2007), could offer "new possibilities for articulating social, economic, political or aesthetic claims" (p. 12).

The mapping process began with a brainstorming session about the resources they felt were significant in helping them establish and sustain themselves as individuals transitioning to a rural livelihood and lifestyle. Some preferred a discussion format while others made use of poster paper and markers. Next, a list of the resources was produced with information pertaining to the nature of the resource and its location. While some had very limited entries, others were quite extensive; this seemed to correspond to how long they have been farming. The length of the exercise ranged from one to three hours. Of the three methods that required direct input from the participants, this was the most demanding. At times, participants expressed feelings of not knowing where to start, stating that many people and experiences led them to where they are, or had difficulty recalling specific details. However, once reminded that the scope of this network 
mapping activity was not to produce an exhaustive list of all the resources they ever accessed or provided, but rather a portrait of the place, people and things they considered most significant in helping them establish and sustain themselves as farmers in these rural communities, there was a sense of relief.

\section{Data Sources}

The methods employed in this study produced a diverse collection of textual, visual and spatial data. Below is a brief description of each data source and the procedures used to process raw data into an organized and manageable format that could be effectively used for the analysis.

- Audio recordings-Audio recordings of the semi-structured interviews and photovoice discussions were transcribed on a word processor using an intelligent verbatim approach. Essentially, this meant excessive use of 'like', 'you know','ums', and 'ers' were excluded unless they had significance to the meaning. The transcriptions were arranged in a table format with the text onto the left side and a blank column to the right to provide space for researcher's notes and coding. Semi-structured interview transcripts were labeled by participant ID number (e.g. F1_INT, F2_INT). Similarly, photovoice transcripts were labeled by participant ID and the main content (e.g. F1_PVM). PV is an abbreviation for 'Photovoice' and the ' $\mathrm{M}$ ', 'C', or ' $\mathrm{S}$ ' designation represented the category each transcript belonged to: meaning, challenges, or support.

- Photographs - The photographs taken by participants during the photovoice activity were saved as digital files and labeled by participant ID and organized into three categories that corresponded to the questions (i.e. meaning, challenges and support). A total of 211 photos were used in this study. A hard copy was printed and helped in the coding and analysis process. 
- Field Notes-A handwritten and electronic journal was kept to record field notes. Entries varied in length and intensity. Notes included the date, time and location of the observations, specific details about an event or a situation such as who was there, what was being talked about, other sensory impressions, and thoughts or questions that came up throughout the fieldwork. The field notes contained descriptive, analytical or reflective information that was used to help contextualize the analysis.

- Network Mapping-An Excel database was created to document the spatial data, organized by resource location and type. Entries were assigned a Resource Identification Number (RIN) to keep the identities of the participants and their resources anonymous. The locations of each resource were provided at the municipal level (e.g. Toronto, Guelph). Next, the distance between each resource and the NUOFs place of residence was calculated using Google Maps based on ground transportation (i.e. driving). This was the preferred method over the "crow flies" approach because it was more likely to reflect actual traveling distance. Resources located within a $100 \mathrm{~km}$ radius were given a value of one. Resources located $100 \mathrm{~km}$ to $200 \mathrm{~km}$ are given a value of two. Resources located $200 \mathrm{~km}$ or more are given a value of three. Resources of a virtual nature (e.g. website) are given the value of four. Next, participants had to label each resource by the nature of its function, or functions as each identified resource could have had multiple roles. Typically, resources that involved a formal exchange of goods or services (e.g. direct sales consumers, the specialty greenhouse equipment store, hired help) were grouped under 'Goods and Services'. Resources under 'Knowledge and Advice' were in general the people or places NUOFs turned to for information. Friends, family or colleagues or 
other individuals who were considered as an important part of NUOFs social network had a 'Personal and Social' designation.

\subsection{RECRUITMENT STRATEGY}

As this research was interested in exploring the experiences of new urban-oriented farmers transitioning into a rural livelihood and lifestyle, each participant had to self-identify as having no direct agricultural or rural background. In other words, they were not raised in a rural farming household or community. One participant shared that he was raised in an urban environment his whole life but acknowledged that his parents farmed at one time in their life. Participants also had to consider farming as their principle activity or profession with no more than five years operating a farm business. The participants had to also demonstrate involvement in the local food movement.

Exploratory by design, this study did not aim for a representative sample, thus a purposive sampling strategy was used. Techniques include snowballing, criterion and opportunity sampling (Hay, 2005, p. 72) to help identify potential participants who might otherwise be difficult to locate. The snowballing technique refers to recruitment by word of mouth. In this case, a farmer whom I knew through my farming experience in Iroquois initiated the process. After explaining the research project to my farmer friend, I asked if she knew of anyone who would be interested or suitable for the research. She forwarded my information to a person who decided to be a part of the study. The majority of the research participants were identified through the snowballing technique. A sample drawn from people based on their availability to participate in the study and meeting the research criteria characterize opportunity and criterion sampling. After attending a conference at the University of Toronto in May 2009, I 
met a few farmers who met the research criteria and expressed interest. Later that month, I followed up with each person and it resulted in having two more individuals join the study. The remaining two farmers responded to an email I sent out using a business directory produced by an environmental education centre showcasing new farmers in Ontario. As a small qualitative study by design, the findings of this research cannot be generalized to the new urban-oriented farmers population as a whole.

As part of the recruitment strategy, a knowledge exchange was used as an incentive to aid the recruitment process. Having worked on farms before, I knew the summer would be a busy time and that an extra pair of hands would be appreciated. In exchange for NUOFs' participation in the study, I would help with daily farm work during my stay. I informed them I had previous farm experience, and emphasized how the research could adapt to their working scheduling (e.g. we could do interviews while weeding or out in the field). This seemed to appeal to the farmers, as one expressed it, "Sweat equity in exchange for a bit of chatting? I'm all for that".

The field research took place from June 29, 2009 to September 5, 2009, with a short break midway through (see Table 3). The break was used as an opportunity to step back and reflect on how the research was going and transcribe recorded interviews. Time spent at each sited varied between 5 to 12 days depending on the agreement that was reached between the farmers and the researcher. A number of variables impacted the length of stay such as the farmer's availability, their work schedule, accommodation considerations as well as the researcher's timeline. There was one exception to this situation where an additional research participant was identified and included in the study. While time was spent at her farm and with her family, over night accommodation was not a part of the routine. 


\section{Table 3. Field Research Synopsis}

\begin{tabular}{lll}
\hline Site & Location $^{3}$ & Field Visit Dates \\
\hline 1 & 42 & June 29-July 8, 2009 \\
2,3 & 41 & July 8-July 19, 2009 \\
4 & 23 & July 19, 2009-July 29, 2009 \\
5 & 23 & July 29, 2009-Aug. 2, 2009 \\
Break & $\ldots$ & Aug. 2, 2009-Aug. 8, 2009 \\
6 & 23 & Aug. 8, 2009-Aug. 13, 2009 \\
7 & 16 & Aug. 13, 2009-Aug. 21, 2009 \\
8 & 23 & Aug. 21, 2009-Aug. 29, 2009 \\
9 & 18 & Aug. 29, 2009-Sept. 5, 2009 \\
\hline
\end{tabular}

\section{Research Ethics}

This research project was reviewed and received ethics approval from the Carleton University Research Ethics Committee. No significant risks were anticipated for individuals participating in the study. As a part of the informed consent process prior to the field research, participants were informed of their right to withdraw from the research at any time and decline from discussing any sensitive topics. Should they decide to withdraw their participation, they could choose whether the information provided may be used or should be destroyed. Also, I would arrange for alternative living and working arrangements immediately. The use of pseudonyms and the exclusion of photos with identifiable people protect the anonymity of the research participants.

\section{An Introduction to the Research Participants}

This ethnographic research involved a small sample of nine individuals who recently migrated to rural Southern Ontario communities in the last five years to farm. These communities are located in the Bruce (CD 41), Durham (CD 18), Grey (CD 42), Kawartha Lakes (CD 16) and Wellington regions (CD 23) (see Figure 3). With fewer than 400 people per square $\mathrm{km}$, the communities are

\footnotetext{
${ }^{3}$ Census District Number, see Figure 3 for location.
} 
considered rural municipalities (see Table 4). These counties experience relatively incremental population growth, and over the past five years, an influx of in-migrants represented $16 \%$ to $20 \%$ of the population. A high percentage of these communities' population self-identified as third generation Canadians. This demographic profile is significantly different from some of the urban communities that NUOFs come from. For instance, the city of Toronto reports that $60 \%$ of their population are first generation Canadians.

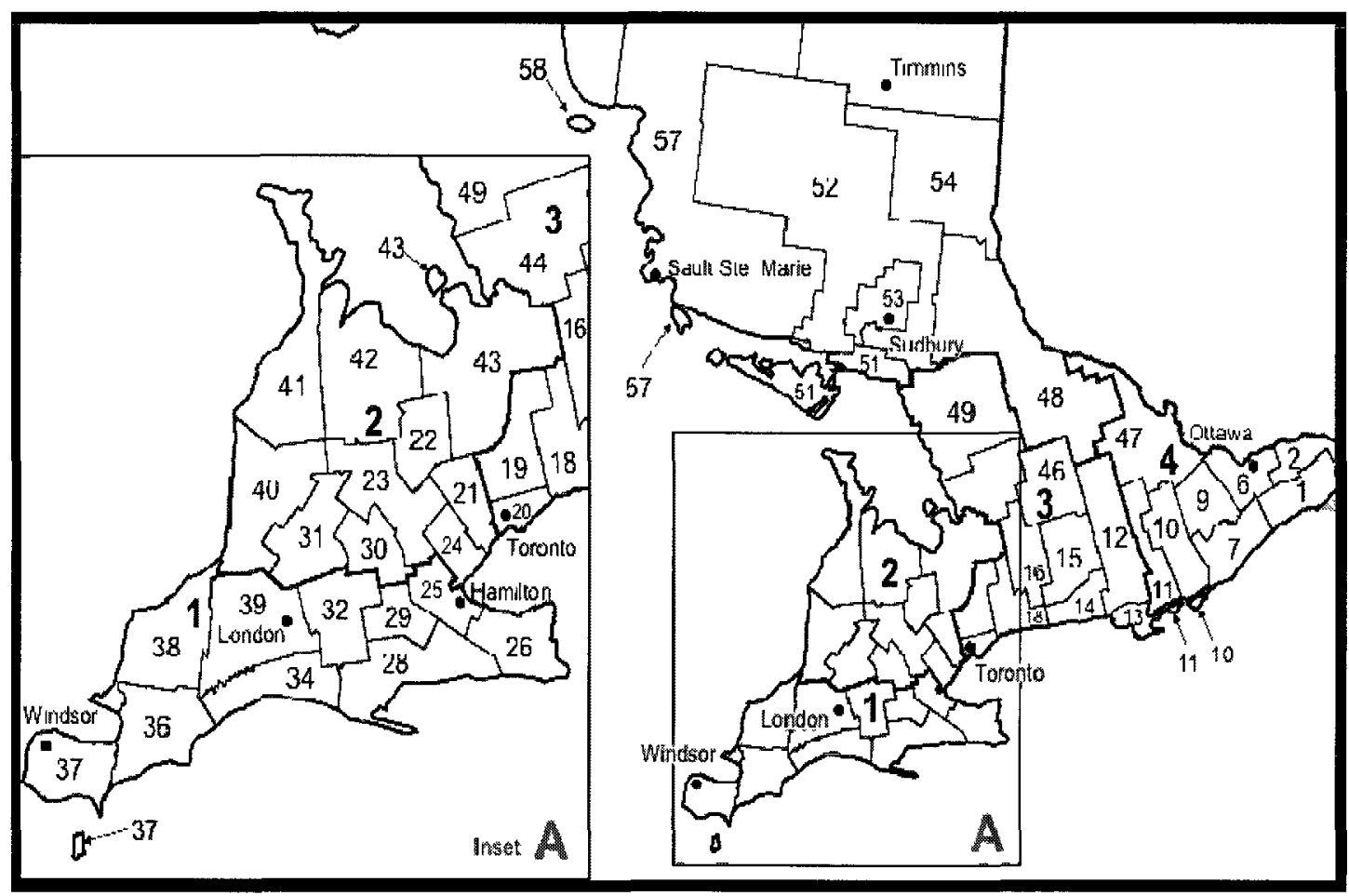

Figure 3. 2006 Census Districts, Southern Ontario ${ }^{4}$

\footnotetext{
${ }^{4}$ Source: Statistics Canada (2006b). 2006 Census of Agriculture, Agriculture Division. Website: http://www.statcan.gc.ca/cara2006/reference map-carte-eng.htm\#仿. Accessed Feb 18, 20011.
} 
Table 4. Census division demographic profile of NUOF'' communities in $2006^{5}$

\begin{tabular}{|c|c|c|c|c|c|}
\hline & Bruce & Grey & Durham & $\begin{array}{c}\text { Kawartha } \\
\text { Lakes }\end{array}$ & Wellington \\
\hline \multicolumn{6}{|c|}{ Population and dwelling counts } \\
\hline Population in 2006 & 65,349 & 92,411 & 561,258 & 74,561 & 200,425 \\
\hline $\begin{array}{l}2001 \text { to } 2006 \text { population } \\
\text { increase }(\%)\end{array}$ & 2.3 & 3.7 & 10.7 & 7.8 & 7 \\
\hline $\begin{array}{l}\text { Population density per } \\
\text { square kilometre }\end{array}$ & 16 & 20.5 & 222.4 & 24 & 75 \\
\hline \multicolumn{6}{|c|}{ Generation Status (Total population 15 years and over) } \\
\hline 1st generation & 5,175 & 5,175 & 7,970 & 111,565 & 5,985 \\
\hline 2nd generation & 6,710 & 6,710 & 10,320 & 99,825 & 10,690 \\
\hline 3rd generation or more & 42,180 & 42,180 & 57,400 & 230,895 & 44,790 \\
\hline \multicolumn{6}{|c|}{ Mobility status-place of residence five years ago (population 5 years and over) } \\
\hline Lived at the same address & 42,645 & 56,090 & 315,030 & 46,435 & 110,080 \\
\hline
\end{tabular}

Overall, the nine farmers included in this study were highly variable (see Table 5) and drawn to farming at various life stages. Participants included a recent university graduate to a person approaching retirement; just under half were married and a third had dependants while all reported attending post-secondary school. With the exception of one farmer, those who owned farmland were older and married whereas younger, single farmers typically had land-sharing arrangements (see Table 6). NUOFs had small-scale agricultural operations using a variety of alternative farming practices and most employed multiple marketing strategies. The majority did not report a steady off-farm income during the main growing season and only one-third consistently incorporated the use of on-farm help from hired laborers, interns and volunteers.

\footnotetext{
5 Source Statıstics Canada (2011) 2006 Communtty Profiles Website http //www12 statcan ca/census-recensement/2006/dp-pd/prof/92591/1ndex cfm Accessed January 9, 2011
} 
Table 5. Demographic profile of NUOFs participants

\begin{tabular}{lccccc}
\hline Farmer* & Sex & Age range & Education level & Civil Status & Dependants \\
\hline Annie & F & $30-35$ & University & Single & No \\
Ethan & M & $20-25$ & University & Single & No \\
Yolanda & F & $40-45$ & College & Married & Yes \\
Gerald & M & $60-65$ & University & Married & Yes \\
Sarah & F & $25-30$ & College & Single & No \\
Chris & M & $25-30$ & University & Single & No \\
Hannah & F & $30-35$ & University & Married & No \\
Nola & F & $25-30$ & University & Single & No \\
Elsie & F & $40-45$ & University & Married & Yes \\
\hline
\end{tabular}

* Pseudonyms are used to provide anonymity.

Table 6. NUOFs' farm operation characteristics

\begin{tabular}{lccccccc}
\hline Farmer & $\begin{array}{c}\text { No. of } \\
\text { Years in } \\
\text { Operation }\end{array}$ & $\begin{array}{c}\text { Land } \\
\text { Tenure }\end{array}$ & Acreage & $\begin{array}{c}\text { Type of } \\
\text { Operation }\end{array}$ & $\begin{array}{c}\text { Primary } \\
\text { Marketing } \\
\text { Strategy }\end{array}$ & $\begin{array}{c}\text { Off-Farm } \\
\text { Work }\end{array}$ & $\begin{array}{c}\text { On-farm } \\
\text { Labourers }\end{array}$ \\
\hline Annie & 1 & Own & 40 & Mixed & 2,3 & Yes & No \\
Ethan & 1 & Renting & 4 & Mixed & $1,2,3$ & No & No \\
Yolanda & 2 & Own & 50 & Mixed & n/a & No & No \\
Gerald & 2 & Own & 12 & Mixed & 1,3 & Yes & Yes \\
Sarrah & 2 & Renting & 2 & Vegetables & 2 & No & No \\
Chris & 2 & Renting & 5 & Mixed & $1,2,3$ & No & Yes \\
Hannah & 2 & Own & 40 & Mixed & 1,2 & Yes & No \\
Nola & 3 & Renting & 4 & Vegetables & 2,3 & No & Yes \\
Elsie & 5 & Own & 40 & Mixed & 1 & No & No \\
\hline
\end{tabular}

*Marketing Strategy: 1= Direct Farm Gate Sales; 2= Community Supported Agriculture; 3= Farmers' Markets

\subsection{DATA ANALYSIS PROCESS}

For this study, an interpretative analytical approach was used to make sense of the qualitative data that Dey, as cited in Kitchen and Tate (2001), describes as "emphasiz[ing] the role of patterns, categories and basic descriptive units" (p. 229). John Creswell (2009, p. 185) has articulated a way of understanding the data analysis process that consists of several key steps. Creswell's original diagram depicted a linear progression but acknowledged that the process is "more interactive in practice; the various stages are interrelated and not always visited in the 
order presented" (p. 185). Figure 4 is an adaption of Creswell's original diagram to reflect my understanding of the quality data analysis process as a non-linear, layered, and iterative process.

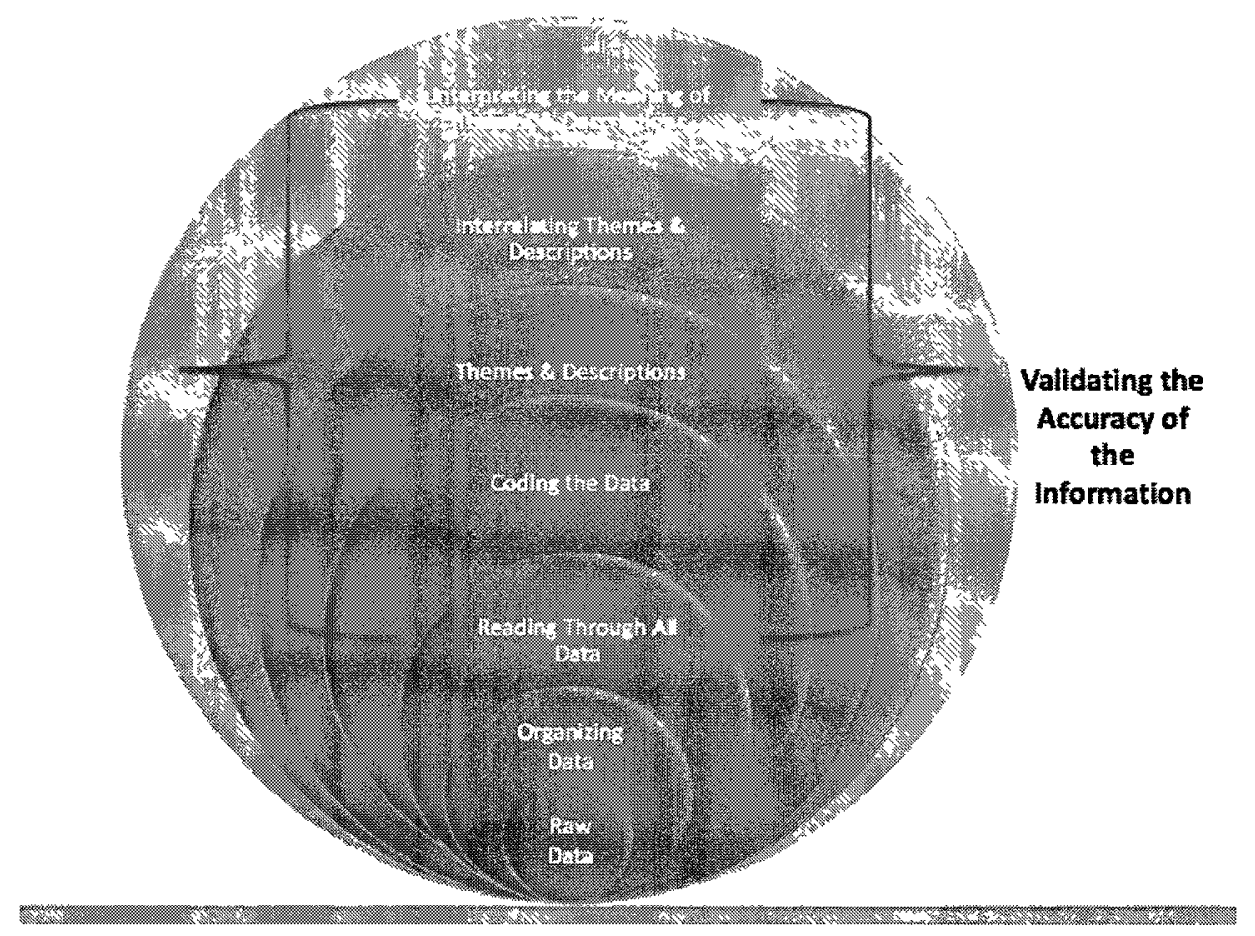

Figure 4. Qualitative data analysis

After data were collected, sorted and organized, a review of the data helped develop familiarity with each data set and provided an initial impression of the information to help inform the coding process. Next, the process of coding entailed fracturing data into units of analysis before "bringing meaning to information" (Creswell, 2009, p.186). Descriptive codes were labeled to pieces of the data. Through several iterations of labeling and categorizing, emergent themes were identified. This procedure is also known as "open coding" and signifies the act of 'breaking open' the data (Punch, 2005, p. 205) to initiate the first analytical engagement with the data. A number of coding cycles occurred before themes based on organizational categories around NUOFs' transition to living and working in rural farming 
communities (e.g. motivations, challenges, rewards) were created. From there, inferential codes were developed to find patterns, explore relationships and connections from the descriptive codes. It synthesized material into smaller, more meaningful units and sought to situate the data with a sense of place theoretical framework. After this stage of the data analysis, key themes, relationships and possibilities were examined and interpreted to makes meaning from the data and reflect on lessons learned. Throughout the whole process, new understanding or discoveries often moved through the different layers of the data analysis framework in both directions as a mechanism to verify the accuracy of the information.

\section{Reflecting on the research process}

My research about the perceptions of NUOFs and their 'sense of place' was the result of a series of decisions regarding the development of the research design, the implementation strategies and the analytical framework. Recognizing that choices were made at each step of the process reveals the role I had in defining the research topic, selecting the participants and deciding the most significant insights to the research. In that respect, the knowledge created is as much situated in the lives of the NUOFs who participated in this study as it was in mine. Here, the concept of situated knowledge includes examining the positionality of the researcher. As Rose (1997) explains, "the need to situate knowledge is based on the argument that the sort of knowledge made depends on who its makers are" (p. 306). While reflecting critically about one's positionality does not eliminate its presence, it does allow for a more mindful discussion about the research, its findings and its potential implications (Rose, 1997).

Robina Mohammad (2001) writes that positionality in part translates to the 'insider'/'outsider' boundary, "a boundary that is seen to circumscribe identity, social position and belonging and as such marks those who do not belong and hence are excluded" (p. 101). 
Throughout the research process, this 'insider'/'outsider' dynamic surfaced in a number of ways that demonstrated how my positionality (i.e. being a female, visible minority researcher) influenced the context and conversations. One of the most notable experiences that highlighted this reality occurred fairly early on in the field research when I accompanied one of the farmers to pick up feed for their livestock at a local mill. Upon our arrival, a person came out to greet us and one of the immediate comments he made was that this was the first time two women came unaccompanied by men to his property to pick up feed, and the first time a Chinese woman ever to set foot on his property. Shortly after, he shared stories about his trip to China and looked to me for approval. Eventually, I had to tell him that I was born in Vietnam but grew up mostly in Alberta and British Columbia. My journal further details:

July 19, 2009 (Tuesday)

Today at Dave's (the feed guy), a funny, particular situation presented itself. Apparently, I had been the first Asian to come to his house (oh, the other was that there are two women at the farm -the mill)...Anyway, [the conversations] went on a little about China, the Chinese population taking over, all in a very jovial manner. However, it is this kind of stuff that makes me wonder how new immigrants who want to farm in less metropolitan areas would feel. I am pretty use to comments like that and was pretty unfazed, they were pretty standard ones...like "I'm sorry I can't tell them apart" or " there's just so many of them" or "When I was in China..." Hannah asked me about how I felt about those comments at dinner. Honestly, I didn't feel offended personally because I know, or it seemed like it wasn't coming from a place of malice or anything like that. However, I know others would have taken offence. At the same time, I wonder how much of that animosity is created by others. For example, I don't think I could tell if someone was German, Polish, Dutch or any sort of European decent or nationality so why would I expect that from another. Is it natural for people to make assumptions and then if they are wrong to be corrected? Is that not the course of figuring things out? 
When we got back to Hannah's farm, we had a discussion about the event and ethnic diversity in rural communities and sometimes it was this lack of cultural diversity or awareness that gives rural communities a provincial feel compared to an urban city, where there is at least the presences of diverse cultures. As a result, the idea of cultural diversity became a thread throughout the research. To some extent, I think this issue would have come out regardless of my ethnicity, but the fact that I am who I am, may have brought this matter much more quickly to the forefront.

Additionally, my gender seemed to influence what people decided to share. For example, I recall driving back to the farm with one of the male farmers after spending some time in town. It was my last day there and during the drive, I casually mentioned that the challenges of being single in a small rural town was something that I heard about and asked him for his opinion. He shared that for him relationships were very important and how being single and farming could jeopardize his ability to continue farming. Interestingly, this was not brought up during the indepth interviews or the photovoice activity. However, it was apparent from our conversation in the car that it had significance. Out of curiosity, I had asked why this was not mentioned during the more structured portion of the research and the farmer responded by saying he did not feel comfortable sharing those thoughts at that time. This comment made me think about why he felt uncomfortable? Could it have been attributed to gender roles and relationships? While the topic of relationships was eventually discussed with the all the single new urban-oriented farmers, it was only the females who brought concerns about relationships forward without much probing whereas with the male participants only discussed it when directly asked. Or perhaps over the course of my stay, a better rapport was established between us that towards the end of our time together, more vulnerable thoughts could be shared. Moreover, in this particular situation, I 
wondered if the farmer felt like he could take off his "researched" mask since all research activities that required explicit farmer participation were done and we were technically just "hanging out". The idea of performativity surfaced as I recognized how fluid the relationships between the farmers and myself were as we "switch[ed] between different identities according to the requirements of the research setting" (Punch, 2001, p. 178). Punch suggests that field research is analogous to "being constantly on stage" (cited in Hoggart et al., 2002, p. 272) where the researcher and the "researched" play an active role in constructing and performing an identity.

Continuing with the idea of performativity, in the process of this research, I found myself consciously trying to convey that I was "one of them". I detailed my own ambitions at one time to be a farmer in my early twenties, pursuing an agricultural science degree at university, and my work experiences on several small-scale farms over the years. In part, by revealing my history with agriculture, they would see that I had a genuine desire to understand their situation. Moreover, I trusted that they would see that this research did not emerge out of a purely academic curiosity but came from a place of experiencing the reality of farming; and that I was "one of them". I knew what it was like to work in the field day in and day out, how it felt when someone really appreciated the effort you took to grow their food, and sometimes how discouraging the sustainable agriculture movement can feel some days. Perhaps, I felt that by being honest about my farming experiences, the good, the bad and the ugly, the farmers would feel comfortable being honest about theirs. But at the end of the day, I was still a researcher and each relationship with the farmers was pursued for a specific purpose. As such, a researcher "can never fully shed their status as outsiders" (Dowler, 2001, p. 153) and can only be privileged to a perspective that is made visible. While furthering an understanding of the world around us is the 
objective of any research, it is important to acknowledge our limitations. For me, reflecting on my research experience illustrated how partial knowledge can be and how the production of knowledge bears an element of "interpretation, translation, stuttering, and the partly understood" (Haraway, 1991 as cited in Rose, 1997). 


\section{CHAPTER 4 | RESULTS AND ANALYSIS}

As stated in Chapter 1, this study explores in detail the construction of a 'sense of place' by NUOFs living and working in rural farming communities. Organized into two sections, this chapter presents research data collected using participant quotations, photographs, tables and figures. The first section provides a spatial overview of NUOFs' 'sense of place' using a resource network analysis. By examining the interaction between farmers and resources, this assessment aims to identify patterns across the majority of farmers as well as individual circumstances that help explain emerging patterns in the construction of community among the NUOFs participating in this study. Next, an examination of the motivations and meanings behind the decision to farm and NUOFs' 'everyday' experiences transitioning into rural farming communities offers insights about their relationship with rural places to contextualize how a 'sense of place' is being constructed.

\subsection{A SPATIAL OVERVIEW}

People can create a sense of place for themselves through networks of exchange (Woods, 2005). From this perspective, constructing a 'sense of place' was a highly diverse practice among NUOFs. Table 7.0 summarizes the farmer-resource ${ }^{6}$ interactions and not surprisingly, the amount of time individuals have been farming in a particular location appears to impact the community that has been and continues to be constructed. The growth of these networks tended to occur relatively close to the farm for most of the farmers included in this study. In all but two cases, networks were dominated by interactions that occur within $100 \mathrm{~km}$ of the farm, and for 6 of the 9 farms included in this study, $+85 \%$ of these interactions occur with an hour's drive (i.e. up to 100

\footnotetext{
${ }^{6}$ To reiterate, resources are categorized based on the function they served the NUOFs. For a detailed description, please refer to page 35 in the Data Source section of Chapter 3.
} 
$\mathrm{km})$ of the farm. Also, this trend did not correlate to the amount of time farming in a particular location. This should not be surprising given that many of the NUOFs were motivated by reducing their environmental footprint and re-establishing rural-urban linkages.

Table 7. Spatial distribution of NUOFs' resource networks

\begin{tabular}{|c|c|c|c|c|c|c|c|c|c|c|}
\hline \multirow[b]{2}{*}{ Farmer } & \multirow[b]{2}{*}{$\begin{array}{l}\text { Years at } \\
\text { Current } \\
\text { Location }\end{array}$} & \multirow[b]{2}{*}{$\begin{array}{c}\text { Years } \\
\text { Farming }\end{array}$} & \multirow[b]{2}{*}{$\begin{array}{c}\text { No. of } \\
\text { Resources }\end{array}$} & \multicolumn{7}{|c|}{$\%$ of total resources at: } \\
\hline & & & & $\begin{array}{c}< \\
20 \\
\text { km }\end{array}$ & $\begin{array}{l}20- \\
40 \\
\mathrm{~km}\end{array}$ & $\begin{array}{l}40- \\
60 \\
\text { km }\end{array}$ & $\begin{array}{r}60- \\
80 \\
\text { km }\end{array}$ & $\begin{array}{l}80- \\
100 \\
\text { km }\end{array}$ & $\begin{array}{c}< \\
100 \\
\text { km } \\
\text { total }\end{array}$ & $\begin{array}{c}> \\
100 \\
\text { km } \\
\text { total }\end{array}$ \\
\hline Annie & 1 & 1 & 27 & 26 & 0 & 0 & 0 & 0 & 26 & 74 \\
\hline Ethan & 1 & 2 & 124 & 34 & 24 & 27 & 6 & 0 & 91 & 9 \\
\hline Yolanda & 2 & 2 & 36 & 19 & 14 & 6 & 0 & 14 & 53 & 47 \\
\hline Gerald & 2 & 2 & 41 & 12 & 61 & 7 & 2 & 5 & 87 & 13 \\
\hline Sarrah & 2 & 3 & 71 & 15 & 61 & 1 & 6 & 6 & 89 & 11 \\
\hline Chris & 2 & 3 & 86 & 33 & 3 & 2 & 1 & 48 & 87 & 13 \\
\hline Hannah & 2 & 8 & 134 & 10 & 4 & 3 & 1 & 30 & 48 & 52 \\
\hline Nola & 3 & 5 & 175 & 5 & 19 & 14 & 2 & 52 & 90 & 8 \\
\hline Elsie & 5 & 5 & 166 & 22 & 37 & 4 & 22 & 6 & 91 & 9 \\
\hline
\end{tabular}

Over time, NUOFs demonstrate that they were able to expand their network. Overall, it appeared that 'Personal and Social' and 'Knowledge and Advice' networks experience less dramatic growth and remain relatively stable in comparison to the "Goods and Services" network over time (see Figure 5). This is not unexpected since new farmers focused on developing production skills and capacity in the first few years. When Gerald's partner asked him about his marketing plan in his first year of farming, he responded, "I don't have a marketing plan, I only have a growing plan." However, after a few seasons of farming, efforts focused on developing and expanding the farm business, which helps explain the noticeable growth of the "Goods and Services" as farmers become more established. This suggests that the total number of resources was at an "essential services" level in the first two years of farming and then grew as a farmer begins to better establish themselves. 


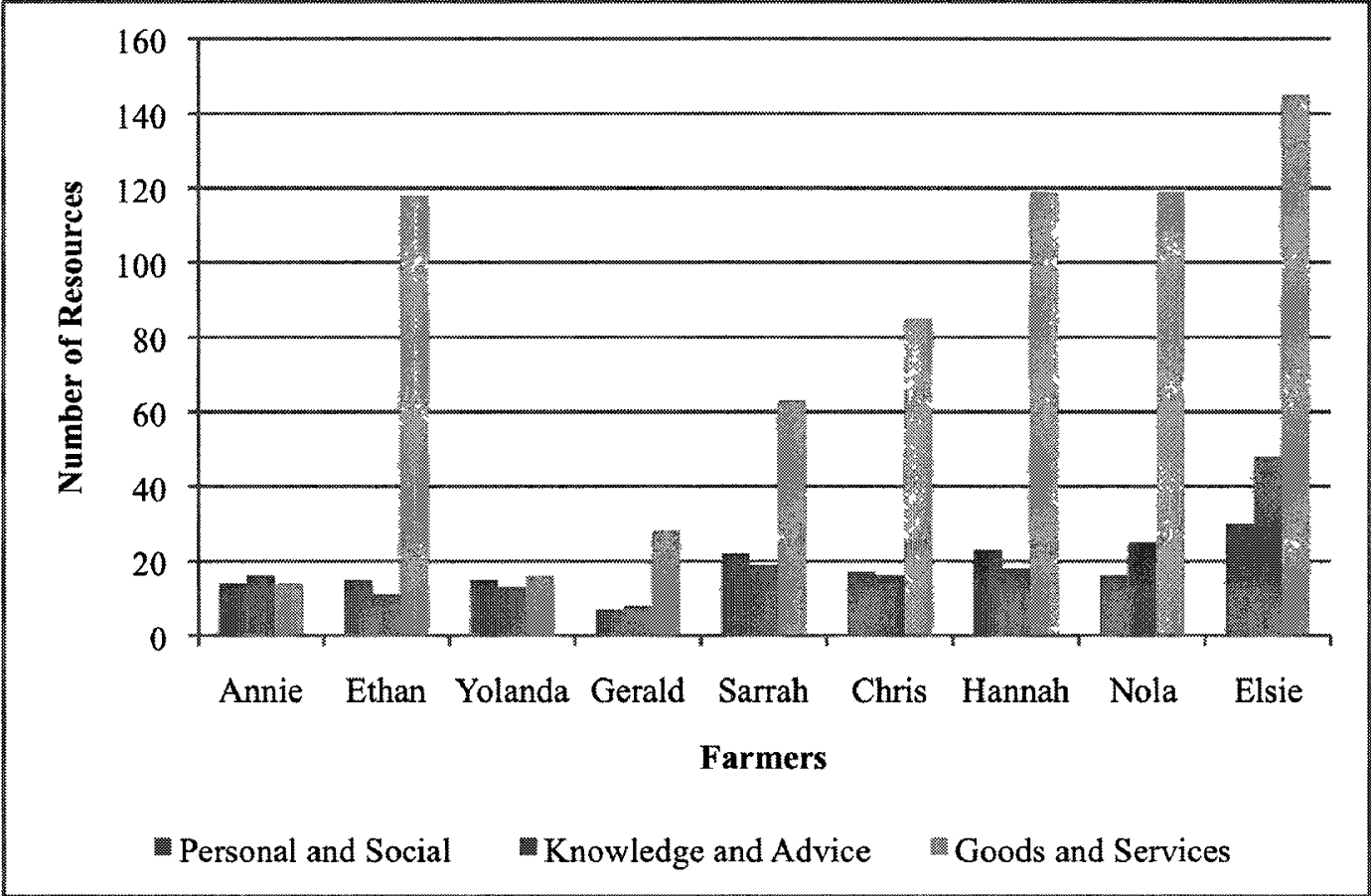

Figure 5. NUOFs' network distribution by resource category

What is interesting in this data was that further analysis point to three key factors that could have influenced the development of NUOFs' sense of community, and contributed to the overall construction of a sense of place as a highly discrete process. First, collaborations appeared to play an important role in the construction of communities within a relatively confined zone as business partnerships or land-sharing arrangements increased and localized resource networks. For instance, a comparison between Annie and Ethan who were both in their first year of farming revealed that Ethan's resource network was four times the size of Annie's. In fact, his profile was more typical of farms that have been in a location for three or more years. This atypical network development could be attributed to the characteristics of his farm operation. Unlike all the other farmers, Ethan did not undertake farming alone. He had a business partner who was equally invested in all aspects of the farm business; thus the network reflected the financial, human and social capital resources of two. Effectively, Ethan was able to develop 
the farm business faster than someone working on his or her own. More importantly, Ethan's business partner had a rural farming background, bringing with her an incredible wealth of knowledge, expertise and resources that allowed Ethan's network to develop rapidly. Furthermore, the decision to farm in his partner's hometown enabled them to benefit from her family's established community connections. Not surprisingly, Ethan's had the highest percentage $(92 \%)$ of resources located within a $100 \mathrm{~km}$ radius; in fact, the majority of his resources were within a $60 \mathrm{~km}$ radius.

Land sharing agreements provided similar benefits. For individuals like Nola, landsharing not only meant having a sense of community near by but also the difference between her farm's success or failure:

Originally, I had thought about having my own farm and being at The Blue Goat has made me realize how unrealistic it might have been for me...I didn't even realize all the benefits I would have from being at an established farm and having access to equipment and infrastructure and customers and advice and all the kind of stuff...it's a good thing because I don't know if I would have been successful if I struck out on my own right off the bat.

Second, proximity to large urban centers had a major role in containing a sense of community within a relatively confined zoned. The majority of farmers were located within a $100 \mathrm{~km}$ radius of a major urban city but for those who were not (e.g. Annie, Hannah, and Yolanda), it is not surprisingly to find that the majority of their resource networks were beyond a $100 \mathrm{~km}$ radius. NUOFs who lived in more remote rural communities had expanded networks because they were willing to travel longer distances in order to connect with people and access a viable market. This supports the findings of other researchers such as Jarosz (2008) who demonstrated the centrality of urban cities to farmers involved in the local, sustainable agriculture market. In the case where Ethan and Nola were able to identify and develop a more 
localized market, it should be noted that they partnered with people who had either farming origins or a history in the area. As previously mentioned, Ethan partnered with someone whose family was a part of the rural farming community. Nola partnered with a family who pioneered the organic scene in that particular region. In both cases, Ethan and Nola were privy to local resources that helped localized the geographical characteristics of their resource network.

Third, the variability in the total number of resources among YEAR 2 farmers suggests that demographic characteristics can also influence their resource development by shaping how and where they can farm. Compared to the others, Yolanda and Gerald had a smaller social network. Sarrah, Chris, and Hannah are in their late twenties and early thirties while Yolanda and Gerald are in their early 40 s and early 60 s, respectively. Sarrah, Chris, and Hannah all had established markets for their produce through a sizeable CSA program which accounts for the large majority of their resource network. While Gerald believes in the CSA model, he recognized the limitation of developing and operating an intensive CSA farm at this stage of his life. Gerald shared:

... a CSA would just kill me. I think, there's no question if I was ten years younger I would do a CSA, if I was in my 20's...god knows I was at one time it's a wonderful time to be but I'm not anymore. I wouldn't think of anything else. So what I decided was that I would concentrate in part on a few perennial crops, particularly things that I really like.

Effectively, the turn to perennials meant that Gerald had a lot of work establishing select crops but the goal was that after the initial planting, maintenance would be less labor intensive than running an annual crops operation like a CSA. At the time of this research, Gerald had a limited customer base while he worked to establish his perennial crops. Sales were mostly from transactions with a few restaurants in nearby townships, neighbours, friends and family members 
as well as from produce he supplied other small-scale farmers looking to supplement their CSA programs or stalls at nearby farmers' market.

For Yolanda, her age was indicative of her life stage as a parent. Having dependants while trying to establish a farm business seemed challenging. For NUOFs with children it seemed to take them a little longer to establish themselves as farmers and entrepreneurs because they did not feel that they were in a place to put the farm first, as Yolanda stated: "So my first order of priorities are the kids". Even for Elsie, who was in her fifth year farming, there is still a struggle to find that balance. As a mother of three young children, she took a picture of a basket of laundry (Photo 1) to represent the challenges of juggling her priorities to establish herself as a farmer while being the primary parent:

So one of the challenges for me is learning to farm, setting up the farm and learning to farm in this stage of life is learning how to weave children into that and family life into that and knowing how to balance their needs and demands with my need to be out getting the job done... and so juggling those tasks with also trying to be the primary farmer, obviously doing it on a small scale, feeling this is pathetic, I'm doing almost nothing on the farm, I don't have a lot to show for my farming efforts, but the basket of laundry sitting there. You got to hang that up cause the sun's shine and if you don't hang it up now it's not going to dry, it's just juggling all those things.

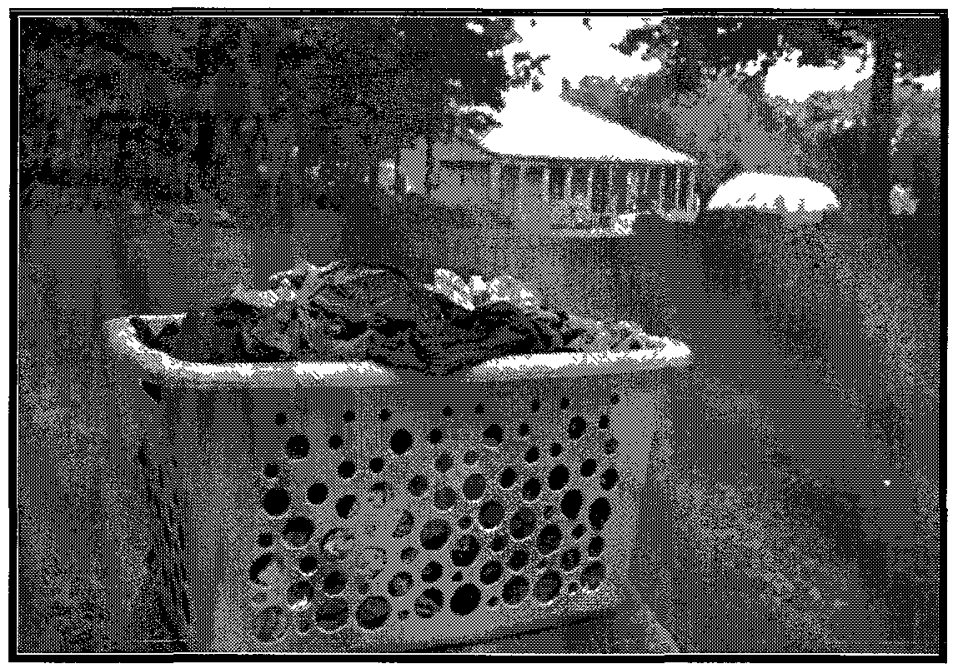

Photo 1. Basket's Full 
Interestingly, while these farmers expressed that their farm was not developing as fast as they would have liked, the presence of children also opened up different opportunities to make other kinds of connections in the community. For instance, for Yolanda, when asked about how and where she finds a 'sense of community' she said the biggest thing was meeting families from her children's alternative school. Likewise, Elsie opened up her farm to host school tours and as a result, Elsie has mentioned about the possibility of diversifying her farm operations to include a place for experiential learning.

Lastly, a look at civic status also revealed some interesting things. With the exception of Hannah, those who were married tended to have fewer resources. One possible explanation is that Yolanda and Gerald had partners who brought in significant off-farm income that could support their family while incubating the farm business. In a sense, they had the resources to develop more slowly since they were not in a dire sink or swim situation. Gerald is still a practicing lawyer and combined with his partner's income as an executive who commuted to the city to work. According to Gerald, they were on their way to acquiring the capital assets of their farm saying, "... the reality is that we already have the farm and we'll get the mortgage paid off easily enough." In Yolanda's situation, her family made the decision to sustain themselves primarily with her partner's income as a technology consultant. This afforded her with the opportunity to develop her farm over the span of a decade if need be:

Like at this point, I've just started telling people I'm ready to take on one family and just start talking to that one family about what they like to eat, ask then to track their food expenses for a few months like how much they spent on food like what are they eating that they would rather not, what way did they want to be eating not necessarily how they are eating and then from there how can we work together. If I worked like that and one family and then one more family and then one more family until I got 12 families that would probably the capacity of the farm to feed that many and that's just a nice size. So that's the ultimate, maybe 10 years from now we'll get to that where we have 12 families 
eating almost exclusively from the farm which is also business wise, that would provide an income.

For new farmers with no partner, there may have been a greater sense of urgency to develop the farm business to ensure that they could support themselves. This explains why their farming social networks generally were greater in numbers. And while Hannah is married and has a partner who earns an off-farm income; they are not necessarily drawing on accumulated resources of a first or second career to carry them through difficult times. Moreover, as one of the two young farmers who own farmland, the responsibility of a mortgage helps explain why her resource network was significantly larger than all the rest. Also of the YEAR 2 farmers, Hannah is the only one of her younger peers to own farm property. The cost of farmland, inflated by property speculators, makes it difficult for younger NUOFs to consider farming closer to urban centers and pushes them further into the rural periphery. Thus, it was not surprising that she lived further from the urban shadow where property was more affordable. Similarly, Annie, who was also a young farm property owner, recalled that she had hoped to farm closer to the city but found herself in a community further than she would have liked because "at the end of the day this was the only one remotely affordable".

In summary, based on the network analysis NUOFs' sense of community is geographically localized in that the majority of significant resources identified by the NUOFs are located within a $100 \mathrm{~km}$ radius. Given that NUOFs are participants in the local food movement, this finding is not unexpected. Data also suggest that a sense of community can grow over time but its development can be influenced by a number of factors. This research highlights that collaborations tend to expand networks faster than farming alone while proximity to large urban centers mean that networks of NUOFs located closer to cities were more geographically dense in comparison to those located further from the urban-rural fringe. Socio-demographic 
characteristics such as age, civic status and the presence of dependents seemed to have a formative role in influencing not only where NUOFs farm but also how as different opportunities and challenges shaped the course of their network development and characteristics. These dynamics point to a discursive understanding of a sense of place as complex, heterogeneous and process oriented.

\subsection{THE 'EVERYDAY' EXPERIENCE}

\section{Place Identity}

Among the company of many, Cresswell $(2004,2009)$ argues that people and places are intricately linked and that to ask someone who they are often entails knowing about where they come from. The importance of place as it relates to identity is paramount to the extent that the "close connection between place, identity and morality creates a world that is difficult for some of those who are apparently "without place" (p. 117). In this study, NUOFs may be transitioning from urban to rural places but they certainly did not give the impression of lacking a sense of who they were nor where they wanted to be. In fact, the relationship between NUOFs and rural landscapes was formidable in that NUOFs created a strong place identity around rural agricultural landscapes because being able to farm was a reflection of who they are and how they wanted to live.

For NUOFs, current industrial farming practices were not seen as ideal and a key factor in deciding to farm began with a personal awareness about the importance of food production and its impact on society. They relayed concerns about losing sight and touch with the people, places and processes that produce food, a basic need required to sustain human life. Some talked about the role of agriculture in terms of community development while others highlighted its potential for civic engagement and economic reform; all, however, shared the opinion that there 
are severe environmental consequences from industrial farming. Moreover, the principle of advocacy versus activism was evident among the NUOFs. Many expressed concerns for the environment but talked about staying away from environmental activism because they didn't want to "get caught up in the damage part", thought the environmental movement was "kind of depressing", "always about bad news" and "fighting this or fighting that". Instead, becoming involved with agriculture as a farmer was viewed with the possibility of doing something 'positive', 'healing', 'proactive' for the environment and the community. As Gerald put it, "I was looking for a way to be alive on this planet and live my values" and the practice of farming itself was an opportunity to "in a very small way, change the way things are". Elsie captured a photograph that exemplifies the significance of being able to 'walk the talk'. Photo 2 and the accompanying text illustrates how NUOFs' relationship with the land through farming was a way to embody and align their values from head to toes:

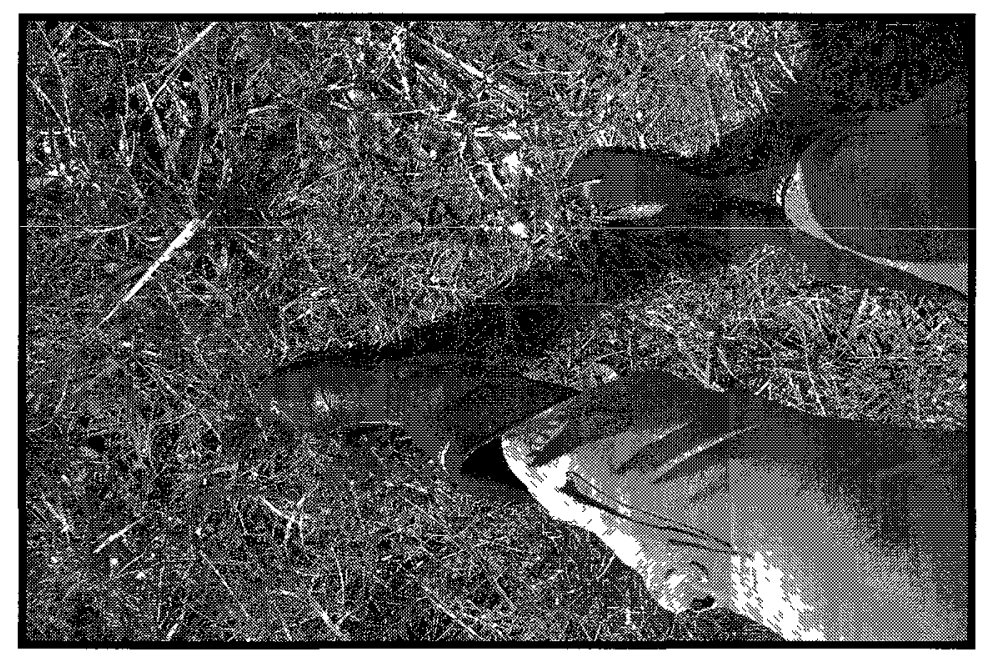

\section{Photo 2. Walking the talk}

And so this picture is of my boots walking, my feet walking is the physicality of my life as a farmer...having a life that involves being outdoors and being active and having that integrated into what I do and who I am and connecting the mind and the body is really powerful. 
Furthermore, when asked to describe what drew them to farming and rural spaces, NUOFs quickly shared that being surrounded by nature made them feel "refreshened", "rejuvenated", and "alive". An opinion held by all NUOFs highlighted the significance of being able to connect and work intimately with the natural world. A strong emphasis was placed on developing a relationship with the land that involved getting to know its characteristics over time and not just about maximizing production capacity. Below is a photovoice by Hannah that captured the affective dimension poignantly:

Being a farmer means having a relationship with the land... this just means understanding your land and getting to know your land as if it was a person, so getting to know its mood, getting to know how to treat it, getting to know how it changes over the seasons and over the years. I find that there are only a few professions or types of work where you really develop a relationship with the land and I find that really rewarding so I took this picture because it is a picture of our wedding rings, which symbolize relationships, and they're in the land.

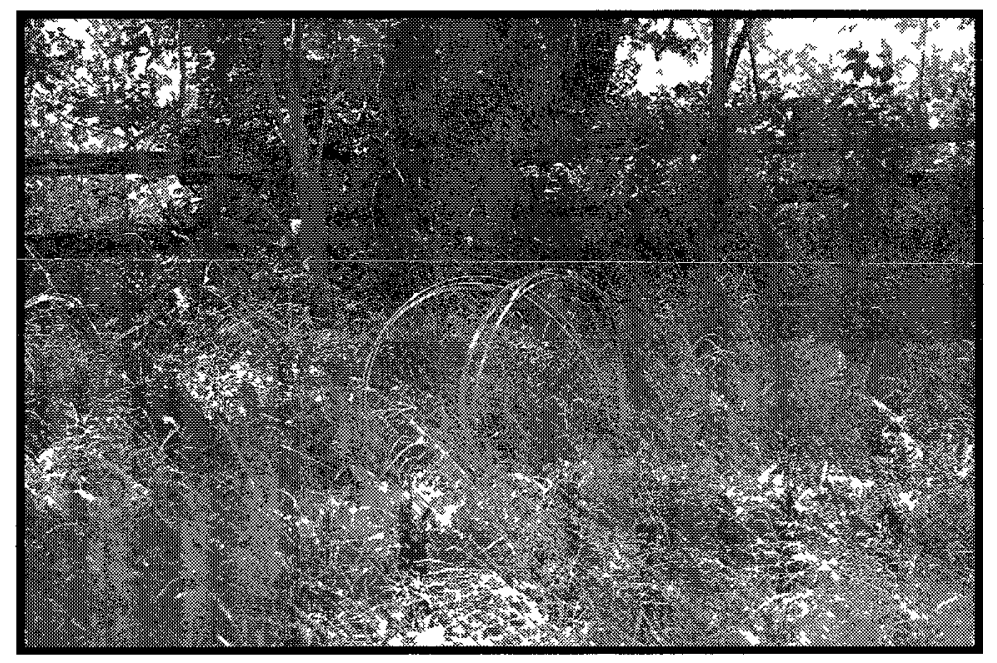

Photo 3. Married to the land

The experiential and relational aspects of Hannah's description resemble a humanistic concept of place where "[t]o know a place fully means both to understand it in an abstract way 
and to know it as one person knows another" (Tuan, 1975, p. 152). In addition to the land, NUOFs' relationship with the rural environment included interactions with animals, which may otherwise be restricted in the city due to animal by-laws. While NUOFs recognized their livestock were being raised for food production, it did not mean that they wished to treat their animals as pieces of meat. It appears that NUOFs sought an alternative approach to agricultural animal-human relations and similar to developing and getting to know the characteristics of the land, NUOFs who worked with animals spoke about getting to know the animals for who they are. In a photo provided by Chris (Photo 4), one can see an element of play between farmer and pig. When asked to describe what farming meant to him, he shared, "These are animal friends. This is my pet, princess Cow, and I've enjoyed making friends with her, and I like the interaction between humans and non-human animals, especially pigs".

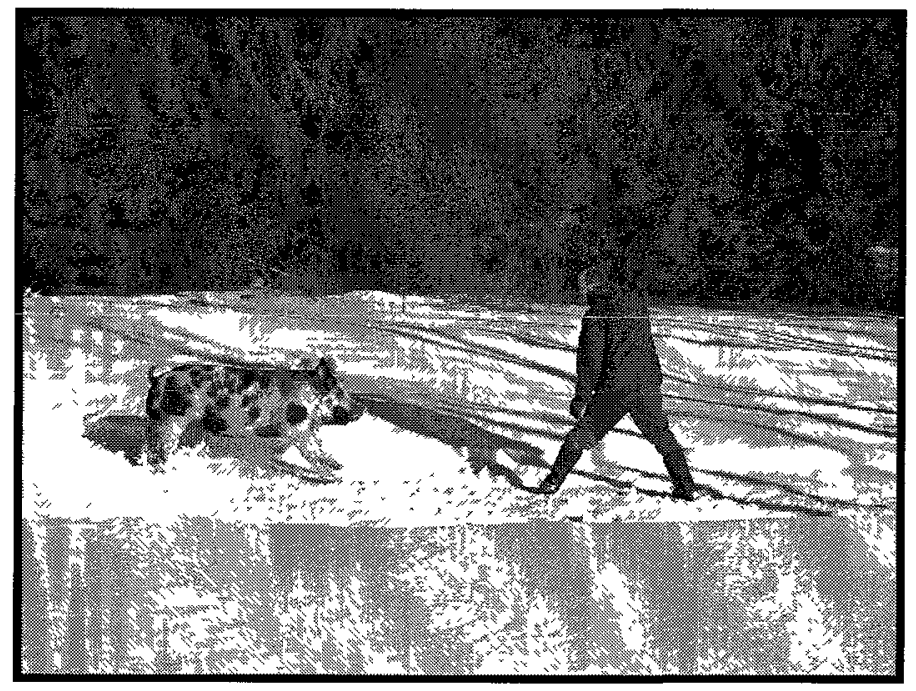

Photo 4. Animal Friends

For NUOFs, it appeared that another major factor in relocating to rural spaces to farm included the motivation to cultivate a sense of community around agriculture. NUOFs were interested in creating opportunities for individuals, especially those coming from an urban 
population, to interact with the people and places involved in the production of food. To that end, NUOFs wanted their farm to be a social space where customers, friends, and family were encouraged to engage with farming in some way. When sharing her vision of the farm, Elsie commented:

... knowing this farm and this place can be, and has been a place where not only children but certainly people of all ages, have an experience of delight and of joy and of respect for the land and feeling motivated by offering an opportunity for people to believe that that connection is reclaimable because that feels like it's crucial.

The importance of extending the farm as a place where others can experience agriculture first hand and come to understand the interconnections between land, food and community seemed fundamental. A focus on reaching an urban audience was evident among the NUOFs. Photo 5 is a photo taken by Annie to illustrate her goal to involve her community in the Greater Toronto Area to visit the farm and experience agriculture first hand. Drawing from her own experience, she believed that the majority of urban population have a removed understanding of agriculture saying:

...one of the key things about being out here is that I just want people to come out here and visit... There's so many people with no knowledge of growing things or farming or about food security or about the labor requirement for organic vegetables and that sort of things. So everything you tell them is new information and so I need to, when I do the tour and stuff, I try to explain certain things... 


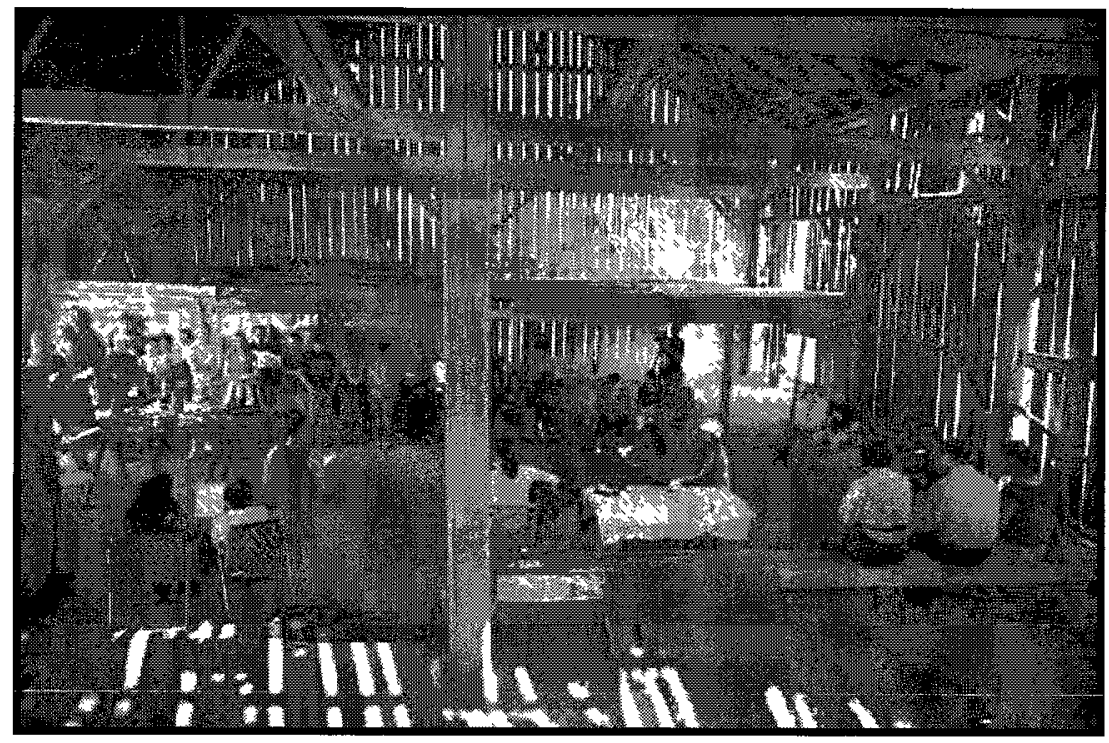

Photo 5. Farm raising

A review of motivations, values and goals suggest that NUOFs' migration to rural communities is entangled with agriculture since farming is identified as an opportunity for NUOFs to live their values, reconnect with nature through meaningful work and create a sense of community. For the NUOFs participating in this study, their connection to rural agricultural landscapes was not only about a place where they could farm but represented a place that reflected who they are and how they wanted to live. 


\section{Place Attachment}

"More field shots, that's why I'm a farmer because I love this setting, working outside."- Sarrah "...it's kind of amazing planting seeds and having them grow into things. I've thought it was always amazing but I especially for some reason I'm amazed by carrots because they are such a tiny little seed and they grow to be this big thing... I don't really know how to translate that into how that means to be a farmer but it's like awe or something or wonder at the natural world and how that works"-Nola

"Everywhere I look, I see beauty and when I don't see beauty I change."-Gerald

The quotations above illustrate there is an inexplicable bond between the farmers, their land and the natural environment. This was to be expected given that in the last section it was determined that NUOFs identified aspects of the rural environment as a part of who they are. An examination of NUOFs place attachment, which is conceptualized as the emotive bond between a person and the physical environment in this study, revealed a mixture of affective and challenging qualities that were attributed to living and working in a rural environment. Considering that the previous section demonstrated how aspects of the rural landscape played a central role in how NUOFs define themselves and how they want to live, a strong attachment between the farmers, their land and the natural environment was not surprising.

NUOFs' connection to aspects of the rural agricultural landscape, visualized through photos of plants, fields, animals (wild and domesticated) and other living creatures (e.g. insects), reinforces the affective emotions NUOFs associate with the countryside. For NUOFs, being out in the country and working with the natural world evokes beauty, inspiration and insights. With a photo of an ant (Photo 6), Ethan depicted how nature supported him by showing how even the smallest ant is a force to be reckoned with; that ants will carry something so much bigger than 
their weight and work so efficiently inspires him to "make [the farm] operation more efficient and work more smoothly".

Parallel to the positive aspects of being situated in rural spaces, NUOFs also described difficult experiences. Having lived in urban environments, NUOFs had to adjust to being further away from things that used to be within arms reach such as basic amenities (e.g. banking, groceries, medical centers) and access to various cultural and recreational services. NUOFs' coping mechanisms included traveling to the city for a "city fix", and for those who could not get away, creative solutions helped to bring a bit of the city to the country. For instance, the photograph below shows a music concert Yolanda organized to mitigate the effects of being physically isolated from people.

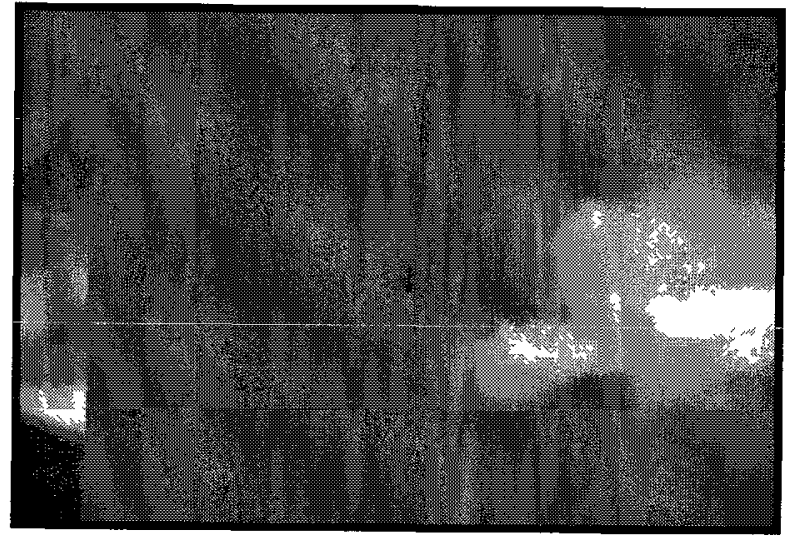

Photo 6. Ants

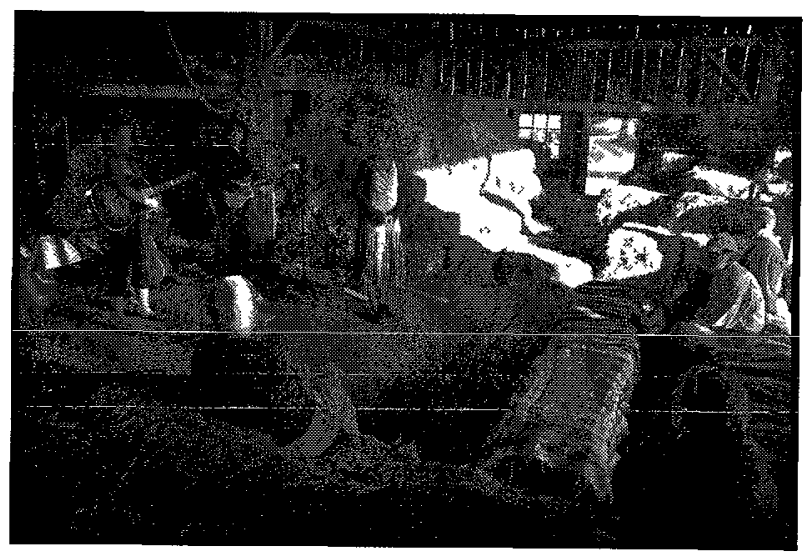

Photo 7. Barnyard concert

The physical isolation was a more immediate challenge but being re-situated in a rural context also forced some NUOFs to reassess their own values and beliefs systems. A few NUOFs talked about the internal conflict they had with car ownership and dependency. With a 
strong position on environmental sustainability, their chosen profession and present location made their dependency on fossil fuels become much more apparent. Nola took a picture of her farmer's licenses plate on her truck (Photo 8) to signify her identity as a farmer but as she discussed the photograph she proceeded to say,

Yeah, it's funny because it's not really a part of, if I wasn't a farmer I wouldn't have a car like that. So that's really a part of my identity as a farmer not really like my identity as a Nola. That's a big freaking truck, it guzzles gas and not good for the environment but a necessity and very practical for what I'm doing.

Similarly, Sarrah shared that she actually had to learn to drive and included a photograph of her car (Photo 9) to illustrate her struggle with owning a car, saying "...so one of the challenges of living in the country is you have to have a car... I'm so reliant on fossil fuel and it's so much more apparent because I never had to fill up a car with gas before because I was always took the bus or metro or walking everywhere...". It was interesting to see that in the discussion about their vehicles both Nola and Sarrah distinguished that if it wasn't for them being in the countryside farming, they would most likely not own the cars that they do now.

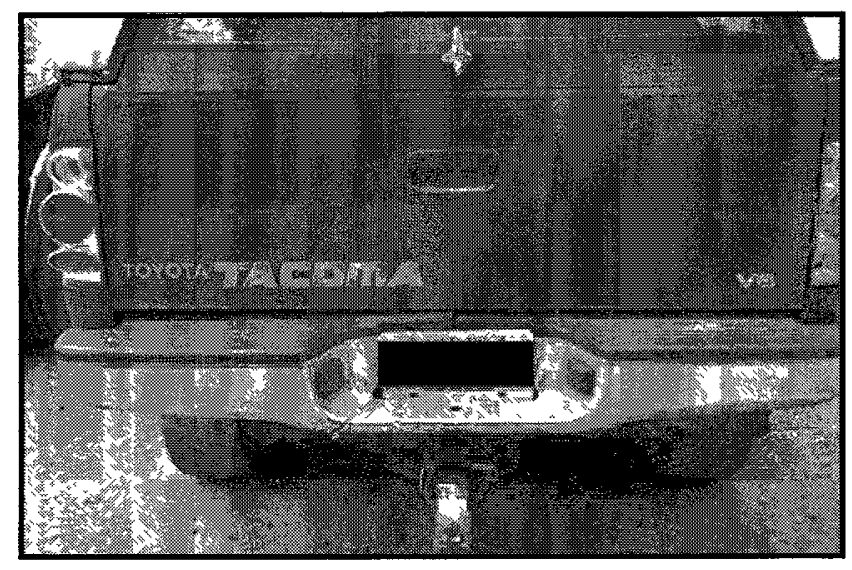

Photo 8. Nola's truck

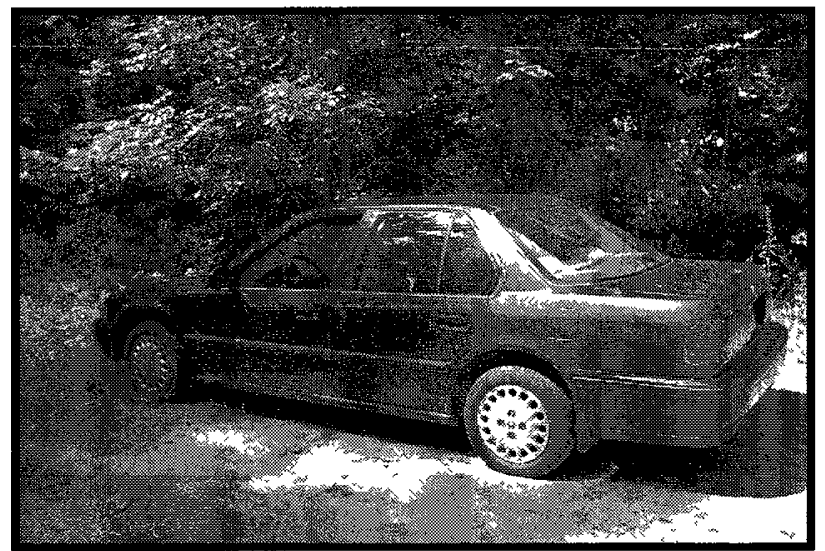

Photo 9. Sarrah's car 
Meanwhile, Ethan's photo of his truck (Photo 10) symbolized how he had to confront his ideas and values about money and the financial implications of being in-debt to pursue a life as a farmer (Photo 10). As he described:

This is my truck and that's a challenge in terms of the financial implications of buying a truck and having a van break down and owing people money for it until it's paid off and the pinch in terms of the economics of starting a small business in agriculture without much capital is a challenge... Owing somebody else money, being in debt that's the most stressful because I'm not use to that, I'm use to much more freedom, not owing anybody anything like that.

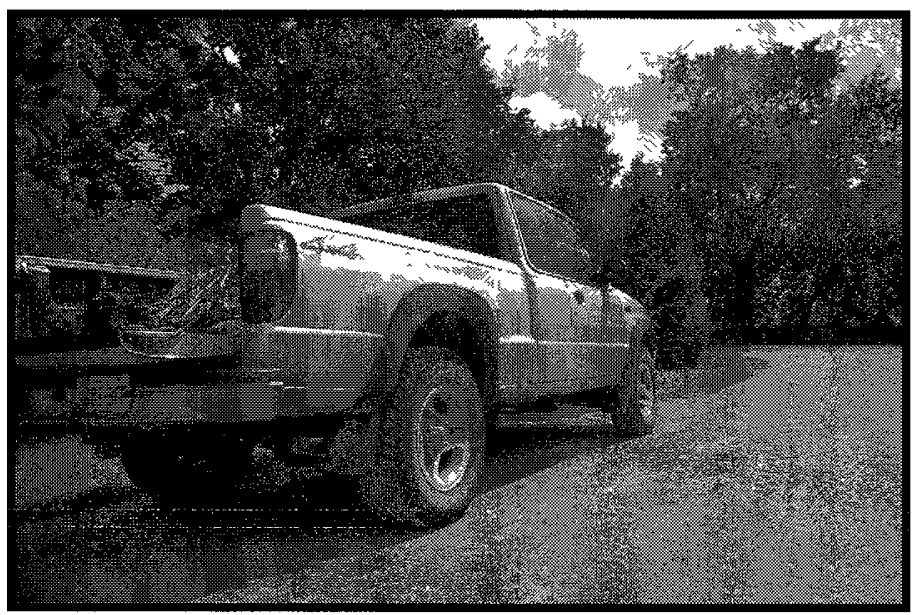

Photo 10. Ethan's truck

Moreover, attempts to discern commonalities between the challenges NUOFs associated with the transition to rural environment proved difficult in that how each individual was situated to respond to a circumstance influenced what was even identified as a challenge. This reiterates how different people experience places differently. For instance, landless NUOFs recognized the value of land-sharing as an important step in their progression to becoming independent farmers, however, an uncertain future seemed to indicate a hint of detachment as they did not feel that they could truly invest in any long-term plans. Accompanied by Photo 11, Ethan discussed this challenge: 


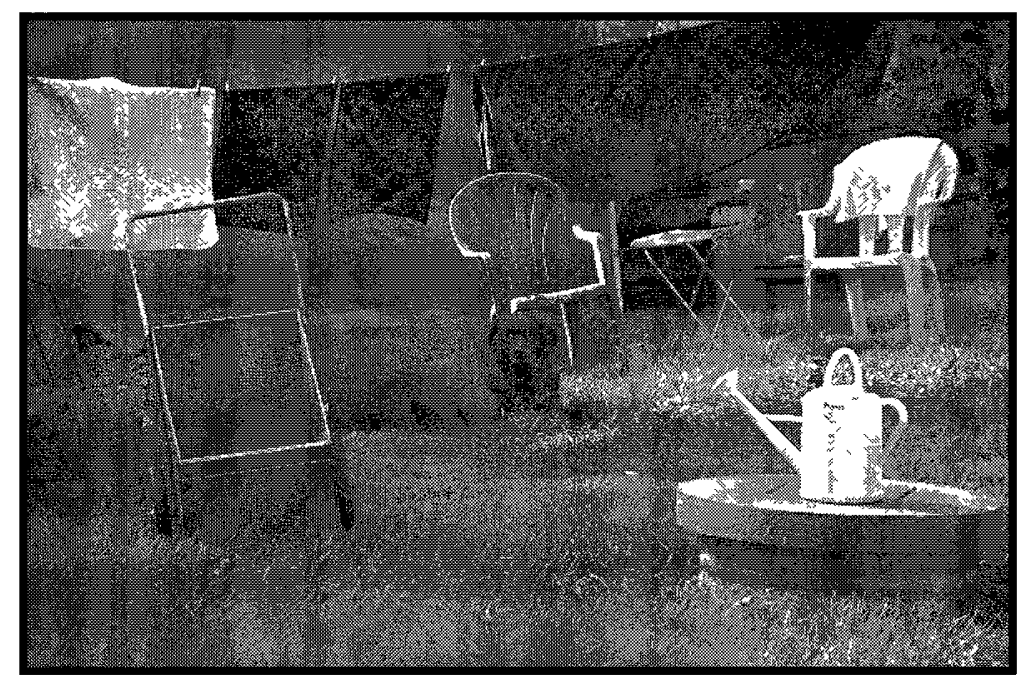

Photo 11. Not our land

This is a picture of Montana, Sue and Maurice's dog. Montana always barks at me. It's indicative of our relationship with Sue and Maurice in that we are renting the land, we have a lot of freedom but it's not our land and that relationship has some challenges, although it's a really great relationship, in terms of, there are something we want to do on the property but we don't want to do if we don't know what is going to happen to the property, like I'd love to plant fruit trees and nut tress and put an eave trough on the barn and all this stuff but before I know, like, if it will just get sold to one of their kids or something, I would feel like at a loss.

An opinion held by the majority of NUOFs in temporary living or working situations was that the lack of certainty and impermanency involved with land-sharing arrangements tempered their place attachment to their environment. This finding supports the argument that physical attachment or "rootedness" is influenced by intentions to stay, duration of residence and ownership (Scannell and Gifford, 2010, p.4). For NUOFs who owned their property, this particular challenge was recognized and while they empathized with their fellow colleagues, they had to deal with a different set of challenges that created a different dynamic with their physical environment. Below are photos of decaying infrastructure that some of the NUOFs farm property owners had to address. In doing so, these NUOFs could be said to have invested more of themselves into their farm and thus intensified an attachment to a place they called home. 


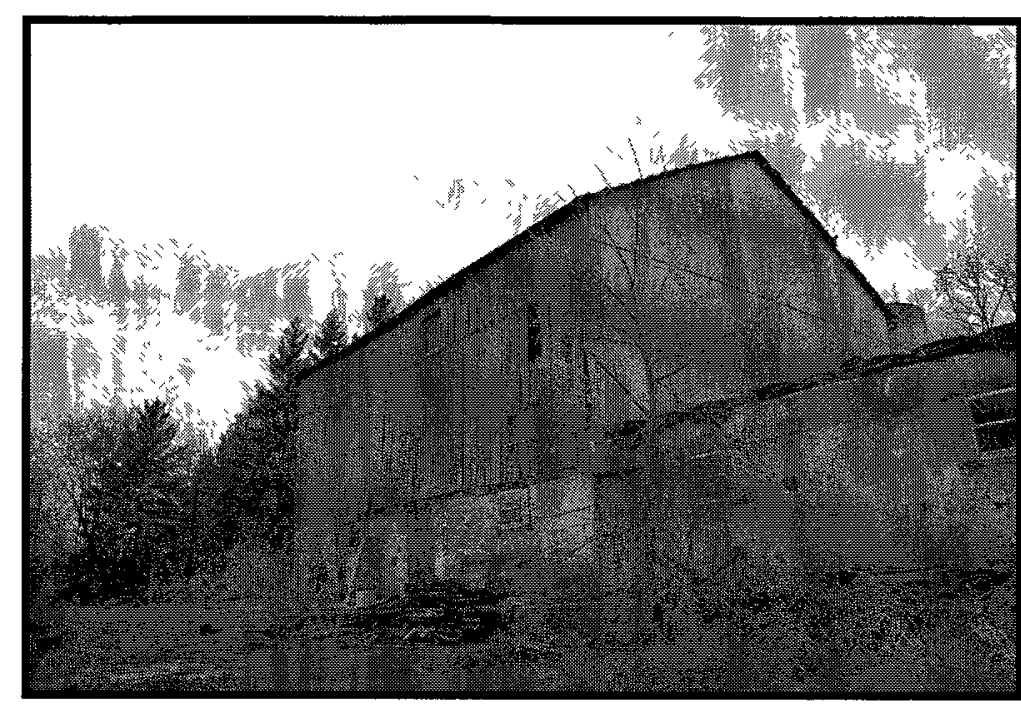

Photo 12. Barn repairs

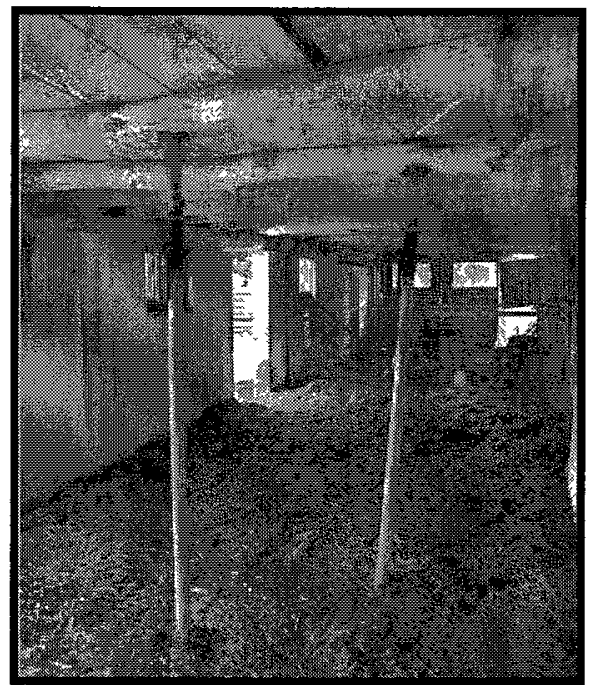

Photo 13. Barn repairs II

Another example illustrating the prismatic effects of a single challenge based on how one is positioned to the experience was winter. Winter was characterized as a challenge for some NUOFs because during the growing season, the farm was an extremely social place, but when winter comes, the realization of their physical seclusion became quite noticeable. Hannah noted that winter in the city is not like winter in the country saying, "because there's not a lot do in the winter I think you could get stir crazy". Nola echoed these sentiments by further elaborating, "Even if you're living by yourself in the city it's not hard to go out and be social with people but when you're living by yourself out here, I find it very isolating. I don't find it super healthy for me to be out here." For some farmers, adaptive strategies included taking full-time residency on the farm during the growing season and then finding alternative living arrangements during the off-season. Chris, on the other hand, offered a different perspective of winter than the others saying that winter increased, not decreased, his sense of mobility. Submitting a photograph of winter (Photo 14), he explained: 


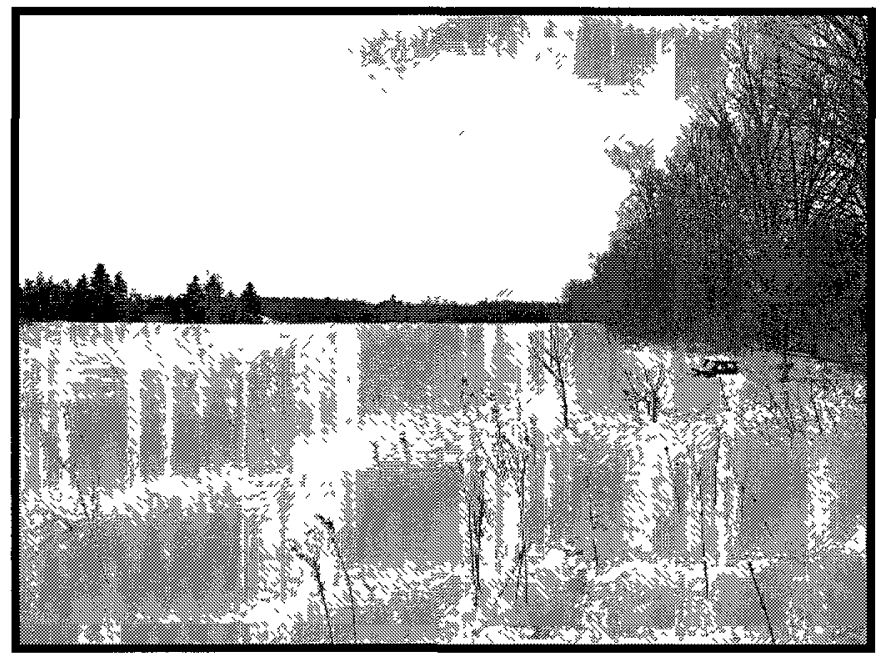

Photo 14. Winter-friend or foe?

I receive support from the winter time because it frees me up because you can see there's no vegetables growing and the last winter I went out east and visited friends and family and this winter I'm going to go somewhere too...By not allowing me to grow vegetables, it supports my going away habits, and it encourages me not to stay.

In terms of dealing with winter, there were three perspectives and responses. Hannah, a property owner, felt that winter was something to be endured while Nola, who was in an informal land-sharing agreement found the physical isolation unhealthy for her and decided to find temporary housing elsewhere during the winter season. In contrast, Chris, who worked on his father's land, viewed it as an opportunity to travel and spend time with friends and family he otherwise did not get to see during the busy growing season. The different ways in which individuals developed a rapport of the physical environment begins to suggest that it is a discrete process contextualized by individual circumstances and the resources they had to address opportunities and challenges. The spectrum of emotions expressed within this small group about their living and working environment points to an animated relationship between people and places. Also, the range of positive, unenthusiastic and, sometimes, contradictory sentiments demonstrated how people could have multiple positions within and understandings of a place 
that were not mutually exclusive. The tension also signified that the process of becoming a part of any place inevitably involves re-orienting, if not re-constructing, a sense of self.

\section{Sense of Community}

The last two sections focused on understanding how NUOFs related to and interacted with the physical rural landscape. The next section turns to the human dimension of finding a sense of place by exploring the ways in which NUOFs navigate the social landscape as a part of their transition to living and working in rural farming communities.

\section{Addressing social isolation}

As residents of a rural farming community, the majority of NUOFs felt that they did not necessarily 'fit in' with the local residents based on what they believed to be differences in values and worldviews. Thus, the process of integrating into community life had its challenges. Elsie reflected that while on the surface she and her family could easily blend into the community further conversations revealed significant differences in values that created apprehension about her immediate local community. In her words:

...we fit the picture, we're white, we 're middle class and it's all good and then you start talking to people and you realize I don't resonate with [them], the worldview that I'm hearing is so different and that was hard for me...People would be so blatant for their disdain about cultural diversity.

For younger NUOFs, some commented on the difficulty of meeting people whom they could connect with. Also for single NUOFs with the future in mind, finding a compatible partner seemed somewhat out of reach. Nola offered her thoughts saying, "...the town here [is] quite conservative so I don't find I meet a ton of like-minded people, so in terms of finding people that you might be interested in dating, it's like yeah, I very very rarely meet anybody that I'm at all interested in up around here." Furthermore, during an interview with Annie (who is of Chinese 
heritage) regarding her thoughts about the local community, she said, "I do feel a disconnect with the people out here a little bit because it's white, very white. It's small town. It's a lot of industrial agriculture out here so organic agriculture out here is laughable or something." The perception of a 'small town mentality' that lacked an appreciation for cultural diversity and the dominance of industrial agriculture seemed to socially isolate NUOFs from bonding with the immediate community.

While the challenges of social isolation were identified by all NUOFs, there were times when it was reported as a positive attribute. In such cases, farmers referred to how the city could be an overwhelming, over-stimulating place. For some, the feeling of being isolated created a better 'sense of community' because with fewer opportunities to socialize, individuals made the effort to participate in community events and be involved whenever possible. Yolanda explained, "We probably do more community stuff now that we're out here...In Toronto there's tons and tons of entertainment going on all the time but we never went out. So this is, it's good. There are a lot of good people around here." So, contrary to feeling isolated from the local community, elements of social isolation seemed to instill within some the resolve to seek out meaningful opportunities for community engagement.

Reclaiming a sense of personal space was another positive attribute associated with social isolation. A self-professed "social addict", Elsie wasn't quite sure how she would cope with moving to a more rural, isolating environment. However, to her surprise (and that of her friends) she discovered the benefits of being somewhat isolated. She noted that moving to a rural community allowed her family to deepen and strengthen their relationship with one another to a level that would not have been necessarily possible in the city. For example, her children spent a lot time with each other because it was simply harder to get them to their friends' houses. Also, 
with on-going projects on the farm, the family worked and spent considerably more time together. In particular, Elsie valued the cross-generational interactions that took place on the farm:

I've often said how many forty odd-year old women spend so much quality time with their 70 odd years old dad? And not just hanging out together but working on projects together, learning together, and being inspired together. Hearing my dad say, 'Well I never thought I'd be telling my retired coffee club friends that I went out and helped my daughter buy a horse drawn manure spreader' and feeling that sense of wonder in just seeing my kids, and Dylan in particular who has always had a special connection to my dad, his Grandpa Ed. But just being moved to see the two of them during maple syrup season or haying season when my parent come here to help and seeing my dad and Dylan go out to work on a project together...

The different experiences of social isolation suggest, again, that context matters. For NUOFs with families, social isolation seemed to strengthen their 'sense of community' by encouraging participation in fewer, but more meaningful community activities in addition to presenting opportunities to focus on their own personal development and cultivating stronger familial relationships. On the other hand, younger NUOFs generally reported incidents of social isolation with a more negative connotation. The reason for this was not clear but it may have something to do with the absence of a central focus on a 'home' like their older colleagues with families. The present finding seem to be consistent with other studies such as Cuba and Hammon's (1993) that found establishing a sense of community could be influenced by one's life stage at the time of migration. Nevertheless, the varying degree in which individuals experienced social isolation reinforced that constructing of a sense of community was not a homogenous process.

As previously discussed, the farmers in this study were interested in participating in the local food movement and practicing alternative agriculture; thus, finding a 'sense of community' 
in rural places where farming was predominantly industrial seemed difficult. This particular dynamic seemed to make some NUOFs feel like "outcasts" and "outsiders". Chris revealed that even people he has hired to do custom work on his farm were not shy in expressing their opinions about him "playing farmer". In his words:

I mean, even people that who have done tractor work for me, will say it outright, like you're not really a farmer, or you're not a true Canadian farmer, backyard gardener, these sorts of things, hobby farmer, city official. It makes it, I don't know, it's not the best. I think that if you work that much; I don't think you're a hobby farmer... Yeah I mean, I remember I met this one guy, I asked him to do some tractor work and he asked me where I was from, I said Toronto and then he got this big grin on his face and then he charged me a ridiculous amount that I didn't know at the time was ridiculous, so that sort of thing, I don't know. Yeah I mean, if you like going to the auctions, they can sort of tell that you don't totally fit in by dress or just by the way you talk, I don't know. But whatever.

Chris's situation demonstrates that NUOFs were negotiating many things, often simultaneously, in their transition to becoming a part of the rural farming community, not only as residents but also as new farmers. While some may have found their paradise, others struggled a little more to find their place. There are similarities between the attitudes expressed by the NUOFs in this study and those described by Mailfert's (2007) who reported that "neo-farmers" were not always accepted as 'proper' farmers within the community they live and work in. Moreover, the situation Chris described could also be interpreted as a microcosm of the power relations that exists between various actors in the struggle to define the food system. Against the backdrop of the global food system, finding a sense of place in relation to the industrial food system was a challenge many NUOFs shared. Elsie captured a photo that exemplifies this struggle where Photo 15 and the accompanying text represent the extent to which the majority of NUOFs viewed the situation: 


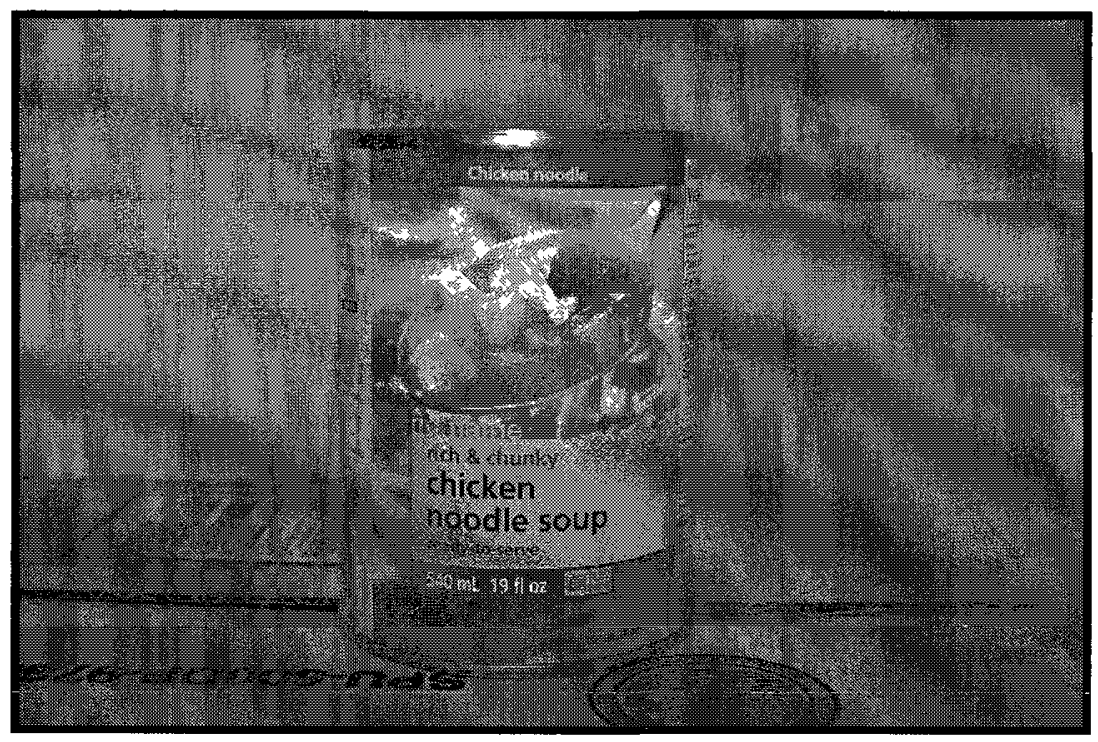

\section{Photo 15. Cheap food}

This is a representation of the cheap food system and knowing that we live in a time where the food system is broken, we source most of our food and the economics of food and what people are use to and willing to pay for food and also the economics of people being able to at the lower end of the income spectrum being able to afford enough good food to eat, that's such a complex thing and how do you fit yourself into that as a producer of food that you know has great value and also a lot of work and cost associated with it not just in terms of the work but in terms of the care?

This challenge has been noted by Trauger (2007), whose research on the Tuscarora Organic Growers cooperative from Pennsylvania in the United States, revealed how deriving a livelihood within a highly competitive capitalist market was one of the most significant practical challenges facing those going "back-to-the-land". While the farmers in this study did not expect, nor necessarily want to gain extensive wealth from farming, they did express the desire to be able to make a decent living, support themselves and contribute to the household income. With limited resources, material and technology available to NUOFs, by and large, the mainstream agricultural community was not viewed as particularly supportive of those practicing alternative agriculture. More often than not, NUOFs reported that the system was set up to make it difficult 
for farmers like themselves to succeed. The photo of Form 300 (Photo 16) represents the institutional barriers structured into the current food system. Hannah argued that,

Regulations and government challenge me. I feel like that's standing in our way... because the government or an arms length government organization has said you can only raise 300 and so that gives us virtually no room to grow so there's more and more of these regulations that are really making it hard for small people with limited funds and limited scale to stay in the game.

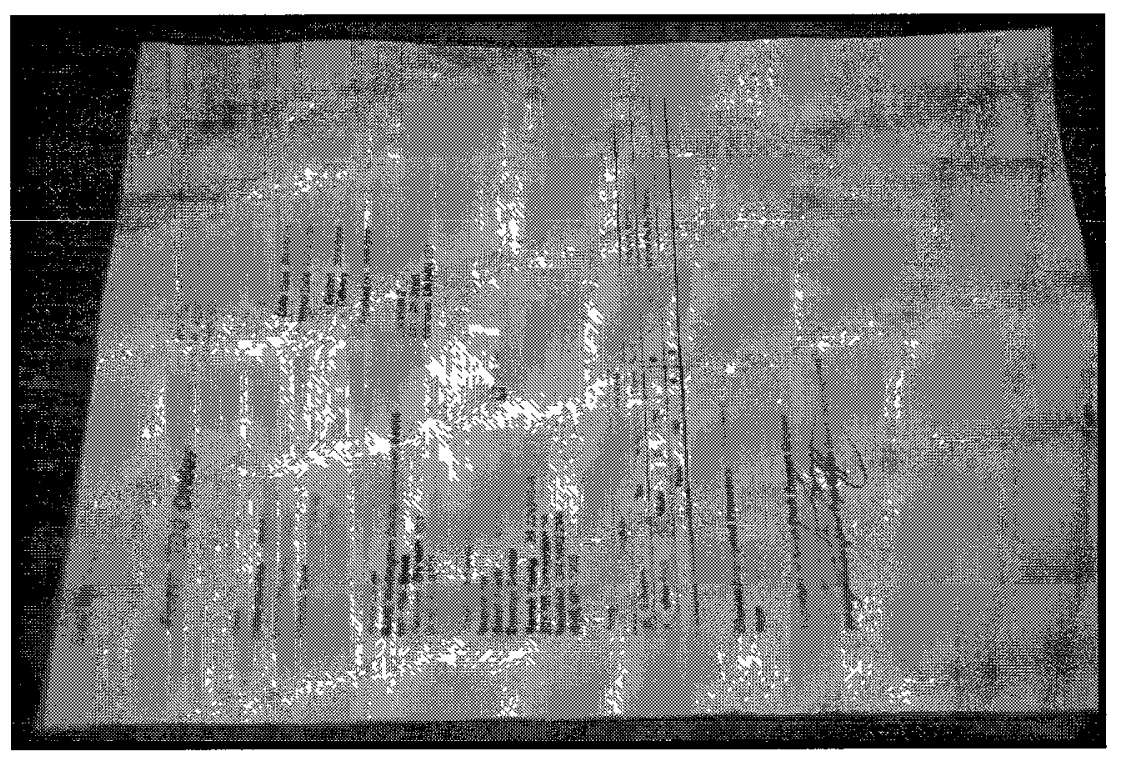

Photo 16. Form 300-Government regulations

In terms of the rural farming community, NUOFs are the new kids on the block, residentially and professionally. Elements of what seems to be resistance and reluctance from both the NUOFs and the veteran residents illuminated the complex dynamic that in any given place, there would be an array of "materiality, meaning and practice" (Cresswell, 2009, p.1). Although the social tensions between long-standing residents and NUOFs were expected as other researchers have reported (see Mitchel1, 2004; Jones et al., 2003; Marshall and Foster, 2003), for NUOFs, this situation seemed to be compounded by their choice to practice sustainable agriculture. Overall, the majority of the farmers expressed the belief they were able to connect with some people in their local community and described a positive, or at least, a working 
relationship with neighbors; however, for these new farmers, integrating and embedding themselves within the local community was not necessarily a priority. In particular, Hannah shared:

I want to be on good terms with everybody but I don't need to be a part of the community. I mean I kind of want to be a part of the organic community which isn't a local type thing, but as far as our neighbors go, we have different tastes, different interests and different cultures.

Although sentiments like Hannah were echoed by others, it was a little surprising to find that as a collective they acknowledged the tension but they did not seem deterred by it. NUOFs managed their expectations and the idea of moving into a community and establishing an immediate connection with the long-term residents was not expected. Interestingly, Gerald was very cautious when reaching out to others in the community and mindful not to give the impression that he was a dependant neighbor when he relocated to farm. He acknowledged that time was necessary to build relationships within any new community, or as he puts it, "I wasn't going to sort of move in on Saturday and then on Sunday all my neighbours were going to show up with cake and embrace me. I knew that wouldn't happen and it didn't bother me that that didn't happen." This view is supported by Burton (2004) and others (Holloway, 2002; Mitchell, 2004) who claim acceptance into rural communities can be a long process for newcomers, often with no guarantees that one will be regarded as a local. Hannah observed in her own community that, “...when you're new in a rural area you're new for a long time. If you are ever to really be a part of this community, we are creating, you know there's a lot of people coming into the community, and [we] make our own."

\section{Building a 'sense of community'}

In the previous section, NUOFs' relationship with their physical environment ranged from being positive where individuals felt re-vitalized by the ability to work outside, work closely with 
nature and enjoyed open spaces to very challenging ones that involved managing expectations. Similarly, identifying a sense of community among NUOFs followed a comparable pattern in that the impacts of social isolation were experienced in different ways and affected some people more so than others. With that said, NUOFs did express strong opinions about the social distance between them and their immediate local community based on what they felt were major cultural and agricultural differences.

Interestingly, in spite of having difficulty relating to the local and industrial agriculture community, NUOFs did not seem to lack a sense of community. While the majority of NUOFs included a few helpful neighbours as part of their support network, NUOFs largely constructed their sense of community from a diverse agricultural community of practice (ACoP) who shared an interest in what they were hoping to accomplish through farming. The composition of the ACoP included an existing body of knowledge. Referring to her photo of a bookshelf (Photo 17), Yolanda explained that the literature "....represents that it's out there, that I'm not on my own. I'm supported by these ideas". Farming colleagues, with whom one can connect, share and learn with were a very important component in NUOFs' community of practice (Photo 18). Given a lack of community with their immediate community, it was not surprising to find that the NUOFs held tightly to their existing networks and looking to expand selectively. In this respect, organizations such as the Ecological Farmers Association of Ontario (EFAO), Collaborative Regional Alliance for Farmer Training (CRAFT) and Stewards of Irreplaceable Land (SOIL) were valuable resources that brought like-minded people together, socially and professionally, by facilitating learning exchanges and networking opportunities. 


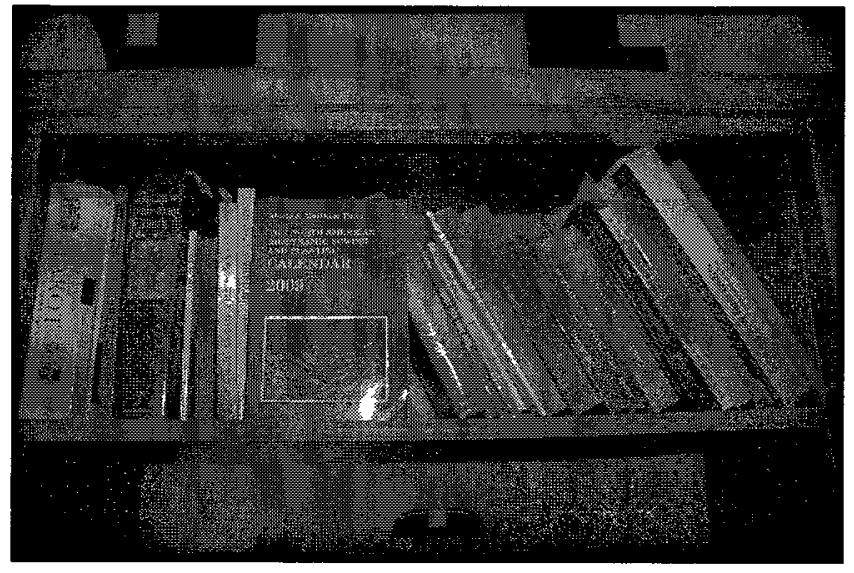

Photo 17. A bigger community out there

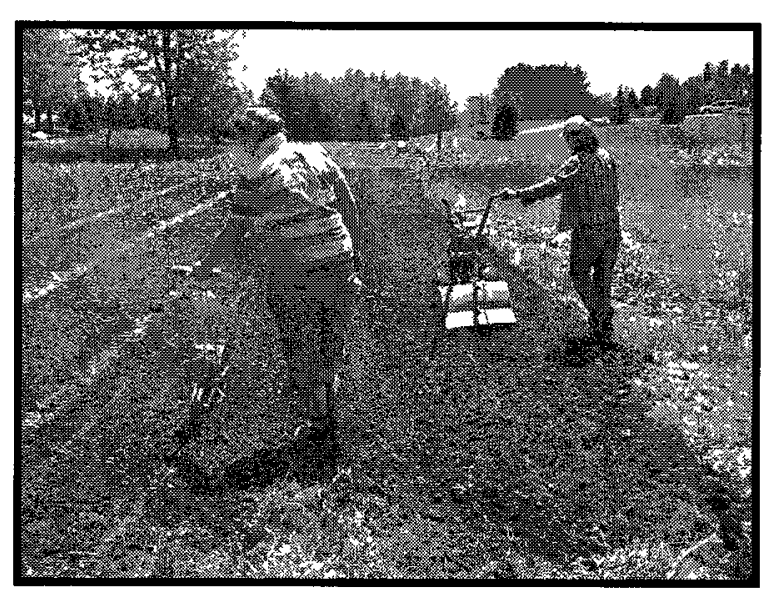

Photo 18. Farming colleagues

Customers and clients, especially those engaged in a community supported agriculture model, were central to NUOFs' sense of community. Nola's photo of a washing table (Photo 19) represents an important element of community shared agriculture for her that included "...finding different ways to work with people if they don't have enough money to pay you for a share". The table in the photo was something one of her CSA members built in exchange to be a part of the CSA. NUOFs were also unanimous about family, whether they were near or far, in playing an important role in helping create and being a part of NUOFs' sense of community by supporting them emotionally, operationally and financially. For NUOFs with partners, they could not stress enough the significance of having a partner who believed in and shared the farm vision. Elsie underscored that she would not be able to do what she is doing without the support from a partner who was "willing to support that and take that risk and do something he's never considered before". Many younger farmers echoed the impact of having supportive parents. Loans for mortgages, farm equipment and an open door policy during winter months were some examples of how parents became embedded in NUOFs' support infrastructure. Hannah's photo of a birthday card represents her parents' interest and financial support in helping make farming 
possible (Photo 20). Lastly, several NUOFs also took pictures of the researcher (Photo 21) to represent a broader community that has an interest in supporting new farmers as part of their community of practice. As Hannah explained, “...people who are starting to take an interest in new farmers... are supporting us by the information you're gathering, the work that you're doing and the resources that will come out of that".

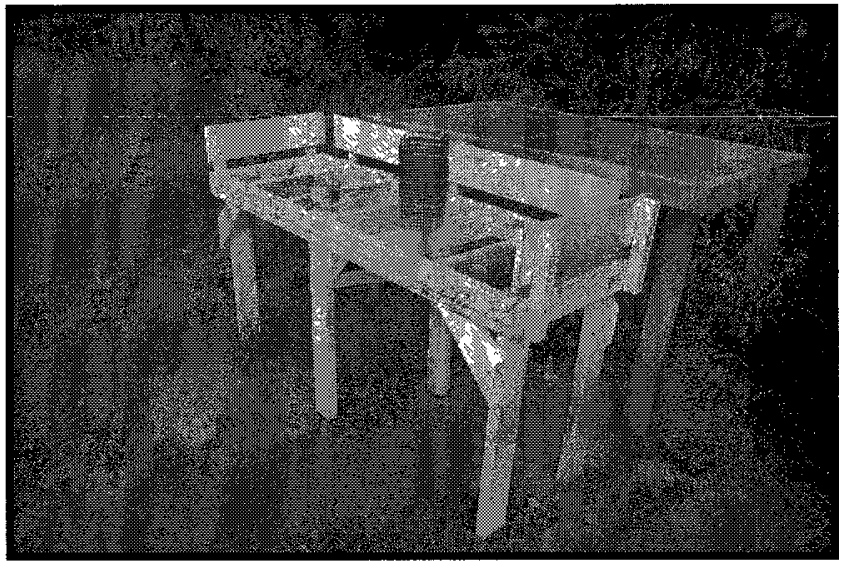

Photo 19. CSA member support

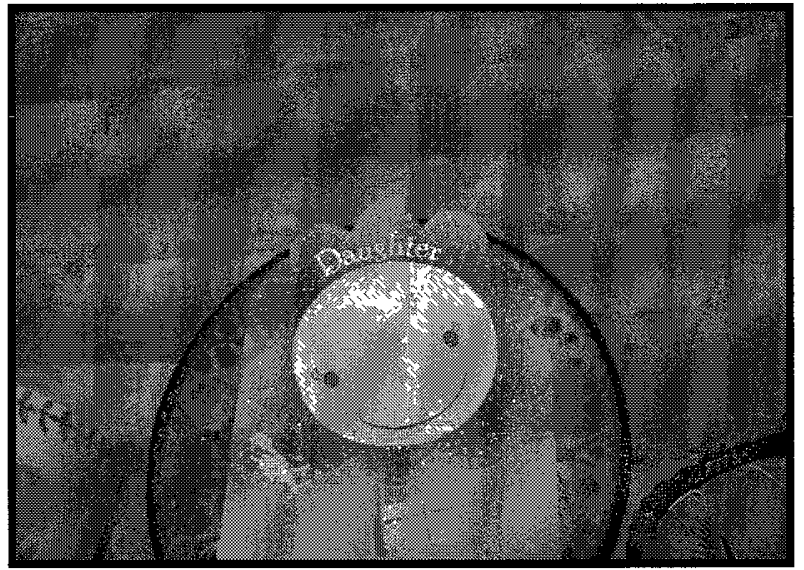

Photo 20. Supportive parents

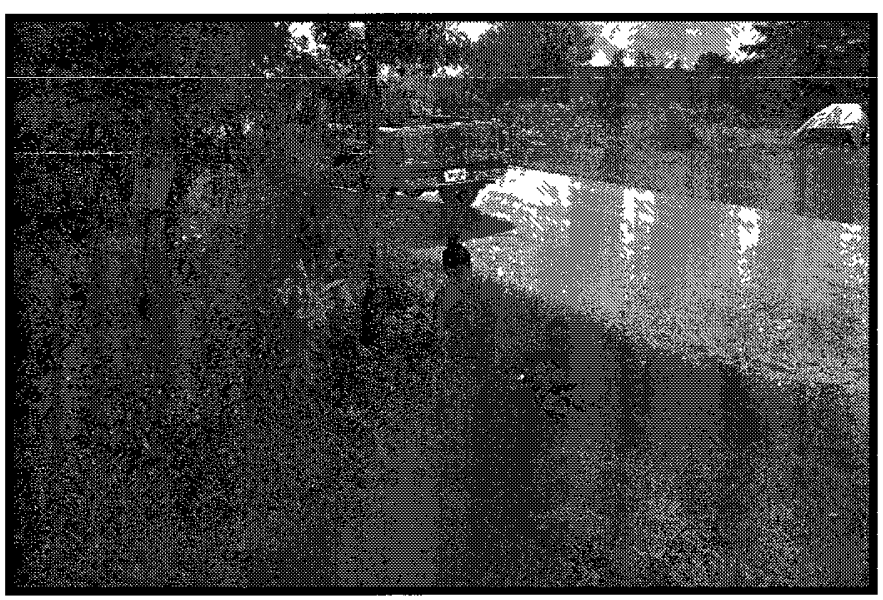

Photo 21. Community of interest (researchers) 
NUOFs constructed a 'sense of community' based on interest, not geography. For the most part, significant components of NUOFs' social network were located outside the boundaries of the individuals' rural communities to include a diverse community of people who may have not been traditionally thought of as being a direct part of the farming community. A study by Mailfert's (2007) comparing networks compositions between French 'neo-farmers', conceptualized as individuals with no agricultural background, and those with farm origins reported similar findings. She reported that strong ties with a close-knit group of people were characteristic of farmers with rural origins while neo-farmers' networks were more geographically and socially diverse (p. 27).

However, NUOFs' ability to build a sense of community should not overshadow the fact that NUOFs have made significant changes in their personal and professional life as a result of deciding to farm and are in a the process of rebuilding:

...I've chosen to leave my community affiliations which have been established in more urban settings so most of my peers, my age peers, people that we were connected to but their lives are very different from my own... friends that would have been my key social support, their lives are so different that my own, sort of the cutting edge of what I struggle with my life in particular as a farmer and parent at home is that those circle [of friends] don't meet that need in the same way. And my circle of other farmers, especially other new farmers are almost entirely at a different stage of life. They don't have kids yet, they have a partner, they may or may not have a partner, they are just at a different stage of life and I think that's a good thing. It's good to interact, but there are a different set of issues I grapple with... -Elsie

The quotation above describes the importance of a social network and the value NUOFs place on finding like-minded colleagues. Elsie's comment reiterates how finding a sense of community is shaped by who you are and what you are looking for. For Elsie, there was a desire to connect with NUOFs who were dealing with parenthood and the lack of such individuals in her life at the moment represented a challenge. More importantly, this situation underscores that 
the migration process is far from a 'cut-and-paste' function as demonstrated by the sense of isolation brought about by the absence of both explicit and latent support structures that allow life, as one knows it, to come together.

Overall, NUOFs' desire for community life is typical among counterurbanization migrants. However, from the start, their motivations for becoming a part of the rural and agricultural landscape seemed to encompass a more mixed ideal of what 'community life' entailed and one that involved meaningful rural-urban interactions. Instead of looking for a sense of community to join, NUOFs sought to create a strong sense of community through an agricultural community of practice. For that, NUOFs differed slightly from some of their counter-urbanite peers who sought after a greater sense of inclusivity among and within rural enclaves (Arnon and Shamai, 2010; Mitchell, 2004). 


\section{CHAPTER 5 | CONCLUSION}

Beginning with a brief summary of the research, this chapter combines the findings and analysis presented in the previous chapter to answer the question of what a 'sense of place' looks like for NUOFs who decide to live and work in rural farming communities. It then moves on to a discussion that situates the research within the sense of place and counterurbanization literature, illustrating the contributions of this study to an area of research that has received little attention to date. The chapter concludes by addressing the scope of the research and identifying potential areas for further research.

\subsection{SUMMARY OF THE STUDY}

A growing interest in the local food movement coupled with a declining farmer population has provoked a rich dialogue among researchers, practitioners and enthusiasts. New farmer training and education programs have been positioned as key strategies to help address the farmer population gap; in particular, there has been a focus on encouraging and supporting individuals with no farm origins to become involved in agriculture. At the same time, there has been relatively little research in Canada examining the experiences of NUOFs with limited agricultural background transitioning into rural farming communities. To this end, the purpose of this study was to gain a better understanding of how NUOFs construct a 'sense of place' for themselves in the context of their lives as new farmers in rural communities.

A mixed methodological ethnographic approach guided the research process in order to capture the essence of the NUOFs lived experiences. Field research took place during the summer of 2009. Data collection methods included participant observations, interviews, photovoice and network mapping. In total, nine NUOFs living and working in rural communities 
in southern Ontario were included in this study. The objective was to develop a basic understanding of who these individuals were, their motivations to farm, experiences, and the spatial dimensions of the communities they constructed to support a rural-based livelihood and lifestyle. Data were analyzed using a multi-dimensional sense of place framework that involved deconstructing a 'sense of place' into three main units of analysis: place identity, place attachment and sense of community. The concept of place identity was about understanding how NUOFs associated themselves in various physical environments and focused on the meaning and motive behind a counter-urbanization migration. The concept of place attachment and sense of community broadened the scope to examine the social and inter-personal dynamics between land and people. Together, the three concepts provided a nuanced understanding of a sense of place.

This study reported that NUOFs, based on their motivations and values associated with farming, constructed a strong place identity with rural landscapes. They saw the rural environment as an intimate part of who they were and how they wanted to live. Compared to place identity, NUOFs' place attachment to the rural environment was more varied and dynamic. NUOFs exhibited a strong affective attachment to the land and natural environment as expressed through an appreciation of nature, their land, and animals (both domesticated and wild). It was also shown that NUOFs experienced challenging situations and commented on having to adjust to aspects of physical and social isolation, being car dependent, and the seasonality of farm life. The need for a "city fix" suggested that a strong place attachment to the rural environment could co-exist with an urban one. Additionally, life stage seemed to play a role in how individuals related to their physical environment where younger NUOFs expressed greater concerns about living out in rural spaces than NUOFs with families. For NUOFs in temporary living or working situations, an uncertain future tempered their place attachment to the environment as a whole. 
From a social perspective, this study found that NUOFs were highly motivated to create a sense of community based around agriculture. However, one of the more significant findings to emerge from this study was that while NUOFs felt somewhat out-of-place with the local residential and agricultural community based on what they believed to be differences in worldviews and values, they did not necessarily emote a deficient sense of community. Instead, NUOFs' created a 'sense of community' from a diverse agricultural community of practice that included the broader sustainable agriculture community, farm colleagues, supportive family and neighbours who shared an interest in what they were hoping to accomplish through farming. Additionally, results from the network analysis show that the spatial construction of NUOFs' sense of community was geographical dispersed with a strong urban connection. Collaborations and proximity to large urban centers seemed to play an influential role in constructing a sense of community within a relatively confined zoned. NUOFs demonstrated that they were capable of expanding their support networks over time but the evidence suggests that this was a highly discrete process shaped by socio-demographic characteristics and underscores the significance of one's social, economic and political position in constructing a sense of community.

\subsection{DISCUSSION}

\section{Constructing a sense of place}

Undergoing a substantial shift in lifestyle and employment, NUOFs involved in the local food movement are in a state of transition. Compounded, these transitions can be complex periods that are characterized by "between belongings" (Marshall and Foster, 2002) and can challenge one's sense of attachment to both the people and places that ultimately define a 'sense of place'. In this study, the concept of place identity, place attachment and sense of community form the basis of what is understood as a 'sense of place'. Looking at the different components that inform an 
understanding of how NUOFs construct a sense of place for themselves in rural farming communities, two major findings can be concluded based on the data collected and analyzed.

First, NUOFs constructed a very dynamic sense of place. For the NUOFs in this study, articulations about the land and natural environment were not only an extension of who they are but also an expression of how they wanted to live which resonates with Burton's (2004) observation that the land and farm itself is a portrait of the farmer. This study found that NUOFs had a strong place identity and attachment to their farm, the land and the natural environment. Moreover, a strong connection to the rural landscape was equally matched by a desire to create a sense of community based around agriculture and food, which meant that they worked hard to sustain and maintain urban connections to raise awareness and support for sustainable, local agriculture. Based on relationships that support their purpose and passion for land, food and community, NUOFs' sense of community was geographically dispersed, as it turns out this network of people were located outside the boundaries of their rural municipalities. Rather, NUOFs used elements of the rural and urban environment to situate themselves in a position to facilitate selective but meaningful connections and relationships. These motivations help to explain why their sense of community was fairly localized within a region but not confined to a specific locality. Together, the attributes of wanting live their values, reconnecting with the land and building a sense of community contributed to a dynamic place identity that was not fixed to one particular place.

Second, constructing a sense of place was an uneven and differentiated process as it was highly contextualized by the lives of NUOFs. Among the NUOFs participating in the study, the range and intensity of positive, negative and challenging experiences associated with the transition to rural farming communities could not be easily generalized. The unevenness refers to 
this range of emotions, feelings and sentiments that converged to create many distinct understandings of a place. For instance, all NUOFs encountered physical isolation but the impacts felt were mixed. At one end of the spectrum, NUOFs with families felt that an element of physical isolation provided opportunities for more family time whereas single NUOFs found being isolated a major challenge and incorporated frequent visits to the city as a coping mechanism. In this regard, a sense of place seemed to be differentiated along some sociodemographic attributes. Put another way, constructing a sense of place was not a standardized process because NUOFs' attachment to the physical and social environment varied accordingly to the particularities of each circumstance and how they were able to respond to those situations. So while NUOFs shared a common goal to be a part of the rural and agricultural landscape as farmers, their positionality, priorities, assets and resources shaped the way in which they experienced and constructed a sense of place. Overall, the evidence from this study suggests that of a sense of place was a highly dynamic, diverse and discrete process for NUOFs.

At first glance, NUOFs participating in this study can be easily described as a new generation of the back-to-the-landers of the $1960 \mathrm{~s} / 70 \mathrm{~s}$. Strong similarities can be drawn between NUOFs and their predecessors in their shared pursuit to be closer to nature and 'counter-cultural' practices that is reminiscent of a "youth-centred and directed cluster of interest and practices around green radicalism, direct action politics" (Halfacree, 2006, p. 313). However, examining the process in which NUOFs took to construct a sense of place shows that they are slightly different since they were not driven by a desire to escape the city. On the contrary, the data suggest that the decision to farm and be a part of the rural community included an earnest desire to remain connected to and cultivate a sense of community with the urban community. 
Interestingly, this dynamic sense of place illustrates how NUOFs embody what scholars have identified as the need for the local food movement to move towards a sense of place that encourages people to re-connect with places. The results of this research indicate that NUOFs participating in this study did this in two significant ways. First, as individuals, they were making the choice to farm and reconnect to rural farming places themselves. Secondly, a relocation to rural farming communities to farm explicitly involved encouraging others, especially urban dwellers, to get involved and educate themselves about agriculture and the production of food. In this respect, perhaps NUOFs can be said to be embodying what DeLind's (2009) declared as the need for the local food movement to move away from a transactional focus and towards facilitating potentially transformative experiences in which people "re-connect to context-to the soil, to work (labour), to history, or to place" (p. 7, my emphasis). In short, NUOFs' desire to farm placed them in rural spaces but it did not mean that they were "opting out of society" since farming was seen as an opportunity to re-position themselves to encourage meaningful ruralurban interactions. NUOFs' enthusiasm to bridge the rural-urban divide reinforces Halfacree's (2007) observation that a strand of the back-to-the-landers today has "little desire to drop out of society or isolate themselves" (p. 5).

With that said, a closer examination at the construction of a sense of community by the NUOFs within their own rural farming communities pointed to some notable dynamics. Jones et al. (2003) write that, more often than not, those drawn to finding a sense of community in rural communities tend to have idyllic expectations about what their new environment and life should be like and when those expectations are unmet, counter-urbanites quickly begin to feel out-ofplace as disappointment and disillusionment set in (p. 222). Given that building a sense of community around agriculture was a central tendency for all the NUOFs, it was somewhat 
surprising to find the degree in which NUOFs felt distanced from their immediate local community and did not appear too distraught by this situation. Reasons remain unclear, but it might be related to how NUOFs manage their expectations and when moving into rural farming communities knew and accepted that they were going to be different. Another possible explanation for this might be that NUOFs' sense of place, conceptualized as their place identity, place attachment and sense of community, was driven by more than finding a tranquil community setting to live in. For NUOFs, a sense of place involved a deep reverence for the land and the rural environment as not only an expression of a lifestyle preference but also a conduit from which they can fulfill their roles as individuals in creating a better society through the practice of sustainable agriculture.

Unlike other counter-urbanites whose relocation may have been motivated by rural amenities (e.g. more green space, less violence, a good place to raise children, a better sense of community and so on), NUOFs' connection to rural landscapes permeated beyond a place of residence. Consequently, NUOFs may have been in a better position to accept the social distance between them and their immediate community since a significant part of their sense of place seemed firmly rooted in the rural landscape itself. Nevertheless, the division between NUOFs and their immediate community raises critical questions about the consequence of having people who share the same community space yet lack a sense of connectivity or see little commonality with each other.

The presence of NUOFs represents visible changes to the rural agricultural landscape. For instance, a collective portrait of the NUOFs reveals that the characteristics of the majority of the NUOFs in this study contrast with that of the majority of Canadian farmers. According to the Census of Agriculture 2006, farm operators in Canada tend to be males in their mid-to-late 50s 
with no university education (Statistics Canada, 2006). Here, the NUOFs were younger (most of them under the age of 35), university educated and female. For some rural communities, this is welcomed as the infusion of young and educated individuals to rural communities represents a potentially valuable source of human capital to help stimulate rural development (Stockdale, 2006) and is consistent with other studies that report counter-urbanites as educated, selfemployed entrepreneurs (Pangiuia, 2002; Mitchell, 2004). For others, it is considered a force that is slowly eroding a certain way of life. In particular, Padel (2004) noted that there have been historical tensions between industrial and alternative forms of agriculture (e.g. organic farming) where the latter has been perceived as a threat to the traditional rural value system (p. 54). As a part of the rural landscape and the politics of place, NUOFs presence "illuminates the absence of any notion of a settled or fixed rural population, despite the dominant imagery of timeless, unchanging countrysides" (Agyeman and Neal, 2010, p. 281). From this perspective, one can see why the NUOFs would feel out-of-place and how their arrival in the countryside contributes to larger, on-going conversations and contestations about who can "belong".

\subsection{RESEARCH IMPLICATIONS}

\section{Implications for theory}

This study explored the lives of NUOFs living and working in rural farming communities. It demonstrated a connection between the counterurbanization movement and the local food movement as the motivation to farm united a lifestyle and livelihood that enabled these individuals to pursue a meaningful life through the practice of agriculture. In reviewing Mitchell's (2004) counterurbanization classification based on motivations, economic and environmental ties to the community of origin and destination, it would seem that instead of fitting into one particular category, NUOFs reflected characteristics of all three. For instance, 
they could be considered as ruralites because they severed employment ties with the community of origin; however, their strong emotional and economic ties with urban centres suggested qualities of an exurbanite. Also, one could potentially argue that they were displaced urbanites, pushed into a rural setting due to municipal by-laws regarding keeping animals and accessing appropriate land appropriate for agriculture in the city. Overall, the results of this study add to a growing body of literature demonstrating that the counterurbanization phenomenon is not homogenous.

Moreover, the construction of a sense of place by the NUOFs participating in the study suggests that counterurbanization takes on new dimensions as it becomes intertwined with the local food movement. This research found evidence of NUOFs' sense of place being largely constructed through a community of practice as a means to strengthen their ability and resolve to cultivate a sense of belonging in their own community where, oddly, some reported feeling culturally and professionally out-of-place. Close-knit networks signified the presence of a strong sense of community among the alternative sustainable agricultural community; but a lack in a sense of community between NUOFs and the people who lived in their immediate rural community is disconcerting. Manzo and Perkins (2006) argue that a sense of place where the nature and quality of interpersonal relationships between the communities within a place are ignored or vacant points to a larger socio-spatial politics at play that can impact "whether we feel marginalized or empowered to participate in community change efforts, and whether we feel we have a place, or a right to a place, at the bargaining table" (p. 340). It would seem that the authenticity of a sense of place might be key to the success of NUOFs' transition into rural farming communities. Currently, it appears that they are compelled to find a sense of community in other places than where they are living. By and large, this dimension of the intra-community 
relationships has been generally overlooked within the popular local food movement and counterurbanization discourse and warrants further investigation.

\section{Implications for practice}

Important lessons can be drawn from the research for those interested in supporting the development of new farmers. First, local food advocates should feel encouraged in that there are people attracted to farming at all ages. Moreover, in a time when the number of young farm operators is dwindling by the thousands, that the majority of the NUOFs in this study were less than 35 years of age is quite significant. Recognizing this population sample might not be representative of the whole movement, it nevertheless indicates that there are young individuals interested in making a career as farmers in the sustainable agriculture sector. Second, it is also important to recognize that for those who have decided to take up farming, the transition to becoming a farmer involves much more than just production and business skills as people have to navigate the social landscape within rural farming communities. As evidenced through this research, it is not always easy. Currently new farmer programs are heavily focused on production and business skills development and an opportunity exists to introduce curriculum and initiate conversations about the (agri)cultural context in which these individuals hope to situate themselves.

Third, the NUOFs highlighted that an agricultural community of practice is a place where they draw strength, inspiration and motivation. Given that the agricultural community of practice plays such an integral part in constructing their sense of place, practitioners may want to look into developing effective strategies that enhance connectivity and opportunities for networking and reciprocal learning exchanges sensitive to the needs of different NUOFs. Lastly, the divide that exists between the industrial farming community and new farmers involved in the local food 
movement should be addressed as their futures are intricately linked through the space that they share. Are there opportunities to bridge the cultural and professional divide? Based on Mailfert's (2007) research comparing network development of new farmers with and without farm backgrounds, she concluded that, "Given the rapid evolution of farming systems, both groups of farmers should benefit from capacity building initiatives that encourage farmers to move across 'boundaries' to access resource in innovative ways from new sources" (p. 291). In other words, developing connections with a larger, more diverse groups of people can support the objectives of the local food movement by strengthening the overall vitality and resiliency of rural communities.

\subsection{RESEARCH SCOPE AND FUTURE RESEARCH AREAS}

The empirical component of this research is based on an intensive 10-week field season in 2009 that explored the day-to-day lives of nine NUOFs. This primary research was situated in the broader geographical research in creating a sense of place. From a 'sense of place' perspective, this research has gone some way towards enhancing our understanding of the construction of place by NUOFs who are in the process of re-establishing themselves in rural communities. The present study supports previous findings and contributes additional evidence to suggest that places are being continuously constructed, while underscoring the significance of the relational dimension in place-making. Like Gombay, this research holds that "places, scales, and identities ought to be understood not as discrete things but as events or processes that are embedded with one another and are in constant relationship, movement, and interaction" (as cited in Feagan, 2007, p. 35). 
Overall, this research provides preliminary insight into NUOFs' motivations and experiences as they construct a sense of place in their new rural communities, and adds to the growing body of literature on the local food movement. The ethnographic approach was central to bringing the research to life. The opportunity to live and work with the NUOFs grounded the research within the context of the participants' environment and offered a very personal and engaging research experience. Moreover, it highlighted the role and importance of practicing reflectivity (e.g. 'insider/outsider' dynamics) when undertaking social sciences research. Inadvertently, an exploration of NUOFs' sense of place unexpectedly provided a perspective into my own.

As is the case with much of early research in emergent fields, one needs to carefully interpret their findings in order to not go beyond the scope of the exploration. In this case, the research relates directly to a relatively small sample of NUOFs during the summer of 2009 . Effectively, the research findings may not be representative of the broader NUOFs population. It is also important to keep the temporal nature of this research in mind as the study captured the experiences of certain NUOFs at a very specific time. For instance, the network analysis captured Annie's position at the start of her growing season. It is possible that an examination at the end of her growing season could have documented a slightly different set of resources and experiences. A final note on the scope of the research directs attention to my experience as a visible minority researcher in the countryside which reinforced that different people will experience places differently. Regarding the specificity of this study, it is noted that the research participants were non-aboriginal, English speaking Canadians. Thus, a study exploring the intersections of race, ethnicity and rurality is an important issue, especially as some local food 
organizations and advocates are putting resources towards encouraging new immigrants to join the local food movement and consider farming in Canada.

With the research drawing to a close, it seems that much more needs to be accomplished to develop deeper insight into not only the construction of place among NUOFs who have decided to become a part of the agricultural landscape but also the changing nature of rural communities themselves. In the context of this study, key areas for further research include establishing a longitudinal study to explore experiences of individuals within the same NUOFs group over several years and examine how their sense of place changes over time. Interestingly after the field research concluded in the fall of 2009 , it came to my attention that two of the farmers had stopped farming and moved on. The fact they were both single, younger farmers in land-sharing agreements raised questions about whether their positionality (e.g. gender, age, civic status, presence of dependants) could have changed the outcome of the situation. An exciting area for further research could examine whether there are socio-determinants that influences who stays, who goes and possible explanations as to why.

In this study, an exploratory network analysis focused on the spatial dimension of NUOFs' social interactions. The research findings point to the significance of networks in constructing a sense of place but considerably more work is warranted. For instance, a study could examine other network characteristics that were not in the scope of this research (e.g. strength of the relationships, quality, quantity and frequency of interactions) to add a different perspective into how network developments contribute to the construction of place. Finally, if the debate about the importance of a sense of place is to move forward, a critical area of further research needs to explore the inter-relationship between NUOFs and long-term rural residents. The present study provides an account of the NUOFs ${ }^{\vartheta}$ perspective and an exploration into 
veteran rural residents' point-of-view would certainly enrich the current dialogue. The question of how do we, as individuals, as a community, find common ground with the people we share space with will undoubtedly provide more food for thought. As Massey (2005) writes: "It poses that most basic social, political, ethical questions: how we are going to live together" (p. 94). 


\section{REFERENCES}

Agnew, J. (2005). Space:place. In P. Cloke \& R. Johnson (Eds.), Spaces of geographical thought: deconstructing human geography's binaries (pp. 89). London, UK: Sage Publications.

Agyeman J. \& Neal, S. (2009). Rural Identity and Otherness. In The Encyclopedia of Human Geography (pp. 277-281). Oxford, UK: Elsevier.

Allen, P. \& Hinrichs, C. (2007). Buying into 'Buy Local': Engagements of United States Local Food Initiatives. In D. May, L. Holloway \& M. Kneafsey (Eds.), Alternative food geographies: representation and practice (pp. 255-273). Oxford, UK: Elsevier.

Allen, P., Fitzsimmons, M., Goodman, M., \& Warner, K. (2003). Shifting plates in the agrifood landscape: the tectonics of alternative agrifood initiatives in California. Journal of Rural Studies, 19, 61-75.

Amin, A. (2004). Regions Unbound: Towards a New Politics of Place. Geografiska Annaler: Series B, Human Geography, 86, 1, 33-44.

Arnon, S. \& Shamai, S. (2010). Community life as a motive for migration from the urban center to the rural periphery in Israel. Journal of Community Psychology, 38 (6), 706-728.

Atkinson, P. \& Hammersley, M. (2010). Ethnography Principles in Practice. London, UK: Taylor and Francis Ltd.

Beilin, R. (2005). Photo-elicitation and the agricultural landscape: "seeing" and "telling" about farming, community and place'. Visual Studies, 20 (1), 56-68.

Berry, B. (1976). Urbanization and Counter-Urbanization. Beverly Hills, US: Sage Publications.

Blay-Palmer, A. (2008). Food Fears: from industrial to sustainable food systems. Burlington, US: Ashgate Publishing.

Born, B. \& Purcell, M. (2006). Avoiding the Local Food Trap: Scale and Food Systems in Planning Research, Journal of Planning Education and Research, 26(2), 195-207.

Buller, H. \& Morris, C. (2004), Growing goods: The market, the state, and sustainable food production, Environment and Planning A, 36(6), 1065-1084.

Burton, R. (2004). Seeing Through the 'Good Farmer's' Eyes: Towards Developing an Understanding of the Social Symbolic Value of 'Productivist' Behaviour. Sociologia Ruralis, 44(2), 195-215. 
Champion, AG. (1994). Population change and migration in Britain since 1981: evidence for continuing deconcentration. Environment and Planning A, 26 (10), 1501-1520.

Cloke, P., Philo C., \& Sadler, D. (2004). Approaching Human Geography. London, UK: Sage Publications.

Cotterill, P. (1992). Interviewing Women. Issues of friendship, vulnerability and power. Women's Studies International Forum, 15, (5/6), 593-606.

Crang, M. \& Cook, I. (2007). Doing Ethnographies. Los Angeles, US: Sage Publications.

Creswell, J. (2009). Research Design: Qualitative, Quantitative, and Mixed Methods Approaches, $3^{\text {rd }}$ Edition. Los Angeles, US: Sage Publications.

Cresswell, T. (2009). Place. In R. Kitchin \& N. Thrift (Eds.), The International Encyclopedia of Human Geography (pp. 169-177). Amsterdam, NL: Elsevier.

Cresswell, T. (2004), Place: A Short Introduction. London, UK: Blackwell.

Cuba, L. \& Hummon, D. (1993). Constructing a sense of home: Place affiliation and migration across the life cycle. Sociological Forum, 8(4), 547-572.

Culver, D., Niekamp, D., \& Zafiriou, M. (2001). Canadian Agricultural Safety Net Programs and Pressures for Change. Canadian Journal of Agricultural Economics, 49 (4), 509-527.

DeLind, L. (2009). Hitching Our Wagons to the Wrong Stars: Considering the Local Food Movement. Paper presented at the Agriculture, Food and Human Values Society meetings, University Park, Pennsylvania, May 28-31, 2009.

Dowler, L. (2001). Fieldwork in the trenches: participant observation in a conflict area'. In M. Limb \& C. Dwyer (Eds.), Qualitative Methodologies for Geographers (pp. 153-164). London, UK: Arnold.

Dunning, H., Williams, A., \& Abonyi, S. (2008). A Mixed Method Approach to Quality of Life Research: A Case Study Approach. Social Indicator Research, 85, 145-158.

DuPuis, E. \& Goodman, D. (2005). Should we go "home" to eat?: toward a reflexive politics of localism. Journal of Rural Studies, 21(3), 359-371.

Eaton, E. (2008). From feeding the locals to selling the locale: Adapting local sustainable food projects in Niagara to neocommunitarianism and neoliberalism. Geoforum, 39(2), 9941006.

England, K. (2006). Producing Feminist Geographies: Theory, Methodologies and Research Strategies'. In S. Aitken \& G. Valentine (Eds.), Approaches to Human Geography (pp. 286-297). London, UK: Sage Publications. 
Erhlich, P., Erhlich, A., \& Gretchen, P. (1993). Food security, Population and Environment. Population Council, 19(1), 1-32.

Errington, A. (2002). Handing Over the Reins: A Comparative Study of Intergenerationsal Farm Transfers in England, France and Canada. Paper presentation for the $\mathrm{X}^{\text {th }}$ EAAE Congress "Exploring Diversity in the European Agri-Food System", Spain.

Foote, K. \& Azaryahu, M. (2009). Sense of place. In R. Kitchin \& N. Thrift (Eds.) The International Encyclopedia of Human Geography (pp.96-100). London, UK: Elsevier.

Feagan, R. (2007). The place of food: mapping out the 'local' in the local food system. Progress of Human Geography, 31(1), 23-42.

Feagan, R., Morris, D. \& Krug, K., (2004). Niagara region farmers' markets: local food systems and sustainability considerations. Local Environment, 9(3), 235-254.

Govers, R. \& Go, F. (2009). Place Branding: Glocal, Virtual and Physical Identities, Constructed, Imagined and Experienced. London, UK: Palgrave Macmillan.

Grix, J. (2002). Introducing Students to the Generic Terminology of Social Research. Politics, 22(3), 175-186.

Halfacree, K. (2007). Back-to-the-Land in the Twenty-First Century-Making Connections with Rurality. Tijdschrift voor economische en sociale geografie, 98 (1), 3-8.

Halfacree, K. (2006). From dropping out to leading on? British counter-cultural back-to-the-land in a changing rurality. Progress in Human Geography, 30 (3), 309-336.

Hall, T. (2009). The Camera Never Lies? Photographic Research Methods in Human Geography. Journal of Geography in Higher Education, 33(3), 453-462.

Hassanein, N. (2003). Practicing food democracy: a pragmatic politics of transformation. Journal of Rural Studies, 19 (1), 77-86.

Hay, C. (2002). Political Analysis: A Critical Introduction. Basingstoke, UK: Palgrave.

Hay, I. (Ed.). (2000). Qualitative Research Methods in Human Geography. Toronto, CA: Oxford University Press.

Hay, I. (Ed.). (2005). Qualitative Research Methods in Human Geography (2 ${ }^{\text {nd }}$ ed.) Toronto, CA: Oxford University Press.

Hinrichs, C. (2007). Practice and place in remaking the food system. In C. Hinrichs \& T.A. Lyson (Eds.), Remaking the North American Food System: Strategies for Sustainability (pp.1- 15). Lincoln, US: University of Nebraska Press. 
Hinrichs, C. (2003). The practice and politics of food system localization. Journal of Rural Studies, 19, 33-45.

Hoey, B. (2006). Grey Suit or Brown Carhart: Narrative Transition, Relocation, and Reorientation in the Lives of Corporate Refugees. Journal of Anthropological Research, $62,347-371$.

Hoggart, K., Lees, L., \& Davies, A. (2002). Part of life: research as lived experience. In Researching Human Geography (pp. 251-301). London, UK: Arnold.

Holloway, L. (2002). Smallholding, hobby-farming, and commercial farming: ethical identities and the production of farming spaces. Environment and Planning A, 34, 2055-2070.

Hunt, AR. (2007). Consumer interactions and influences on farmers' market vendors. Renewable Agriculture and Food Systems, 22 (1), 54-66.

Jacobson, M. (2007). Food Matters. Community Food Assessments as a Tool for Change. Journal of Community Practice, 15 (3), 37-55.

Jarosz, L. (2008). The city in the country: Growing alternative food networks in Metropolitan areas. Journal of Rural Studies, 24 (3), 231-244.

Jones, R., Fly, M., Talley, J. \& Cordell, K. (2003). Green migration into rural America: The new frontier of environmentalism? Society and Natural Resources, 16, 221-238.

Jorgensen B. \& Stedman, R. (2001). Sense of place as an attitude: lakeshore owners attitudes toward their properties. Journal of Environmental Psychology, 21 (3), 233-248.

Kalogirou, S. (2005). Examining and presenting trends of internal migration flows within England and Wales. Population, Space and Place, 11(4), 283-297.

Kearns, R. (2000). Being There: Research through Observing and Participating. In Qualitative Research Methods in Human Geography (pp. 103-121). Toronto, CA: Oxford University Press.

Kingsolver, B. (2007). Animal, Vegetable, Miracle: A Year of Food Life. New York, US: HarperCollins.

Kitchin, R. \& Tate, N. (2000). Conducting Research in Human Geography: Theory, Methodology and Practice. Harlow, US: Prentice Hall.

Kobayashi, A. (2002). Negotiating the personal and the political in critical qualitative research. In M. Limb \& C. Dwyer (Eds.) Qualitative Methodologies for Geographers (pp. 55-70). London, UK: Arnold. 
Lappegard, H. \& Kolstad, A. (2007). Dwelling as an Express of Identity: A Comparative Study among Residents in High-Priced and Low-Priced Neighbourhoods in Norway. Housing Theory and Society, 24 (4), 272-292.

Long, N. (2001). Development Sociology: Actor perspectives. New York, US: Routledge.

Lucas Jr., R. (2001). Life Earnings and Rural-Urban Migration. The Journal of Political Economy, 112(1), 29-59. Papers in Honor of Sherwin Rosen: A Supplement to Volume 112.

Mailfert, K. (2007). New Farmers and Networks: How Beginning Farmers Build Social Connections in France. Tijdschrift voor economische en sociale geografie, 98(1), 21-31.

Malenfant E., Milan A., Charron, M. \& Belanger, A. (2007). Demographic Changes in Canada from 1971-2001 across an Urban-to-Rural Gradient. Demography Division of Statistics Canada: Ottawa.

Manzo, L. \& Perkins, D. (2006). Finding common ground: the importance of place attachment to community participation and planning. Journal of Planning Literature, 20(4), 335-350.

Manzo, L. (2005). For better or worse: Exploring multiple dimensions of place meaning. Journal of Environmental Psychology, 25 (1), 67-86.

Marsden, T. \& Smith, E. (2005). Ecological entrepreneurship: Sustainable development in local communities through quality food production and local branding. Geoforum, 36(4), 440451.

Marsden, T. (2004). The Quest for Ecological Modernization: Re-spacing Rural Development and Agri-Food Studies. Sociologia Ruralis, 44(2), 129-146.

Marshall, J. \& Foster, N. (2002). Between Belonging: Habitus and the Migration Experience. The Canadian Geographer, 46, 63-83.

Martin, P. (2006). Managing Labor Migration: Temporary Worker Programmes for the $21^{\text {st }}$ Century. International Symposium on International Migration and Development UN Secretariat, Turin, Italy, p. 1-44.

Massey, D. (2005). Space, time, and political responsibility in the midst of global inequality. Erdkunde, 60(2), 89-95.

Massey, D. (1994). A Global Sense of Place. In Space, Place and Gender. Minneapolis, US: University of Minnesota Press.

McMillan, D. \& Chavis, D. (1986). Sense of Community: A Definition and Theory. Journal of Community Psychology, 14, 6-23. 
Mendes, W. (2007). Negotiating a Place for 'Sustainability" Policies in Municipal Planning and Governance: The role of Scalar Discourses and Practices. Space and Polity, 11(1), 95119.

Milbourne, P. (2007) Re-populating rural studies: Migrations, movements and mobilities. Journal of Rural Studies, 23, 381-386.

Mitchell, C. \& Bryant, C. (2009). Counterurbanization. In The Encyclopedia of Human Geography (pp. 319-324). Amsterdam, NL: Elsevier.

Mitchell, C. (2004). Making sense of counterurbanization Journal of Rural Studies, 20(1), 1534.

Mitchell, C., Bunting, T. \& Piccioni, M. (2004). Visual artists: counter-urbanites in the Canadian Countryside? Canadian Geographer, 48(2), 152-167.

Mohammad, R. (2001). "Insiders" and/or "Outsiders": positionality, theory and praxis. In M. Limb \& C. Dwyer (Eds.), Qualitative Methodologies for Geographers (pp. 101-117). London, UK: Arnold.

Nielsen-Pincus, M., Troy, H., Force, J. \& Wulfhorst, J.D. (2010). Sociodemographic effects on place bonding. Journal of Environmental Psychology, 30(4), 443-454.

Niewolny, K. \& Lillard, P. (2010). Explanding the boundaries of beginning farmer training and program development: A review of contemporary initiatives to cultivate a new generation of American Farmers. Journal of Agriculture, Food Systems, and Community Development, 1(1), 65-88.

Padel, S. (2001). Conversion to Organic Farming: A Typical Example of a Diffusion of Innovation? Sociologia Ruralis, 41(1), 41-61.

Pain, R. (2004). Social geography: participatory research. Progress in Human Geography, 28(5), 652-663.

Pain, R. \& Francis, P. (2003). Reflections on participatory research. Area, 35 (1), 46-54.

Paniagua, A. (2002). Urban-rural migration, tourism entrepreneurs and rural restructuring in Spain. Tourism Geographies, 4(4), 349-371.

Perez, J. (2004). Community Supported Agriculture on the Central Coast: The CSA Grower Experience. Research Brief No. 4 (Winter), 1-4. Centre for Agroecology \& Sustainable Food System, University of California.

Perkins, C. (2007) Community Mapping. The Cartographic Journal, 44(2), 127-137. 
Phillips, M. (2010). Counterurbanisation and rural gentrification: an exploration of the terms. Population, Space and Place, 16(6), 539-558.

Pollan, M. (2009). Food Rules: An Eater's Manual. New York, US: Penguin.

Pollan, M. (2007). The Omnivore's Dilemma. New York, US: Penguin.

Pretty, G., Chipuer, H. \& Bramston, P. (2003). Sense of place amongst adolescents and adults in two rural Australian towns: The discriminating features of place attachment, sense of community and place dependance in relation to place identity. Journal of Environmental Psychology, 23, 273-287.

Potts, D. (2004), "Counter-urbanization on the Zambian copperbelt? Interpretations and implications", Urban Studies, 42 (4), p. 583-609.

Preiblish, K. \& Binford, L. (2007). Interrogating Racialized Global Labour Supply: An Exploration of the Racial/National Replacement of Foreign Agricultural Workers in Canada. Canadian Review of Sociology, 44(1), 5-36.

Punch, K. (2005). Introduction to Social Research: Quantitative and Qualitative Approaches Second Edition. Los Angeles, US: Sage Publications.

Punch, S. (2001). Multiple methods and research relations with children in rural Bolivia', in M. Limb \& C. Dwyer (Eds.) Qualitative Methodologies for Geographers (pp. 165-180). London, UK: Arnold.

Renting, H., Marsden, T. \& Banks, J. (2003). Understanding alternative food networks: exploring the role of short food supply chains in rural development. Environment and Planning A, 35, 393-411.

Roff, R. (2007). Shopping for change? Neoliberalizing activism and the limits of eating nonGMO. Agriculture and Human Values, 24(4), 511-522.

Rose, G. (2007) Visual methodologies: An introduction to the interpretation of visual materials. London, UK: Sage Publications.

Rose, G. (2002) 'Researching visual materials’, in Visual Methodologies. London: Sage.

Rose, G. (1997). Situating knowledges: positionality, reflexivities and other tactics. Progress in Human Geography, 21(3), 305-320.

Scannell, L. \& Gifford, R. (2010). Defining place attachment: A tripartite organizing framework. Journal of Environmental Psychology, 30(1), 1-10. 
Schneider, M. \& Francis, C. (2005). Marketing Locally Produced Foods: Consumer and Farmer Opinions in Washington County, Nebraska. Renewable Agriculture and Food Systems, $20,252-260$.

Smith, A \& MacKinnon, J.B. (2007). The 100-Mile Diet: A Year of Local Eating. Vancouver, CA: Random House.

Sonnino, R. \& Marsden, T. (2006). Alternative Food Networks in the South West of England: Towards a New Agrarian Eco-Economy in Between the Local and the Global: Confronting Complexity in the Contemporary Agri-Food Sector. Research in Rural Sociology and Development, 12, 299-322.

Statistics Canada. (2011). 2006 Community Profiles.

Website: http://www12.statcan.ca/census-recensement/2006/dp-pd/prof/92591/index.cfm. Accessed January 9, 2011.

Statistics Canada. 2008. Canada's Farm Population: Agriculture-Population Linkage Data for the 2006 Census. Agriculture-Population Linkage Data for the 2006 Census. The Daily Dec. 2, 2008. Statistics Canada Catalogue no. 95-633-XWE. Website: http://www.statcan.gc.ca/daily-quotidien/081202/dq081202a-eng.htm. Accessed Dec 4, 2009.

Statistics Canada. (2006a). Census of Agriculture, 2006.

Website: http://www.statcan.gc.ca/pub/95-632-x/2007000/t/4185586-eng.htm. Accessed Dec 4, 2008.

Statistics Canada (2006b). 2006 Census of Agriculture, Agriculture Division.

Website: http://www.statcan.gc.ca/ca-ra2006/reference_map-carte-eng.htm\#on. Accessed Feb 18, 2011.

Statistics Canada. No Date. Census of Population, 1851 to 2006.

Website: http://www40.statcan.ca/101/cst01/demo62a-eng.htm. Accessed January 9, 2009.

Stedman, R. (2003). Is it Really Just a Social Construction?: The Contribution of the Physical Environment to Sense of Place. Society and Natural Resources, 16(8), 671-685.

Streubert Speziale, H., \& Carpenter, D. (2003). Qualitative Research in Nursing: Advancing the Humanistic Imperative $3^{\text {rd }}$ Edition. New York, US: Lippincott Williams and Wilkins.

Taylor J. \& Martin, P. (2001). Human Capital: Migration and rural population change. In B. Gardner \& G. Rausser (Eds.) Handbook of Agricultural Economics (pp. 457-511).

Tonts, M. \& Greive, S. (2002). Commodification and Creative Destruction in the Australian Rural Landscape: the Case of Bridgetown, Western Australia. Australian Geographical Studies, 40(1), 58-70. 
Trauger, A. (2007). Un/ReConstructing the agrarian dream: going back to the land with an organic marketing cooperative in Pennsylvania, USA. Tijdschrift voor Economische en Sociale Geografie, 98(1), 9-20.

Troughton, M. (1995). Rural Canada and Canadian Rural Geography-An appraisal. Canadian Geographer, 39(4), 290-305.

Tuan, Y. (1975). Place: An Experiential Perspective. Geographical Review, 65(2), 148-155.

Vallianatos, M., Gottlieb, R. \& Haase, M.A. (2004). Systems Approach Farm-to-School:

Strategies for Urban Health, Combating Sprawl, and Establishing a Community Food Systems. Journal of Planning Education and Research, 23(4), 414-423.

Walker, G. (2000). Urbanites Creating New Ruralities: Reflections on Social Action and Struggle in the Greater Toronto Area. The Great Lakes Geographers, 7(2), 106-118.

Wang, C. \& Burris, M. A. (1994). Empowerment through Photo Novella: Portraits of Participation. Health Education \& Behavior, 21(2), 171-186.

Williams, A., Kitchen, P., DeMiglio L., Eyles, J. \& Newbold, B. (2010). Sense of Place in Hamilton, Ontario: Empricial Results of a Neighbourhood-Based Survey. Urban Geography, 31(7), 905-931.

Wilson, D., Urban, M., Graves, M. \& Morrison, D. (2003). Beyond the Economic: Farmer Practices and Identities in Central Illinois, USA. The Great Lakes Geographer, 10(1), 21-33.

Winter, M. (2003). Geographies of food: agro-food geographies-making reconnections. Progress in Human Geography, 27(4), 505-513.

Woods, M. (2007). Engaging the global countryside: globalization, hybridity and the reconstitution of rural place. Progress in Human Geography, 31(4), 485-507.

Wylie, J. (2009). Sense of place. In D. Gregory, R. Johnston, G. Pratt, M. J. Watts, \& S. Whatmore (Eds.) The Dictionary of Human Geography, 5th Edition. Chichester, UK: Wiley-Blackwell, 676. 